2014-01-01

\title{
Atomic spectrometry updates. Review of advances in elemental speciation
}

Clough, $\mathrm{R}$

http://hdl.handle.net/10026.1/4668

10.1039/c4ja90029d

Journal of Analytical Atomic Spectrometry

All content in PEARL is protected by copyright law. Author manuscripts are made available in accordance with publisher policies. Please cite only the published version using the details provided on the item record or document. In the absence of an open licence (e.g. Creative Commons), permissions for further reuse of content should be sought from the publisher or author. 
Cite this: J. Anal. At. Spectrom., 2014, 29,1158

Received 29th May 2014

Accepted 29th May 2014

DOI: $10.1039 / c 4 j a 90029 d$

www.rsc.org/jaas

\section{Atomic spectrometry updates. Review of advances in elemental speciation}

\author{
Robert Clough, ${ }^{\star a}$ Chris F. Harrington, ${ }^{b}$ Steve J. Hill, ${ }^{c}$ Yolanda Madrid ${ }^{d}$ \\ and Julian F. Tyson ${ }^{\mathrm{e}}$
}

1.

2.

3.

3.1

3.2

3.3

4.

5.

5.1

5.2

5.3

5.4

5.5

5.6

5.7

5.8

5.9

5.10

5.11

5.12

5.13

5.14

5.15

5.16

5.17

5.18

5.19

6.

6.1
Topical reviews

Sample preparation

Instrumental techniques and developments

Developments in species separation

Developments in instrumentation

Chemical vapour generation

CRMs and metrology

Elemental speciation analysis

Antimony

Arsenic

Cadmium

Chromium

Cobalt

Copper

Gadolinium

Iron

Halogens

Mercury

Phosphorus

Platinum

Selenium

Silver

Tellurium

Tin

Uranium

Vanadium

Zinc

Macromolecular analysis

Metalloproteins, metalloproteomics and metallomics

${ }^{a}$ Biogeochemistry and Environmental Analytical Chemistry Research Group, University of Plymouth, Plymouth, UK. E-mail: rclough@plymouth.ac.uk

${ }^{b}$ Supra-regional Assay Service, Trace Element Laboratory, Surrey Research Park, 15 Frederick Sanger Road, Guildford, UK GU2 $7 Y D$

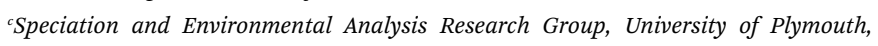
Plymouth, UK

${ }^{d}$ Departamento de Química Analitica, Facultad de Ciencias Químicas, Universidad Complutense de Madrid, Avda Complutense s/n, 28040 Madrid, Spain

${ }^{e}$ Department of Chemistry, University of Massachusetts Amherst, 710 North Pleasant Street, Amherst, MA 01003, USA

\author{
6.2 Tagging and labelling of molecules \\ 6.3 Elemental imaging \\ 7. Abbreviations \\ 8. References
}

This is the sixth Atomic Spectrometry Update (ASU) to focus specifically on advances in elemental speciation and covers a period of approximately 12 months from December 2012. This review deals with all aspects of the analytical speciation methods developed for: the determination of oxidation states; organometallic compounds; coordination compounds; metal and heteroatom-containing biomolecules, including metalloproteins, proteins, peptides and amino acids; and the use of metal-tagging to facilitate detection via atomic spectrometry. The review does not specifically deal with fractionation, sometimes termed operationally defined speciation. As with all ASU reviews ${ }^{1-5}$ the coverage of the topic is confined to those methods that incorporate atomic spectrometry as the measurement technique. However, molecular MS techniques are covered where the use is in parallel or series with atomic spectrometry. As with previous years As and Se speciation continues to dominate current literature. However, research is moving further towards understanding the toxicological and beneficial mechanisms of these two elements. There is also in increase in macromolecular analysis, with a decrease in detection limits for some methodologies, which increases the potential clinical use of the techniques employed. The use of both atomic and molecular spectrometry is well developed in these fields, highlighting the interdisciplinary nature of today's research environment. The trend towards lower cost more rapid analytical methods, often involving non-chromatographic speciation, also continues apace.

\section{Topical reviews}

There has been an increase in the number of reviews of aspects of elemental speciation in the past 12 months compared with the number that had appeared in the previous review period. A 
textbook devoted to 'speciation studies in soil, sediment, and environmental samples' has been published. ${ }^{6}$ After several introductory chapters devoted to sample preparation and analyte separation, there is a series of chapters devoted to individual elements (As, Cr, Hg, I, Sb, Se, Sn, Te, Tl, and V). The contents of some of the chapters are confined to a limited sample type, such as edible seaweed for I and atmospheric aerosols for $\mathrm{Sb}$. A fairly broad range of topics, of which aspects of food and pharmaceutical analysis might be of interest, is covered in a book describing 'analytical techniques for clinical chemistry'.7 Atomic spectrometry (including X-ray) techniques are featured prominently among the 25 chapters that cover fundamentals, selected applications and future trends. A review of elemental speciation for toxicology is of broad coverage. ${ }^{8}$ As only 71 references are cited and the reviewers deal, in 8 pages, with a range of topics that includes (a) separation techniques coupled with spectrometric techniques and (b) techniques for imaging the spatial distribution of elements and molecules in various solid samples, the article might be better described as a tutorial introduction. A shorter version (35 references) is available for French language readers. ${ }^{9}$

In an overview ${ }^{\mathbf{1 0}}$ of the latest development of electrophoresis in capillaries and microfluidic devices coupled with MS detection, based on 178 publications in the period January 2010 to June 2012, special attention is paid to improvements in three interfaces: ESI, MALDI, and ICP. The ICP section contains 23 references, two of which concern the interface between CE and ICP whilst the rest are CE-ICP-MS applications. In a review ${ }^{\mathbf{1 1}}$ focused on elemental speciation covering a much longer period (20 years), 424 references are cited (no titles are given), the vast majority of which are to articles describing applications of atomic spectrometry. The others mostly concern the detection of separated nitrogen or sulfur anions by UV absorption spectrometry. The introduction features a well-written account of the current status of speciation analysis in analytical chemistry and although HPLC-ICP-MS is described as "unquestionably a premier technique," the reviewer makes a good case for CZE separations with ICP-MS detection, acknowledging the problems of detection capability associated with the small sample volumes. There are extensive tables summarising the separation of the species of different elements.

The possibilities for solid-state speciation have been mentioned in three review articles. Bertrand et al. ${ }^{\mathbf{1 2}}$ discuss development and trends in synchrotron studies of ancient and historical materials in a comprehensive, 46-page, 202-reference review. The authors explain the reasons why such methods are being increasingly used (high photon flux, continuous tenability, extended energy distribution over wide energy domains). It was concluded that microfocused hard X-ray spectroscopy (absorption, fluorescence, diffraction), full-field X-ray tomography and infrared spectroscopy are currently the leading techniques in this area of application. The application of $\mu$-XANES for elemental speciation is discussed in some detail with numerous examples. The use of scanning transmission $\mathrm{X}$ ray microscopy for $\mathrm{C}$ speciation is mentioned alongside several other techniques (IR, UV, small angle X-ray scattering and phase contrast micro computed tomography) that have been applied to obtain information on the organic fraction of ancient materials. The possibilities for soft X-ray techniques are also discussed with respect to molecular identification and speciation of organic materials. Majumdar et al. ${ }^{13}$ have reviewed (16-pages, 80-references - no article titles) the applications of synchrotron $\mu$-XRF to study the distribution of biologically important elements in various environmental matrices. The authors conclude that $\mu$-XRF combined with other synchrotron techniques such as $\mu$-XAS, $\mu$-XRD, $\mu$-SRCT, and $\mu$-FTIR, gives a more complete picture of chemical speciation, structure, and element association with functional groups in both two and three dimensions. Examples of speciation analysis are discussed for almost every sample type considered, which include soils, sediments, and biological materials.

There are several reviews of particular combinations of analytes and matrices. The activity related to the determination of Gd-based MRI contrast agents in biological and environmental samples has reached a stage where a 16-page 79-reference (no titles) review is warranted. ${ }^{\mathbf{1 4}}$ It was concluded that Gd-based contrast agents represent challenges in both medical and environmental studies. In addition, there are still analytical problems as it was noted that despite the development of methods exhibiting excellent sensitivity, the species information often got lost during sample pre-treatment or analysis itself. A review of the speciation and determination of $\mathrm{Hg}$ by various analytical techniques, confined to work published in 2010 and 2011, cites 144 references. ${ }^{15}$ The contents of 129 of the articles are featured in summary tables, the largest of which, by far (nine pages and 102 references), is devoted to spectrometry of which the largest subgroup (about 80 articles) feature atomic spectrometry. Not all of the articles concern speciation. Electrochemical methods get a 2-page, 19-reference table, and seven papers appear in a table titled 'determination of $\mathrm{Hg}$ by GC and HPLC' that includes a paper in which results were obtained by GC with ICP-MS detection. Readers are urged to avoid contamination and use CRMs to evaluate accuracy. In a review covering Se measurements in Se-enriched yeast the reviewers make the case that in the last 10 years or so, the quality of the analytical methodology and hence of the results has improved dramatically. ${ }^{\mathbf{1 6}}$ The importance of the availability of a CRM certified for the SeMet content, SELM-1 (NRCC, Ottawa, Canada), was heavily stressed. However, some cautionary words were offered concerning the accuracy of analysis of commercial products. A method that gave accurate results for the analysis of SELM-1, could well produce low values for the "real" samples with different morphology and texture. Useful summary tables, not only of the various sample preparation stages but also of the range of chemical species in yeast are provided. There is no discussion of the possible degradation of SeMet releasing dimethyldiselenide, or of the formation of selenomethionine selenoxide, or of compound-dependent responses. Perhaps surprisingly, it was concluded that 2D gel electrophoresis with parallel ICP-MS and Orbitrap-MS protein identification has become a routine approach. A survey of the determination and speciation of $\mathrm{Cr}$ in environmental matrices, ${ }^{17}$ which covered a variety of measurement techniques, cites 211-references published since 2006 . The material is presented non-critically in a 
series of tables. The introductory text deals with sources and toxic effects of chromium compounds. In a comprehensive 206article review $^{\mathbf{1 8}}$ of analytical methods for the determination of halogens in bioanalytical sciences materials, the authors cover work published in the last 20 years. As might be imagined, few ( 9 to be exact) of the references deal with speciation analysis. Atomic spectrometry is featured in only one article of a different review (21 pages, 196 references) concerning the analytical methodology for the determination of organochlorine pesticides in vegetation published over the past 15 years. ${ }^{19}$ However, a considerable portion of each these two reviews is devoted to sample preparation topics and is, therefore, of interest. In contrast, many of the articles cited in a (11-page, 70-reference) review of the toxicity and speciation analysis of OTC $^{20}$ feature determinations by atomic spectrometry, but the analytical part of the review is a non-critical history of published methods going back to 1993 . There is considerable overlap with a slightly later review of the environmental fate and "analytics" of OTC that cites 100 articles (with titles) ${ }^{21}$ and also includes a discussion of the toxicity of these compounds. Again, there is little or no critical evaluation of the quality of the various analytical methods, though both advantages and disadvantages of various derivatisation procedures and of various separations are listed in two of the tables. Compound-dependent responses are discussed in some detail by Tyson in a review (24-pages, 134 references with titles) of the determination of arsenic compounds (with particular emphasis on the analysis of rice). ${ }^{22}$ Other potential problems with ICP-MS measurement are discussed, including the roles of chlorine and carbon in the plasma. Sample preparation is also discussed, as is the validation of the speciation analysis of arsenate, arsenite, MMA and DMA with the NIST rice flour CRM SRM 1568a which was certified for total As only. The results of about 40 analyses of this material are collated in a summary table, which will be of interest to those laboratories using this material. It is pointed out that some of the partial collections of the results of the speciation analysis of NIST 1568a that have appeared in the literature contain inaccuracies. The replacement material, CRM $1568 \mathrm{~b}$, is the remainder of the $1568 \mathrm{a}$ material repackaged and re-analysed (including the determination of the arsenic species), the previous performance of the analytical community can now be evaluated against the certified values of the arsenic species. Interestingly, the total arsenic content has been revised downward slightly, from 290 to $285 \mu \mathrm{g} \mathrm{kg}^{-1}$ and the uncertainty term decreased from \pm 30 to $\pm 14 \mu \mathrm{g} \mathrm{kg}^{-1}$.

Two reviews are concerned with the determination of biomolecules. Giesen et al. $^{23}$ reviewed the history of ICP-MSbased immunoassays, 124-references with titles which date from 2001, are cited. It is pointed out that the determination of biomolecules requires highly sensitive and selective detection methods capable of tolerating a complex, biological matrix. The first applications of ICP-MS depended on heteroelements as the labels for quantification, though more recent elemental tagging facilitates multi-parametric analyses, which provide a powerful alternative to common bioanalytical methods. The fundamentals of the topic are introduced and the power of ICP-MS for the detection of different immunoassays, with a special focus on
LA-ICP-MS (10 references) is discussed. Another application of metal atoms as tags is discussed by Tanner et al. ${ }^{24}$ in a tutorial on the fundamentals and applications of ICP mass cytometry. The authors point out that the many enriched stable isotopes of the transition elements available can provide up to 100 distinguishable reporting tags, which can be measured essentially simultaneously by the mass spectrometer. The article is written for a readership not familiar with plasma source mass spectrometry, but very familiar with flow cytometry and cell biochemistry. None-the-less, the discussion of the processes that occur as a cell, containing multiple elemental tags, enters the plasma from which a cloud of ions is generated is very informative for the reader and probably also applies to the use of the ICP for single (nano)particle monitoring. Chemometric data handling is also covered with particular emphasis on unsupervised multivariate clustering analysis.

There have also been large numbers of reviews of sample preparation and sample introduction, many of which feature speciation analysis by a method that includes atomic spectrometry. An overview (17 pages, 89 references with titles) of extraction techniques in methods for the determination of species of $\mathrm{As}, \mathrm{Ge}, \mathrm{Hg}$, $\mathrm{Sb}$, Se in plant and animal tissues featuring chromatography with ICP-MS detection has been published. ${ }^{25}$ Target species were divided into two categories: (a) easy to extract species, being stable species existing as either discrete molecules or relatively weakly bound to cellular constituents, and (b) hard to extract species, being unstable species that dissociate on extraction or species incorporated within cellular constituents such as proteins. Several examples of cryogenic trapping for extraction and concentration in speciation analysis were presented. Examples of both LC and GC separations were included and the performance of the methods chosen for inclusion relating to extraction efficiencies, stability of species and artifact formation are critically reviewed. The article includes methods for $\mathrm{AB}$, arsenoribosides, lipidbound As, phytochelatins and thioarsenic species as well as the more commonly determined inorganic and methylated forms of As. Protection of any $-\mathrm{Se}-\mathrm{H}$ groups in organoselenium compounds is also discussed. For readers of the Czech language a review of sample storage, methods of extraction of $\mathrm{Hg}$ species and their derivatisation for GC has been published. ${ }^{26}$ Most of the methods are tabulated and cover detection with AFS, CVAFS, ICP-MS and MIP-AFS in 75 references. Anthemidis and Mitani $^{27}$ have covered advances in liquid-phase, micro-extraction techniques for metal, metalloid and organometallic species determination. It is noted that sample preparation is the most time-consuming and polluting step in the analytical method. Andruch et al. have reviewed the present state of coupling of DLLME with AAS citing 126 references (without titles), about 10 of which are concerned with speciation analysis. ${ }^{28}$ In a different review of liquid-phase micro-extraction procedures for the determination and speciation of trace elements sample preparation is characterised as the bottleneck in the method. ${ }^{29}$ Most of the speciation applications are either to the determination of two oxidation states or to the extraction of multiple species prior to chromatographic separation with elementspecific detection. There are also very few applications of ionic 
liquids for liquid-liquid microextraction relevant to elemental speciation; only two (both dealing with Cr speciation) were cited in a 95-reference review of the topic ${ }^{30}$ though clearly there is a growing literature describing applications of ionic liquids for sample preparation. Four elements (As, $\mathrm{Co}, \mathrm{Hg}$ and $\mathrm{Tl}$ ) are mentioned by Escudero et al. in a 108-reference (with titles) review of an apparently narrower field: bioanalytical separation and preconcentration using ionic liquids. ${ }^{31}$ The review covers both contaminants and functional biomolecules in biological systems (urine, blood, saliva, hair, and nails) and, again, electrothermal vaporisation is proposed for sample introduction to plasma spectrometers.

Urgast and Feldmann ${ }^{32}$ are enthusiastic about the possibilities of isotope ratio measurements in biological tissues using $L A$ $I C P-M S$, combined with information obtained from molecular MS techniques, to deliver valuable information on trace metal metabolism which would be a powerful tool for any metallomics study. The authors make a good case for the wider use of the technique pointing out a wide range of possibilities for stable isotope tracer studies to investigate the kinetics of trace elements on a microscale level that will support studies of the physiology and pathophysiology of trace metals in organisms. The drawbacks, in terms of the cost of the instrumentation and the level of expertise that is needed to operate it, is also acknowledged.

In a 254-reference (with titles) review of chemical vapour generation sample introduction systems for plasma optical emission and mass spectrometry, the topic of speciation, mainly for As and Se species separated by CE, is discussed in about 12 references. $^{33}$ All methods of vapour generation, including chemical, electrochemical and photochemical generation to produce hydrides, alkyls and other volatile species, such as metal chelates, as well as cold vapour, are included in a review of applications with ICP-MS. ${ }^{34}$ Just over one-quarter of the articles cited concern speciation and the review, while not particularly critical, does give a good indication of the current status of speciation by chemical vapour generation and ICP-MS, including a discussion of the possibilities for IDA. In addition, it was concluded that techniques, such as plasma-induced, microwave- and ultrasound-assisted vapour generation are promising areas for further exploration. In a parallel review (107 reviews, no titles) focused on GC separations, the derivatisation of metals and organometallics by borate reagents, including $\mathrm{BH}$ and tetraalkylborates were discussed by Zachariadis. ${ }^{35}$ The underlying chemistry of the reactions is discussed in some detail from which it is clear that the reviewer is familiar with the current work on the mechanism of HG reactions. A separate section is devoted to each of the elements, $\mathrm{As}, \mathrm{Hg}, \mathrm{Pb}$, $\mathrm{Se}$, and $\mathrm{Sn}$, of which those for $\mathrm{Hg}$ and $\mathrm{Sn}$ are the longest. There is also a section devoted to multi-element speciation and there is some discussion of derivatisation with Grignard reagents. Yin et $a .^{36}$ have focused even further: on the speciation analysis of just three elements (As, $\mathrm{Hg}$ and $\mathrm{Se}$ ). Furthermore, the use of enhanced cold vapour generation as an interface for LC and atomic spectrometry, speciation of volatile compounds in the gas phase, and IDA is emphasised. In this latter regard, the potential of MC-ICP-MS for species specific IDA is discussed, together with the possibility of the characterisation of the phytochelatin complexes of As and $\mathrm{Hg}$.

\section{Sample preparation}

Clearly almost all elemental speciation analyses involve sample preparation of some kind, and so all relevant research over the past year could be discussed in this section. Blanket coverage of the topic in this fashion does not serve the purpose of this Update, namely to highlight recent novel work that is of interest to the elemental speciation community. Only if sample preparation was the focus of the study or had some novel feature that makes the methodology of potential application to a number of elements is the work reviewed in this section. This means, for example, that speciation based on selective SPE chemistry that will only work for As species, for example, is reviewed in the later section devoted to As. The same comment applies to other "binary-type" speciation strategies such as the various forms of LLE.

Two research groups have investigated the possibilities of $U A E$. In the determination of monoiodotyrosine and diiodotyrosine (DIT) in edible seaweed, an ultrasound-assisted enzymatic hydrolysis procedure was developed. ${ }^{37}$ Pancreatin was chosen after preliminary evaluation of cellulose, $\beta$-glucosidase, $\alpha$-amylase, lipase, and pepsin. Parameters affecting the extraction efficiency ( $\mathrm{pH}$, temperature, mass of enzyme and extraction time) were evaluated by univariate approaches. The ultrasonic bath $(45 \mathrm{kHz})$ could heat solutions up to $80{ }^{\circ} \mathrm{C}$. The conditions chosen were $0.2 \mathrm{~g}$ of pulverised (agate mortar grinder mill) seaweed, $7 \mathrm{~mL}$ of a pancreatin solution containing $40 \mathrm{mg}$ of enzyme in a $0.2 \mathrm{M} / 0.2 \mathrm{M}$ dihydrogen phosphate/sodium hydroxide buffer at $\mathrm{pH}$ 8.0. Mixtures were irradiated at $50{ }^{\circ} \mathrm{C}$ for $12 \mathrm{~h}$, centrifuged at $3000 \mathrm{rpm}$ for $15 \mathrm{~min}$, washed with water, filtered through $0.20 \mu \mathrm{m}$ cellulose acetate filters. Solutions for total element determinations were prepared by MAE of $0.2 \mathrm{~g}$ with $5 \mathrm{~mL}$ of ultrapure water and $5 \mathrm{~mL}$ of TMAH $(25 \% \mathrm{~m} / \mathrm{m})$ followed by the centrifugation and filtration steps. Five different types of edible seaweed were analysed. To extract $\mathrm{Sb}$ species $\left(\mathrm{Sb}^{\mathrm{III}}, \mathrm{Sb}^{\mathrm{V}}\right.$ and $\left.\mathrm{TMSb}\right)$ from soils, an UAE procedure with citric acid has been developed. ${ }^{38}$ The researchers report that they evaluated other possible extractants but no details were given, though a table showing results by other workers for water, water-methanol, phosphate, citric acid, and EDTA is included. In the procedure selected, $0.1 \mathrm{~g}$ powdered sample (freeze dried, ground to $100 \mathrm{mesh}$ ) was weighed into $25 \mathrm{~mL}$ centrifuge tubes and extracted with $10 \mathrm{~mL}$ citric acid $(100 \mathrm{mM} \mathrm{pH} 2.03)$ in an ultrasonic bath (no details given) for $1 \mathrm{~h}$ followed by centrifugation at $8000 \mathrm{~g}$ at $48{ }^{\circ} \mathrm{C}$ for $10 \mathrm{~min}$. After dilution with the mobile phase, solutions were filtered $(0.22 \mu \mathrm{m})$. Multiple extractions were performed, and although a significant improvement was obtained by combining two extracts, no further benefits were obtained with three extracts. Though the recovery of spikes of the three species ranged from 90 to $120 \%$, the extraction efficiency for Sb already in the sample was 53\%. It was acknowledged that this number is poor compared with what is possible for the extraction of As species. The authors' introduction contains a useful discussion of almost 40 articles. 
Amaral et $a l .{ }^{39}$ evaluated six different procedures for the extraction of As species from plants and chicken feed. The methods for the plants involved using water, methanol, and nitric acid as solvents, and heating on a water bath, or with microwave radiation, and/or ultrasonic agitation. The chicken feed was extracted by nitric acid at $100{ }^{\circ} \mathrm{C}$ in a microwave oven. The best results for the plants were obtained using the acid extractants (around 90\%), followed by those for water (60-70\%). The poorest recoveries were obtained for methanol-water mixtures (50-60\%). For the water and nitric procedures, some As ${ }^{\mathrm{III}}$ was oxidised to $\mathrm{As}^{\mathrm{v}}$; and for the methanol procedures, some $\mathrm{As}^{\mathrm{V}}$ was reduced to $\mathrm{As}^{\mathrm{III}}$. The results are discussed in relation to some previously reported findings and some agreement noted. Inaccurate results were obtained for DORM-2 (dogfish muscle) by the procedure developed for the chicken feed suggesting the method is matrix specific. Guo et al..$^{\mathbf{4 0}}$ determined phenylarsenic compounds spiked into chicken and feed samples by HPLCICP-MS after preconcentration by hollow-fibre liquid-liquidliquid extraction. The analytes were extracted from the solid (lyophilised, ground and homogenised) sample materials by water in a two-stage, ultrasound-assisted procedure. In the experimental section of the paper, the description of the preconcentration is rather vague, and close reading of the results and discussion section is needed to discover that the pores of the fiber were filled with $20 \%$ methyltrioctylammonium chloride (an ionic liquid) in toluene, which acts as a "carrier" to transport the analytes across the membrane, that the stir-bar was rotating at $1000 \mathrm{rpm}$ and that the extraction time was $20 \mathrm{~min}$. The sample solution was adjusted to $\mathrm{pH} 10.2$ and the acceptor solution (in the interior channel of the fibre) was $0.3 \mathrm{M}$ $\mathrm{NaBr}$. Only $9 \mu \mathrm{L}$ of this solution was injected for the subsequent HPLC separation. Although enrichment factors (defined as the ratio of sensitivities) ranged from 86 to 372 -fold, only one phenylarsenic compound was found in one of the samples, whereas $\mathrm{As}^{\mathrm{V}}$ was found in all three of the feed samples and in one of the three chicken muscle samples. Spike recoveries (200 and $500 \mu \mathrm{g} \mathrm{kg} \mathrm{kg}^{-1}$ ) were not significantly different from $100 \%$. A reversed-phase, ion-pair HPLC method was employed with butanesulfonate, malonate and methanol (in water) as the mobile phase in which $\mathrm{As}^{\mathrm{V}}$ eluted, rather unusually, first (maybe even in the solvent front). Solution LODs ranged from 1 to $20 \mathrm{ng}$ $\mathrm{L}^{-1}$; as the sample preparation involved a 500-times dilution $(0.05 \mathrm{~g}$ to $25 \mathrm{~mL})$, the corresponding range of LODs in the solid would be 0.5 to $10 \mu \mathrm{g} \mathrm{kg}^{-1}$.

A similar approach has been applied ${ }^{41}$ to the speciation of $\mathrm{Cr}$ spiked into in natural waters, though the procedure was different. Four hollow fibres filled with octanol and the ends sealed, were placed in the sample solution to which acid, DDTC and 1-butyl-3-methylimidazolium tetrafluoroborate (an ionic liquid) were added to give the optimised concentrations. After heating to $40{ }^{\circ} \mathrm{C}$, stirring at the prescribed rate for $15 \mathrm{~min}$ (to extract $\mathrm{Cr}^{\mathrm{VI}}$ ), the contents of the fibres were combined to give $35 \mu \mathrm{L}$ of solution to which was added $65 \mu \mathrm{L}$ of a solution $95 \%$ ethanol and $1 \%$ nitric acid followed by measurement by FAAS. Following oxidation of $\mathrm{Cr}^{\mathrm{III}}$ with permanganate, total $\mathrm{Cr}$ was determined. The LOD was $0.7 \mu \mathrm{g} \mathrm{L}^{-1}$ for an enrichment factor of 175. The method was applied to three water samples, but could not detect either $\mathrm{Cr}$ species in any of them. Spike recoveries of 15 to $40 \mu \mathrm{g} \mathrm{L}^{-1}$ were reported, but not subject to any statistical analysis. Visual inspection suggests that those for $\mathrm{Cr}^{\mathrm{VI}}$ may be significantly lower than $100 \%$. Accurate analysis of a CRM (GSBZ5027-94, IERM environmental water) with certified value for $\mathrm{Cr}^{\mathrm{VI}}$ of $99 \mu \mathrm{g} \mathrm{L}^{-1}$ was obtained.

There are significant challenges for the preparation of small samples. In the determination of $\mathrm{Br}$ and $\mathrm{Cl}$ species in atmospheric particulates by HPLC-ICP-MS, ${ }^{42}$ water was a suitable extractant. The hot, pressurised extraction (of ten circular pieces cut from each collection filter) was carried out in a Dionex ASE-200 system equipped with $11 \mathrm{~mL}$ stainless steel extraction cells and cellulose filters $(1.983 \mathrm{~cm}$ diameter, Dionex). The variables studied included temperature, concentration of modifier (dilute acetic acid), static time, pressure, number of cycles and mass of dispersing agent (diatomaceous earth). The researchers found that the modifier and dispersing agent were not needed, and that only one extraction was needed at $100{ }^{\circ} \mathrm{C}$ and a pressure of $1500 \mathrm{psi}$. The total time for each extraction was $9 \mathrm{~min}$ (including $2 \mathrm{~min}$ static time). For the speciation of Se in cells by HPLC-ICP-MS, an on-chip magnetic SPE procedure has been developed. ${ }^{43}$ The processes of enzymatic digestions, selective retention of the analytes and desorption for subsequent HPLC separation were carried out in an integrated microfluidic chip. However, the real samples were pre-digested with snailase. Magnetic $\mathrm{Fe}_{3} \mathrm{O}_{4}$ NPs coated with sulfonated polystyrene, held in a magnetic field, retained selenoamino acid and peptide species by cation exchange (at the appropriate $\mathrm{pH}$ ). After washing, the analytes were released with the help of ultrasonic agitation into sodium carbonate solution. A batch procedure based on the same chemistries was run in parallel. The procedures were validated by the accurate analysis of CRM SELM-1 (selenium-enriched yeast). For the on-chip method, the contents of only 800 cells were analysed; both SeMet and SeCys2 could be quantified, but SeMetSeCyst, although detected, could not. The LODs ranged from 0.06 to $0.1 \mu \mathrm{g} \mathrm{L}^{-1}$. For the batch procedure the values were 0.03 to $0.09 \mu \mathrm{g} \mathrm{L}^{-1}$. An ionic liquid, 1-butyl-3-methylimidazolium tetrafluoroborate, was added to the mobile phase rather than trifluoroacetic acid as the ion-pair reagent, and the column was heated to $50{ }^{\circ} \mathrm{C}$.

Problems related to the stability of species in environmental samples and the costs of transport from sampling site to the analytical laboratory can be mitigated by suitable field sampling strategies. For the speciation of Fe in waters, Arpadjan et al. ${ }^{\mathbf{4 4}}$ selectively retained the species on Chelex-100 columns: $\mathrm{Fe}^{\mathrm{III}}$ was retained by a column in the $\mathrm{H}^{+}$form and $\mathrm{Fe}^{\mathrm{II}}$ was retained by a column in the $\mathrm{NH}_{4}{ }^{+}$form. After elution with $0.03 \mathrm{~mol} \mathrm{~L}^{-1} \mathrm{NH}_{4}-$ EDTA, the solution was analysed by FAAS or ETAAS. Concentrations of humic acid up to $0.01 \%$ did not interfere. For ETAAS, the LOD was $0.8 \mu \mathrm{g} \mathrm{L}^{-1}$. Badiei and co-workers ${ }^{45}$ have devised a method for $\mathrm{Cr}$ speciation in which species in seawater were electrodeposited in the field on portable Re coiled-filament assemblies, which, after drying, were transported to the lab for ICP-OES analysis with electrothermal, near-torch vaporisation. Selective deposition of $\mathrm{Cr}^{\mathrm{VI}}$ was obtained at $-0.3 \mathrm{~V} v$ s. $\mathrm{Ag} / \mathrm{AgCl}$ and of $\mathrm{Cr}^{\mathrm{III}}$ and $\mathrm{Cr}^{\mathrm{VI}}$ at $-1.6 \mathrm{~V}$. It was also found that in the 
absence of an electrodeposition potential $\mathrm{Cr}^{\mathrm{VI}}$ was spontaneously and selectively adsorbed on the coil. The LOD for $60 \mathrm{~s}$ electrodeposition were $20 \mathrm{ng} \mathrm{L}^{-1}$ for $\mathrm{Cr}^{\mathrm{III}}$ and $10 \mathrm{ng} \mathrm{L}^{-1}$ for $\mathrm{Cr}^{\mathrm{VI}}$. The method gave accurate results for the analysis of CRM 544 (BCR lyophilised simulated tap or natural water) and was able to detect $\mathrm{Cr}$ species in some real seawater samples taken from Halifax (Nova Scotia) harbour. On the other hand, a method developed by Hsu et al. ${ }^{\mathbf{4 6}}$ in which the Cr species were separated in a microfluidic device by SPE connected directly to the ICP mass spectrometer could not detect the species in real samples. The extractant was a polyoxometalate cluster $\left(\mathrm{Cs}_{2} \cdot 5 \mathrm{H}_{2} 0.5 \mathrm{PW}_{12} \mathrm{O}_{40}\right)$, which selectively retained $\mathrm{Cr}^{\mathrm{III}}$ (capacity $5.8 \mathrm{mg} \mathrm{g}^{-1}$ ) allowing $\mathrm{Cr}^{\mathrm{VI}}$ to pass directly to the instrument. The retained $\mathrm{Cr}^{\mathrm{III}}$ was eluted with $1 \mathrm{M}$ nitric acid.

\section{Instrumental techniques and developments}

Compared with last year's ASU, this section has been streamlined a bit. Procedures involving electrophoresis, GC, field flow fractionation or a novel flow-based procedure are included, but methods involving HPLC are discussed in the later relevant element section.

\subsection{Developments in species separation}

An interface developed for CE-ESI-MS has been used to deliver As species separated by $C E$ to an ICP mass spectrometer. ${ }^{47}$ The device was described as a sprayer consisting of a stainless steel capillary surrounded by an outer stainless steel tube. The CE capillary passed through the inner stainless steel capillary of the sprayer with a gap between them and protruded approximately $0.1 \mathrm{~mm}$ out of the sprayer tip. Sheath flow liquid was delivered into the inner stainless steel capillary to close the electric circuit and delivered a suitable flow rate to produce a stable electrospray. The carrier gas was added at the outer stainless steel tube. The sheath flow liquid was mixed with the CE effluent at the sprayer tip and the mixture was then nebulised by the carrier gas from the outer tube. To maintain a steady separation voltage, the stainless-steel shell of the sprayer was grounded. The device was installed at the base of the spray chamber to ensure that the liquid from the capillary was directly introduced into the ICP-MS after nebulisation. After appropriate optimisation, baseline separation of ten arsenic species was achieved on a $100 \mathrm{~cm}$ of $50 \mu \mathrm{m}$ ID fused-silica capillary with a buffer containing $12 \mathrm{mM} \mathrm{NaH}_{2} \mathrm{PO}_{4}$ and $8 \mathrm{mM} \mathrm{HBO}_{3}$ at $\mathrm{pH} 9.20$ with an applied voltage of $+30 \mathrm{kV}$. The LOD of the ten As compounds ranged from 0.9 to $3.0 \mu \mathrm{g} \mathrm{kg}^{-1}$ (as arsenic). Compound-dependent responses, which appear to be considerable from visual inspection of the electropherogram for the set of standards were not discussed. There is also ambiguity as to whether the concentrations refer to the compound or to the arsenic content. The range of LOD values obtained also suggests that sensitivity (i.e. slope of the calibration) is species dependent. No calibration slope values were given, and it is not clear how each species was quantified. The word "calibration" does not appear anywhere in the article. Water extracts of two CRM (TORT-2, lobster hepatopancreas, and DORM-3, fish protein) were analysed for As species. For the TORT-2 material AB, DMA and As ${ }^{\mathrm{V}}$ were found, the sum of whose concentrations was not significantly different from the certificate value for the total; however, for the DORM-3 material (which contained AB, DMA, MMA and $\mathrm{As}^{\mathrm{V}}$ ) the total was inaccurate, which was considered to be because of low extraction efficiency. Water extracts of two herbal plants and one chicken sample were also analysed. The plants contained $\mathrm{AB}, \mathrm{As}^{\mathrm{III}}$ and $\mathrm{As}^{\mathrm{V}}$, whereas only $\mathrm{As}^{\mathrm{III}}$ was found in the chicken.

A procedure for the determination of $\mathrm{Hg}$ species (as the dithizone complexes) by TLC with AFS detection has been developed. ${ }^{48}$ $\mathrm{The} \mathrm{Hg}$ atoms were generated by a plasma jet, sustained in Ar in a $300 \mu \mathrm{m}$ quartz capillary, that impinged on the surface of the plate to desorb the separated compounds. The LODs for $\mathrm{iHg}$, $\mathrm{MeHg}$ and phenyl $\mathrm{Hg}$ were 3, 9, and $6 \mathrm{pg}$, corresponding to 3, 9 and $6 \mu \mathrm{g} \mathrm{L}^{-1}$, as the sample volume applied to the plate was $1 \mu \mathrm{L}$. No mercury species were detected in the water and urine sample examined, though recoveries of spikes of 500 and $1000 \mu \mathrm{g} \mathrm{L}^{-1}$ were not significantly different from $100 \%$. The researchers propose that it would be possible to design a portable, miniature, and mobile instrument for field speciation analysis, which seems a bit optimistic given that both an argon supply and a power supply capable of providing $2.5 \mathrm{kV}$ at $10 \mathrm{kHz}$ are needed. A Chinese language $\operatorname{article~}^{\mathbf{4 9}}$ describes a miniaturised long-optical path atomic absorption spectrometer with a dielectric barrier discharge as atomiser for the detection of $\mathrm{iHg}$ and $\mathrm{MeHg}$ following vapour generation with $\mathrm{BH}$ in a sequential injection system. The absorbance from $\mathrm{iHg}$ was measured with the atomiser off, while the total absorbance from both species was measured with the atomiser on. The LODs were 0.3 and $0.4 \mu \mathrm{g} \mathrm{L}^{-1}$. It was indicated that the reliability of the system was demonstrated by analysing certified reference materials and real samples for mercury species, but it is not possible to verify that this really was the case.

Researchers writing in Japanese ${ }^{50}$ have reported on the determination of $S$ and $P$ compounds separated by $G C$ using an in-tube microplasma torch and $\mathrm{AE}$ detection. The device is a radio frequency plasma sustained in helium into which a grounded tubular platinum electrode $(0.3 \mathrm{~mm}$ i.d., $0.5 \mathrm{~mm}$ o.d.) was inserted. The emitted light was transferred to a spectrometer with a CCD by an optical fibre. For thioanisole the LOD (as S) was $4 \mathrm{pg} \mathrm{s}^{-1}$ and for triethyl phosphate as a test $\mathrm{P}$ compound, the LOD was $22 \mathrm{pg} \mathrm{s}^{-1}$.

A procedure for the indirect determination of aminopolycarboxylic acids in surface water has been developed, in which the complexes with In are determined by IC-ICP-MS. ${ }^{51}$ Competition from iron in real samples was offset by the addition of sulfite to reduce $\mathrm{Fe}^{\mathrm{III}}$ to $\mathrm{Fe}^{\mathrm{II}}$, whose complexes with the analytes are much less stable. Excess In was removed by a cation-exchange guard column. The method was validated by the analysis of 62 samples that had already been analysed by a GC-MS method. A linear regression of the results (for the determination of EDTA and diethylene triamine pentaacetic acid) showed no significant difference based on the $95 \%$ confidence intervals about the slope and intercept. Visual inspection of the plot for EDTA showed what the authors 
described as "some scatter...around the middle." which actually looks like poorly correlated data.

\subsection{Developments in instrumentation}

Pfeifer et al..$^{52}$ have developed a low-flow ion source and sampling cone for ICP-MS and demonstrated applications with both LC and GC. The device is a bulb-shaped quartz torch with a PEEK mount that positions the torch inside the rf load coil, and which also contains the gas connectors, the electrical contacts for the ignition spark, and the torch cooling system. A series of eight $1 \mathrm{~mm}$ nozzles arranged in a circle in the demountable lid of the device allow cooling of the external torch wall by compressed air at a pressure of $600 \mathrm{kPa}$ (flow rate not given). To prevent secondary discharges an electrostatic shield, consisting of an electrically grounded platinum sheet, $0.4 \mathrm{~mm}$ thick, was placed between torch and load coil. The assembly can be used for elemental analysis by solution nebulisation and hence is a suitable interface for LC. For GC detection, the GC capillary was inserted into the device and positioned close to the plasma with the aid of an alumina capillary and special fasteners. The "nebuliser" gas flow was introduced tangentially around the GC capillary. A new ionsampling interface was needed to minimise interferences caused by entrainment of cooling air into the conventional sampler. The low-flow ICP-MS sampler has a straight tip that extends from the tapered part of the sampler, which is placed very close to the torch (the gap was only $0.2-0.3 \mathrm{~mm}$ ). The total argon consumption was around $1.3 \mathrm{~L} \mathrm{~min}^{-1}$, whereas for conventional operation the consumption was about $17 \mathrm{~L} \mathrm{~min}^{-1}$, and the power was decreased from the conventional $1.4 \mathrm{~kW}$ to $1 \mathrm{~kW}$ or less (in the case of GC detection). The performance parameters were degraded: LODs for most elements were poorer by factors that ranged from 2-10, internal standardisation was necessary, and matrix interferences (as observed in the analysis of NIST 1643e, simulated fresh water) were encountered. The possibilities for GC detection were demonstrated by the measurement of dimethyl $\mathrm{Hg}$ and dibutyl $\mathrm{Hg}$ standards; and for LC, a cobaltlabeled model protein ( $\beta$-lactoglobulin). The excess derivatising agent, cobaltocene, was also observed in the chromatogram. The Co LOD was $0.9 \mu \mathrm{g} \mathrm{L}^{-1}$ (though for the direct nebulisation of aqueous solutions the Co LOD was $2 \mathrm{ng} \mathrm{L}^{-1}$ ). Compounddependent responses were not discussed.

Work undertaken at NIST found compound-dependent responses in the determination of Co species by HPLC-ICP-MS. ${ }^{53}$ The signal intensity for Co as cyanocobalamin was $89 \%$ of that of Co from NIST standard solution (SRM 3133), which was attributed to decreased of atomisation and ionisation efficiency because of the sequestration of $\mathrm{Co}$ in the corrin ring. The method developed was applied to the determination of vitamin B-12 in fortified breakfast cereal (SRM 3233) and multivitamin tablets (SRM 3280) and results comparable to those obtained by other agencies obtained. As the typical values of vitamin B-12 in dairy and meat products range from 2 to $900 \mu \mathrm{g} \mathrm{g}^{-1}$, the LOD of $0.9 \mathrm{ng} \mathrm{g}^{-1}$ means that the method has sufficient detection capability to determine vitamin B-12 in these products. It was emphasised that care must be taken to ensure stability of cyanocobalamin during the measurement, as the chemical is unstable in ambient light. Some problems with the storage of samples for subsequent evaluation of the size dependence of metal-organic matter complexation by SEC-ICP-MS have been reported..$^{54}$ The signal-to-noise ratio and peak reproducibility between duplicate analyses were used as QC parameters for the examination of various environmental samples. Consistent peak times and heights were obtained for $\mathrm{Br}, \mathrm{Cl}, \mathrm{Cu}, \mathrm{Mg}, \mathrm{Mn}$, and $\mathrm{Pb}$. Those for $\mathrm{Al}, \mathrm{Cd}, \mathrm{Co}, \mathrm{Fe}, \mathrm{Ni}, \mathrm{Sb}, \mathrm{Se}, \mathrm{Sn}, \mathrm{V}$, and $\mathrm{Zn}$ were less consistent, though the same parameters were consistent in some samples. It was reported that ultrafiltering and centrifuging produced similar peak distributions, but that filtering through glass fibre produced more high-molecular weight (MW) peaks, a result also obtained for storage in glass compared with storage in plastic bottles.

\subsection{Chemical vapour generation}

Two versions of a device for the photochemical generation of volatile Se compounds have been described. ${ }^{55,56}$ The titles and abstracts of the two papers are very similar and the earlier paper is not discussed in the later paper, so close reading of the contents of each is needed to see what the differences are. The chip device was fabricated from poly(methyl methacrylate), which has good UV transmission characteristics for the $365 \mathrm{~nm}$ light that illuminates a channel coated with nano titanium dioxide photocatalyst. In the later paper, the addition of poly(diallyldimethylammonium chloride) as a mediator for $\mathrm{TiO}_{2}$ deposition was described. However, the analytical performance, in terms of LOD, is one order of magnitude worse than that described in the earlier paper, ${ }^{55}$ where LODs for $\mathrm{Se}^{\mathrm{IV}}$ and $\mathrm{Se}^{\mathrm{VI}}$ of 0.005 and $0.004 \mu \mathrm{g} \mathrm{L} \mathrm{L}^{-1}$, respectively are reported. In this paper, results for three samples are reported (NIST 1643e, simulated natural water; NASS-3, seawater; and a river water), though none of them contained measurable amounts of both species. In the slightly later paper ${ }^{56}$ reporting poorer LODs, the results for the analysis of an irrigation water, which does contain both species, are given (in addition to those for NIST 1643e). Spike recoveries of concentrations between 0.2 and $0.5 \mu \mathrm{g} \mathrm{L} \mathrm{L}^{-1}$ ranged from 93 to $112 \%$. Two different ion-exchange HPLC procedures were described. Both papers contain detailed discussions of the mechanisms by which the Se species are adsorbed on the catalyst surface and the role of formic acid as a hole scavenger.

Inorganic As speciation has been performed by CE separation with a HG-based interface with AAS detection. ${ }^{57}$ The eluent from the capillary was mixed with a solution containing $\mathrm{HCl}$, ascorbic acid and thiourea. The latter two reagents were added, presumably, to reduce $\mathrm{As}^{\mathrm{V}}$ to $\mathrm{As}^{\mathrm{III}}$, though this is not discussed by the authors. Under the optimum conditions, the signal for $\mathrm{As}^{\mathrm{III}}$ is about $50 \%$ greater than that for the same concentration of $\mathrm{As}^{\mathrm{V}}$. Either an electrothermal or a heated-tube atomiser was used. The well-separated peaks eluted with about $5 \mathrm{~min}$ between them. Only one sample was analysed, a river sediment sample that was extracted (after grinding and drying) with phosphoric acid in a microwave oven. Both species were detected at concentrations of 0.45 and $0.81 \mathrm{mg} \mathrm{kg}^{-1}$, for $\mathrm{As}^{\mathrm{III}}$ 
and $\mathrm{As}^{\mathrm{V}}$, respectively. Spikes equivalent to $2.5\left(\mathrm{As}^{\mathrm{III}}\right)$ and $5\left(\mathrm{As}^{\mathrm{V}}\right)$ $\mathrm{mg} \mathrm{kg}{ }^{-1}$ were 97 and $96 \%$ recovered, respectively.

The relative merits of HPLC-ICP-MS and HG-cryotrappingAAS have been evaluated for the support of a study of the formation and fate of methylarsonous acid (MMA $\left.{ }^{I I I}\right)$ and dimethylarsinous acid $\left(D M A^{I I I}\right)$ in the course of iAs metabolism. ${ }^{58}$ Using reversed-phase ion-pair chromatography, significant losses of both compounds from the in vitro methylation mixture were observed, with total As recoveries of approximately $25 \%$. It was concluded that the compounds were bound to $\mathrm{As}^{\mathrm{III}}$ methyltransferase or had interacted with other components of the methylation mixture, forming complexes that did not elute from the column. In addition, compound dependent responses were observed. Oxidation of the mixture with $\mathrm{H}_{2} \mathrm{O}_{2}$, which converted trivalent arsenicals to their pentavalent analogues, prior to HPLC separation increased total arsenic recoveries to about $95 \%$. The cryotrapping method was based on differences in boiling points of the three hydride species generated (arsine, monomethylarsine and dimethylarsine). The trap was filled with Chromosorb WAW-DCMS 45/60, 15\% OV-3. Reaction conditions were selected so that only the trivalent species formed volatile derivatives, then after the addition of $\mathrm{L}$-cysteine, the total of each species was determined and hence the concentration of the pentavalent compounds by difference. In the analysis of the in vitro methylation mixture, the total recovery was about $72 \%$. The authors conclude with some cautionary words for other researchers: if quantifying the trivalent methylated arsenicals as biomarkers is an essential part of the study objectives, then the existing HG-CT-AAS technique provides far less negative bias compared with that of the existing HPLC-ICP-MS approach. This negative bias should also be expected when analysing other biological matrices that provide binding sites for $\mathrm{MMA}^{\mathrm{III}}$ and $\mathrm{DMA}^{\mathrm{III}}$, including human urine. Thus, laboratories that do not attempt to quantify species-specific recoveries or quantify the chromatographic mass balance within the matrix are choosing not to estimate a source of uncertainty that may undermine the reliability and utility of the results.

\subsection{Solid-state speciation}

As the number of synchrotron sources continues to increase and access for researchers becomes easier, the use of the various $X$-ray techniques that provide information about chemical speciation is also going to increase. For a large number of applications, XAS is a unique spectroscopy that can potentially unravel the coordination chemistry of bio-inorganic elements particularly in metalloproteins. The accurate measurement of bond lengths and active site geometries is particularly important in deriving an understanding of reaction mechanisms.

A detailed tutorial introduction to XAS of biological materials has been provided by Ortega et al. ${ }^{59}$ It was noted that XAS can be divided into X-ray absorption near edge structure (XANES) spectroscopy, which provides information primarily about the geometry and oxidation state, and extended X-ray absorption fine structure (EXAFS) spectroscopy, which provides information about the nearest neighbours of the atom of interest. The main advantages of the XAS method are listed as follows: subatomic (angstrom) resolution, ability to analyse almost any type of samples (including amorphous materials), and the possibility to analyse such materials in situ with little or no sample preparation. The main limitations of XAS were considered to be its low detection capability (in the $\mathrm{mM}$ or $\mu \mathrm{g} \mathrm{g}^{-1}$ range), the difficulty of deconvoluting the data when the sample is composed of a mixture of structures of the target element, and the limit to ligands containing elements in one row of the periodic table. The technique is also compared with alternative or complementary methods, such as X-ray diffraction and X-ray photoelectron spectroscopy. The specific needs of sample preparation and preservation throughout the process of storage and analysis are explained, and the importance of cryogenic methods for biological samples discussed. Future trends involving micro- and nano-XAS, time-resolved XAS, and high energy resolution XAS are also discussed.

An authoritative discussion of the quantitative determination of $S$ functional groups in natural organic matter by XANES spectroscopy is also presented in similar tutorial format. ${ }^{60}$ In this paper two new approaches to quantify $\mathrm{S}$ functionalities in natural organic matter are presented. In the first, the K-edge spectrum is decomposed into Gaussian and two arctangent functions, as in the usual Gaussian curve fitting method, but the applicability of the model is improved by a rigorous simulation procedure that forces convergence on chemically and physically realistic values. Fractions of each type of functionality are obtained after spectral decomposition by correcting Gaussian areas for the change in X-ray absorption cross-section with increasing oxidation state. In the second method, the K-edge spectrum is partitioned into a weighted sum of component species, as in the usual linear combination fitting (LCF) method, but is fit to an extended database of reference spectra under what is described as the constraint of non-negativity in the loadings (Combo fit). The fraction of each S functionality is taken as the sum of all positive fractions of references with similar oxidation state of sulfur. The two methods are then applied to eight humic and fulvic acids from the International Humic Substances Society producing results about the nature and fractions of sulfur functionalities consistent with each other. The reviewers also discuss experimental difficulties and uncertainties in the results associated with the analysis of concentrated and heterogeneous samples. Finally the spectra of the humic and fulvic materials and the reference compounds are made available as an open source for further interlaboratory testing.

In the interests of making the best use of synchrotron beam time, Wright et al. ${ }^{61}$ show that usable results from small-angle $X$-ray scattering characterisation of protein complexes can be performed "at home," which in this case is the Barkala X-ray biophysical laboratory at the University of Liverpool. Copperzinc superoxide dismutase (SOD1) was studied and its complex formed with the human copper chaperone for SOD1 at concentrations that reflect those expected after dilution during chromatography and with exposure times short enough to match protein eluting from a standard preparation-grade SEC column. It was shown that with a Rigaku FR-E + Superbright 
rotating copper anode X-ray generator (operated at $45 \mathrm{kV}$ and $55 \mathrm{~mA}$ giving a flux density of about 1011 photons s $\mathrm{sm}^{-1}$ ) and a PILATUS $300 \mathrm{~K}-20 \mathrm{~Hz}$ hybrid pixel detector, a $10 \mathrm{~min}$ exposure provided data of quality sufficient to assign accurately the radius of gyration, maximum dimension and molecular mass. It was also suggested that structural biologists who are studying systems containing transient protein complexes, or proteins that tend to aggregate, could make advanced preparations in-house for more effective use of limited synchrotron beam time.

In the same vein of using in-house commercial instrumentation the possibilities for chromium speciation in solids using wavelength dispersive XRF spectrometry of $\mathrm{Cr} \mathrm{K}$ beta lines have been evaluated. ${ }^{62}$ Known reference samples were tested with three approaches to data processing, including a peak height calibration, a partial least squares and principal components regression, which were compared for accuracy. Twenty-three pure compounds were selected from which seven mixtures of known composition were prepared. In addition, three wellstudied real samples were used to demonstrate the potential of the method for practical speciation cases: a soil (NIST SRM 2701, a contaminated soil composed largely of chromite ore processing residue), a paint (NIST SRM 2571, paint-coated, polyester sheets which were prepared by using known concentrations of a lead chromate pigment) and a polymer (polypropylene plastic) PP-H GBW08405 (National Institute of Metrology, Beijing, China) prepared by doping a polypropylene base material with $\mathrm{Cd}, \mathrm{Cr}, \mathrm{Hg}$ and $\mathrm{Pb}$ in the form of oxides, salts or pigments. The researchers found the accuracy of the methods to be about the same, with an average relative error of about $15 \%$. It was pointed out that whereas the partial least squares and principal components regression can be easily implemented in an automated way to provide information about the other oxidation states present in the sample, the peak fitting method cannot be automated (and is considered to be analyst-dependant) and does not provide the information about other oxidation states. Finally, the authors note that the partial least squares and the peak height approaches can be used up to $0.5 \%$ total $\mathrm{Cr}$ which make XRF methods viable alternatives to $\mathrm{X}$-ray induced photoelectron spectroscopy.

\section{CRMs and metrology}

From the literature searched it is apparent that no new CRMs certified for individual species have appeared this year.

Triple isotope dilution mass spectrometry (ID-MS) has been used to quantify transferrin in a human serum CRM, ERMDA470k/IFCC. ${ }^{63}$ The hetero atom used for quantification was Fe, with ${ }^{57} \mathrm{Fe}$ being the spike isotope and an Fe saturation procedure was used to ensure a uniform Fe/protein stoichiometry. An anion exchange column, Mono-Q, 5/50 GL, with an aqueous based gradient elution was used to separate the transferrin from other matrix components. The required isotope amount ratio measurements from the transient signals were made using a quadrupole ICP-MS with $\mathrm{H}_{2}$ as the collision/reaction gas. The developed procedure was compared with double ID-MS by the use of full uncertainty budgets and to demonstrate the suitability of triple ID-MS as a reference procedure. The relative expanded uncertainty $(k=2)$ for triple ID-MS $(3.6 \%)$ was smaller than that for double ID-MS $(4.0 \%)$. The major uncertainty contributions arose from the precision obtained for the isotope ratio measurements and, to a much lesser extent, the purity of the transferrin in the CRM. The content of transferrin found in the human serum reference material ERM-DA470k/IFCC with both methods was in good agreement with each other, triple IDMS $\left(2.426 \pm 0.086 \mathrm{~g} \mathrm{~kg}^{-1}\right)$, double ID-MS $\left(2.317 \pm 0.092 \mathrm{~g} \mathrm{~kg}^{-1}\right)$, and the certified value $\left(2.41 \pm 0.08 \mathrm{~g} \mathrm{~kg}^{-1}\right)$. Although triple IDMS is a little more time consuming compared to double ID-MS, there is the advantage that the isotopic composition of the spike material does not have to be determined.

\section{Elemental speciation analysis}

\subsection{Antimony}

An investigation of Sb-EDTA complexes and their use in $\mathrm{Sb}$ speciation analysis has been undertaken by Kolbe et al. ${ }^{64}$ The aim of the study was to minimise the C intake into the HPLCICP-MS system in order to lower the LOD achievable. The flow rate of EDTA was decreased to $0.4 \mathrm{~mL} \mathrm{~min}^{-1}$ by using a HPLC column with a smaller inner diameter (Hamilton PRP X-100, $150 \mathrm{~mm} \times 2.1 \mathrm{~mm}, 10 \mu \mathrm{m})$. This approach results in shorter retention times, a LOD of $<50 \mathrm{ng} \mathrm{L}^{-1}$ and a considerable reduction in $\mathrm{C}$ intake. However, different sensitivities were observed for $\mathrm{Sb}^{\mathrm{V}}$ and $\mathrm{Sb}^{\mathrm{III}}$. This was studied using structural information from ESI-MS measurements on the formed complexes. Antimonite was shown to be mainly complexed as negatively charged ${ }^{64}$ independently from initial reference substance: $\mathrm{Sb}_{2} \mathrm{O}_{3}, \mathrm{SbCl}_{3}$ and $\mathrm{Sb}^{\mathrm{III}}$-tartrate. For complete formation of the $\mathrm{Sb}^{\mathrm{III}}$-EDTA complex, a pre-treatment of the samples and standard solutions was found to be necessary. The addition of EDTA (final concentration $20 \mathrm{mM}$ ) resulted in similar intensities for $\mathrm{Sb}^{\mathrm{V}}$ and $\mathrm{Sb}^{\mathrm{III}}$. The EDTA complex was formed completely in less than two minutes and in water samples with initial $\mathrm{pH}$ values of 2-11. Hollow fibre liquid phase microextraction and DLLME methods combined with TXRF for the determination of low amounts of isb species in waters have been reported. ${ }^{65}$ Various experimental parameters were optimised but the best analytical strategy for the determination of $\mathrm{Sb}^{\mathrm{III}}$ and $\mathrm{Sb}^{\mathrm{V}}$ in the low $\mu \mathrm{g} \mathrm{L}^{-1}$ range was found to be the application of the DLLME mode before TXRF analysis. The developed methodology was successfully applied to the determination of inorganic Sb speciation in different types of spiked water samples.

A study to determine whether structural Fe in clays can affect the oxidation state of As and Sb adsorbed at the clay surface, and to compare the reactivity of clay structural $\mathrm{Fe}^{\mathrm{II}}$ with systems containing $\mathrm{Fe}^{\mathrm{II}}$ present in dissolved/adsorbed forms has been reported. ${ }^{66}$ The experimental systems included batch reactors with various concentrations of $\mathrm{As}^{\mathrm{III}}, \mathrm{Sb}^{\mathrm{III}}, \mathrm{As}^{\mathrm{V}}$, or $\mathrm{Sb}^{\mathrm{V}}$ equilibrated with oxidised (NAu-1) or partially reduced (NAu-1-Red) nontronite, hydrous aluminium oxide (HAO) and kaolinite (KGa-1b) suspensions under oxic and anoxic conditions. The reaction times ranged from 0.5 to $720 \mathrm{~h}$, and $\mathrm{pH}$ was constrained at 5.5 (for As) and at 5.5 or 8.0 (for $\mathrm{Sb}$ ). The oxidation 
state of $\mathrm{As}$ and $\mathrm{Sb}$ in the liquid phase was determined by HPLCICP-MS and in the solid phase by XAS. The results show that structural $\mathrm{Fe}^{\mathrm{II}}$ in NAu-1-Red was not able to reduce $\mathrm{As}^{\mathrm{V}}$ or $\mathrm{Sb}^{\mathrm{V}}$ under the conditions examined, but reduction was seen when aqueous $\mathrm{Fe}^{\mathrm{II}}$ was present in the systems with kaolinite (KGa-1b) and nontronite (NAu-1). The ability of the structural $\mathrm{Fe}$ in nontronite clay NAu-1 to promote oxidation of $\mathrm{As}^{\mathrm{III}} / \mathrm{Sb}^{\mathrm{III}}$ was greatly affected by its oxidation state: if all structural Fe was present as $\mathrm{Fe}^{\mathrm{III}}$, no oxidation was observed. However, when the clay was partially reduced NAu-1-Red promoted the most extensive oxidation under both oxic and anoxic conditions. Long-term batch experiments revealed the complex dynamics of As aqueous speciation in anoxic and oxic systems when reduced As was initially added: rapid disappearance of $\mathrm{As}^{\mathrm{III}}$ was observed due to oxidation to $\mathrm{As}^{\mathrm{V}}$ followed by a slow increase of aqueous As ${ }^{\mathrm{III}}$.

The speciation of $\mathrm{Sb}$ in samples of brake linings, brake pad wear residues, road dust, and atmospheric particulate matter PM10 and PM2.5 has been studied using SEM, ICP-MS and SRXAS. ${ }^{67}$ The advantage of SR-XAS is that samples do not undergo any chemical treatment prior to measurements, thus excluding possible alterations. These analyses revealed that the samples of wheel rims dust, road dust, and atmospheric particulate matter are comprised of a mixture of $\mathrm{Sb}^{\mathrm{III}}$ and $\mathrm{Sb}^{\mathrm{V}}$ in different relative abundances. Brake linings were composed of $\mathrm{Sb}^{\mathrm{III}}$ oxide $\left(\mathrm{Sb}_{2} \mathrm{O}_{3}\right)$ and stibnite $\left(\mathrm{Sb}_{2} \mathrm{~S}_{3}\right)$. Stibnite was also detected in some of the particulate matter samples. The results suggest that $\mathrm{Sb}_{2} \mathrm{~S}_{3}$ during the brake abrasion process is easily decomposed forming more stable compounds such as $\mathrm{Sb}$ mixed oxidic forms. Therefore, Sb redox speciation may enhance the selectivity of this element as a tracer for motor vehicle emissions.

Meglumine antimonate is the active compound in commercial treatments for leishmaniasis, a tropical disease caused by parasitic protozoa, which is estimated to affect 12 million people worldwide. This drug mainly contains $\mathrm{Sb}^{\mathrm{V}}$ in the form of an organic complex with $N$-methylglucamine (NMG). During the synthesis of this molecule, traces of $\mathrm{Sb}^{\mathrm{III}}$ may be present, and also probably complexed. Since $\mathrm{Sb}^{\mathrm{III}}$ is considered more toxic than $\mathrm{Sb}^{\mathrm{V}}$, it is important to evaluate the $\mathrm{Sb}^{\mathrm{III}}$ concentration in the drug samples. The literature reports very different concentrations for residual concentrations of $\mathrm{Sb}^{\mathrm{III}}$ in drug ampoules, and so Seby et al. ${ }^{68}$ have compared an anion exchange method coupled to ICP-MS cross-referenced with an electrochemistry method (differential pulse polarography (DPP)) that could be used for routine analysis on the production site. To obtain Sb species in detectable forms, the complexes between Sb species and NMG need to be broken. This was done by diluting samples in hydrochloric acid in deaerated conditions to avoid $\mathrm{Sb}$ redox reactions. For the two analytical methods, the $\mathrm{HCl}$ concentration were optimised to obtain simultaneously a complete destruction of the complexes as well as limited redox reactions for $\mathrm{Sb}^{\mathrm{V}}$ and $\mathrm{Sb}^{\mathrm{III}}$ released species. For HPLC-ICP-MS, a dilution with $5 \mathrm{M} \mathrm{HCl}$ gave the better results. The side reaction is an oxidation of $\mathrm{Sb}^{\mathrm{III}}$ which can be limited by the removal of oxygen. When DPP is used, the major problem is the reduction of $\mathrm{Sb}^{\mathrm{V}}$ which is present in high amount in the samples. Working with $0.6 \mathrm{M} \mathrm{HCl}$ allows this problem to be minimised. When applied to a range of different samples the $\mathrm{Sb}^{\mathrm{III}}$ concentration values were in good agreement for the two analytical methods, with HPLC-ICP-MS offering the advantage of the simultaneous detection of both $\mathrm{Sb}$ redox species.

\subsection{Arsenic}

The speciation of As continues to attract many workers although many publications report on applications rather than fundamental studies or improved analytical techniques. Unsurprisingly, ICP-MS (coupled to HPLC for speciation studies) is by far the most widely used technique. The effect of common As species on the ICP-MS signal working at a low liquid flow rate has been investigated by Grotti et al. ${ }^{69} \mathrm{~A}$ significant decrease (up to $65 \%$ ) in the relative sensitivity of $\mathrm{As}^{\mathrm{III}}$ compared to $\mathrm{As}^{\mathrm{V}}$ was found, while MMA, DMA and AB gave the same response (within $6 \%$ ) as $\mathrm{As}^{\mathrm{V}}$, throughout the $20-1000 \mu \mathrm{L} \mathrm{m^{-1 }}{ }^{-1}$ liquid flow rate range. The effect was independent of the analytical concentration in the 1-100 $\mu \mathrm{g} \mathrm{L}^{-1}$ range, and it was ascribed to processes related to both the sample introduction system and the ion generation and transport. Ion defocussing due to dissimilar kinetic energy of the As ions generated from $\mathrm{As}^{\mathrm{III}}$ and $\mathrm{As}^{\mathrm{V}}$ was ruled out. Results obtained by various micronebuliser/spray chamber configurations showed that the temperature of the spray chamber is relevant in determining the relative responses of the As species: Heating the spray chamber at $60{ }^{\circ} \mathrm{C}$ caused a decrease in relative sensitivity of $\mathrm{As}^{\mathrm{III}}$ and DMA compared to $\mathrm{As}^{\mathrm{V}}$, while the $\mathrm{As}^{\mathrm{III}}{ }^{\mathrm{IIO}}-\mathrm{As}^{\mathrm{V}}$ signal ratio was improved by cooling at 4 ${ }^{\circ} \mathrm{C}$. The relative response of $\mathrm{As}^{\mathrm{III}}$ and $\mathrm{As}^{\mathrm{V}}$ was also significantly influenced by the presence of ammonium phosphate, which mitigated the difference between the species using conventional sample introduction devices. The influence of the chemical species on the ICP-MS signal was also investigated for species of other elements, and significant differences in sensitivity for $\mathrm{Hg}$, Se and Sn compounds were found when working at a low liquid flow rate. These effects were shown to influence the accurate quantification of total concentration, as well as for As speciation analysis by $\mu$ HPLC-ICP-MS.

Multi-wall carbon nanotubes have been modified with branched cationic polyethyleneimine to serve as a novel adsorbent for the selective adsorption of $\mathrm{As}^{\mathrm{V}} .^{70}$ About $5 \mathrm{mg}$ of the composites were used to pack a mini-column for on-line SPE preconcentration of iAs in a sequential injection system prior to detection by HG-AFS. At pH 5.8 a sorption efficiency of $80 \%$ was achieved for $\mathrm{As}^{\mathrm{V}}$ at $10 \mu \mathrm{g} \mathrm{L}^{-1}$, resulting in a sorption capacity of $26.2 \mathrm{mg} \mathrm{g}^{-1}$. The sorption efficiency for $\mathrm{As}^{\mathrm{III}}$ was $<5 \%$. The retained $\mathrm{As}^{\mathrm{V}}$ was readily recovered by $100 \mu \mathrm{L} \mathrm{NH}_{4} \mathrm{HCO}_{3}(0.6 \%$, $\mathrm{m} / \mathrm{v}$ ). With a sample volume of $2.0 \mathrm{~mL}$, an enrichment factor of 16.3 for $\mathrm{As}^{\mathrm{V}}$ was obtained along with a LOD of $14 \mathrm{ng} \mathrm{L}^{-1}$ within a linear range of $0.05-1.50 \mu \mathrm{g} \mathrm{L}^{-1}$. A RSD of $3.6 \%$ was derived at $0.5 \mu \mathrm{g} \mathrm{L}^{-1}$. Total As was obtained by converting $\mathrm{As}^{\mathrm{III}}$ to $\mathrm{As}^{\mathrm{V}}$ and following the same procedure. Although used on snow water and rain water samples, a human hair CRM (GBW09101) was used to validate the method.

A method has been developed for iAs speciation analysis of water samples using a microsample injection system coupled with ICP-MS following DLLME. ${ }^{71}$ A sampling volume of $90 \mu \mathrm{L}$ 
provided almost the same signals as the signals obtained by means of a conventional continuous nebulisation sampling system for the ICP-MS instrument. Under the optimised conditions, the analyte from only $5.0 \mathrm{~mL}$ water sample was concentrated by a factor of 48 with an LOD reaching $0.0031 \mu \mathrm{g}$ $\mathrm{L}^{-1}$ for As. The calibration curve had a linear range of $0.0084-$ $0.0800 \mu \mathrm{g} \mathrm{L}^{-1}\left(r^{2}=0.999\right)$, and the RSD was $<4(n=6)$. The determination of $\mathrm{As}^{\mathrm{III}}$ and total As in river, pond, tap and bottled water samples was achieved by the standard addition method. Recoveries for spiked $\mathrm{As}^{\mathrm{III}}$ and $\mathrm{As}^{\mathrm{V}}$ were in the range of 95-108\%. A microextraction and speciation method for $\mathrm{As}^{\mathrm{III}}$ and $\mathrm{As}^{\mathrm{V}}$ species based on ionic LLLME and ET-AAS has been reported. ${ }^{72}$ The $\mathrm{As}^{\mathrm{III}}$ was chelated with APDC at $\mathrm{pH} 2$ and then extracted into the fine droplets of 1-butyl-3-methylimidazolium bis(trifluormethylsulfonyl) imide which acted as the extractant. $\mathrm{As}^{\mathrm{V}}$ remained in the aqueous phase and is then reduced to $\mathrm{As}^{\mathrm{III}}$. The concentration of $\mathrm{As}^{\mathrm{V}}$ was calculated by difference between total iAs and $\mathrm{As}^{\mathrm{III}}$. The $\mathrm{pH}$ values, chelating reagent concentration, types and volumes of extraction and dispersive solvent, and centrifugation time were optimised. At an enrichment factor of 255, the LOD and the RSD for 6 replicate determinations of $1.0 \mu \mathrm{g} \mathrm{L}^{-1} \mathrm{As}^{\mathrm{III}}$ are $13 \mathrm{ng} \mathrm{L}^{-1}$ and $4.9 \%$, respectively. The method was successfully applied to the determination of $\mathrm{As}^{\mathrm{III}}$ and $\mathrm{As}^{\mathrm{V}}$ in spiked samples of natural water, with relative recoveries in the range of $93.3-102.1 \%$ and $94.5-101.1 \%$, respectively.

A macrocycle-immobilised SPE system, commonly known as molecular recognition technology (MRT) gel, has also been used to selectively separate $\mathrm{As}^{\mathrm{III}}$ and $\mathrm{As}^{\mathrm{V}}$ in aqueous matrix. ${ }^{73}$ The As species in solution (or in the eluent) were subsequently quantified with ET-AAS. It was found that $\mathrm{As}^{\mathrm{V}}$ can be selectively collected on the SPE system within the range of $\mathrm{pH} 4$ to 9 , while $\mathrm{As}^{\mathrm{III}}$ was passed through the MRT-SPE. The retention capacity of the MRT-SPE material for $\mathrm{As}^{\mathrm{V}}$ was $0.25 \pm 0.04 \mathrm{mmol} \mathrm{g}^{-1}$. The LOD for $\mathrm{As}^{\mathrm{V}}$ was $0.06 \mu \mathrm{g} \mathrm{L}{ }^{-1}$, with a RSD of $2.9 \%(n=10,1 \mu \mathrm{mol}$ $\mathrm{L}^{-1}$ ). Interference from the matrix ions was studied. In order to validate the method, CRM effluent wastewater and groundwater samples were analysed, and the determined values were in good agreement with the certified values. A miniaturised SPE procedure has been developed for ultra-trace determination of iAs species. ${ }^{74}$ The pyrrolidinedithiocarbamate complex with As ${ }^{\text {III }}$ was selectively adsorbed on $30 \mathrm{mg}$ poly(hydroxyethyl methacrylate) micro beads, which were simply packed into a micropipette-tip. The adsorbed As was quantitatively eluted by $700 \mu \mathrm{L}$ $0.25 \mathrm{M} \mathrm{NH}_{3}$ and determined by ET-AAS. Injection of a larger volume (i.e., $50 \mu \mathrm{L}$ ) and the use of $\mathrm{Mg}\left(\mathrm{NO}_{3}\right)_{2}$ as chemical modifier improved the AA signal intensity (characteristic mass of $25 \mathrm{pg}$ ) and precision (RSD of $2.6 \%, 10 \mu \mathrm{g} \mathrm{L}^{-1}, n=11$ ). The total As was determined after reduction of $\mathrm{As}^{\mathrm{V}}$ to $\mathrm{As}^{\mathrm{III}}$ by thiourea- $\mathrm{HCl}$ system. The $\mathrm{As}^{\mathrm{V}}$ concentration was calculated by the difference between $\mathrm{As}^{\mathrm{III}}$ and total As. The LOD $(3 \mathrm{~s})$ of the method was $10 \mathrm{ng} \mathrm{L}^{-1} \mathrm{As}^{\mathrm{III}}$ with an enrichment factor of 86 . The RSD and relative error for six replicate determinations of $0.5 \mu \mathrm{g} \mathrm{L}^{-1} \mathrm{As}^{\mathrm{III}}$ were found to be $4.0 \%$ and $0.7 \%$, respectively. The method was successfully applied to drinking water, snow and reference water (SEM-2011) samples. When the samples were spiked with 0.5 and $1.0 \mu \mathrm{g} \mathrm{L}{ }^{-1} \mathrm{As}^{\mathrm{III}}$ and $\mathrm{As}^{\mathrm{V}}$, the recoveries varied between 96 and 100\%. Sol-gel based amine-functionalised SPME fibres (PDMS-weak anion exchanger) were prepared and used for the direct extraction of DMA, MMA, and $\mathrm{As}^{\mathrm{v}}$ from aqueous solutions followed by species determination by HPLCICP-MS. ${ }^{75}$ Two different methods of coating were employed: (i) electrospinning and (ii) dip coating. Electrospinning was found to be superior in terms of extracted amount of arsenicals, coating homogeneity, accessibility of amine groups on the surface, and preparation time for a single fibre. The optimum extraction conditions were determined as $\mathrm{pH}$ of 5.0, extraction time of $30 \mathrm{~min}$, agitation speed of $700 \mathrm{rpm}$, and extraction temperature of $20^{\circ} \mathrm{C}$. The extraction ability of the novel coating decreased with the addition of $\mathrm{NaCl}$ as a consequence of the competition between anionic As species and chloride ions for active sites of the weak anion exchanger. Vibrational spectroscopy revealed the alignment of PDMS chains by elongational force under electrospinning process.

A method for As speciation based on selective HG with preconcentration by cryotrapping and ICP-MS detection has been presented. ${ }^{76}$ Determination of the valency of the As species was performed by selective HG without prereduction (trivalent species only) or with L-cysteine prereduction (sum of tri- and pentavalent species). Methylated species were resolved on the basis of thermal desorption of the formed methyl substituted arsines after collection at $-196{ }^{\circ} \mathrm{C}$. Detection limits of 3.4, 0.06, 0.14 and $0.10 \mathrm{pg} \mathrm{mL}^{-1}$ were achieved for iAs, mono-, di- and trimethylated species, respectively, from a $500 \mu \mathrm{L}$ sample. Validation using CRMs, river water (NRC SLRS-4 and SLRS-5) and sea water (NRC CASS-4, CASS-5 and NASS-5) was used to assess the mass balance for As species and good agreement was found. The HG-ICP-MS method was successfully used for analysis of microsamples of exfoliated bladder epithelial cells isolated from human urine. Samples of lysates of 25 to 550 thousand cells contained typically tens of pg up to ng of iAs species and from single to hundreds of pg of methylated species, well within detection power of the presented method. A significant portion of As in the cells was found in the form of the highly toxic trivalent species.

Arsenic speciation in food is the largest field of application during this review period.

In a comprehensive study of around 1300 samples, locally grown fruits and vegetables from historically mined regions of SW England were compared similarly locally grown produce from the NE of Scotland to determine the concentration of total and iAs present in produce from these two geogenically different areas of the U.K. ${ }^{77}$ On average $98.5 \%$ of the total As found was present in the iAs form. For both groups of samples, the highest total As was present in open leaf structure produce (i.e., kale, chard, lettuce, greens, and spinach) being most likely to soil/dust contamination of the open leaf structure. The concentration of total As in potatoes, swedes, and carrots was lower in peeled produce compared to unpeeled produce. For baked potatoes, the concentration of total As in the skin was higher compared to the total As concentration of the potato flesh, this difference in localisation being confirmed by LA-ICPMS. For all above ground produce (e.g., apples), peeling did not have a significant effect on the concentration of total As present. 
The determination of As in rice continues to attract attention, perhaps not surprisingly given that for many people, rice is far and away the major source of potentially harmful As compounds in our diet. A recording of a web seminar on this topic is available for free online. ${ }^{78}$ An investigation of the mechanisms of uptake, transport and distribution of $\mathrm{As}^{\mathrm{V}}$ and DMA in rice plants (Oryza sativa L.) in hydroponic trials has been undertaken by Zheng et al. ${ }^{79}$ Thus, HPLC-ICP-MS and microprobe SR-XRF were used to determine As concentration and the in situ As distribution. The DMA induced abnormal florets before flowering and caused a sharp decline in the seed setting rate after flowering compared to As-i. Rice grains accumulated 2-fold higher DMA than iAs. The distribution of iAs concentration (root $>$ leaf $>$ husk $>$ caryopsis) in $\mathrm{As}^{\mathrm{V}}$ treatments was different from that of the DMA treatment (caryopsis $>$ husk $>$ root $>$ leaf). The SXRF showed that iAs mainly accumulated in the vascular trace of caryopsis with limited distribution to the endosperm, whereas DMA was observed in both tissues. The DMA tended to accumulate in caryopsis and induced higher toxicity to the reproductive tissues resulting in markedly reduced grain yield, whereas iAs mainly remained in the vegetative tissues and had no significant effect on yield. The separation of iAs from organoarsenic compounds in rice by off-line SPE followed by HG-AAS detection has been reported. ${ }^{80}$ Water bath heating $\left(90{ }^{\circ} \mathrm{C}, 60 \mathrm{~min}\right.$ ) of samples with dilute $\mathrm{HNO}_{3}$ and $\mathrm{H}_{2} \mathrm{O}_{2}$ solubilised and oxidised all iAs to $\mathrm{As}^{\mathrm{V}}$. Loading of buffered sample extracts ( $\mathrm{pH} 6 \pm 1$ ) followed by selective elution of $\mathrm{As}^{\mathrm{V}}$ from a strong anion exchange SPE cartridge enabled the selective iAs quantification by HG-AAS, measuring total As in the SPE eluate. The mean recoveries were $101-106 \%$ for spiked rice samples and in two reference samples. The LOD was $0.02 \mathrm{mg}$ $\mathrm{kg}^{-1}$, and repeatability and intra-laboratory reproducibility were less than 6 and $9 \%$, respectively.

When rice is under cultivation under flooded conditions, it is often exposed simultaneously to Fe excess and As contamination. The impact of these combined stresses on yield-related parameters and As distribution and speciation in various rice plants has been studied. ${ }^{81}$ Rice (cv I Kong Pao) was exposed to Fe excess (125 mg L $\mathrm{L}^{-1} \mathrm{Fe}_{2} \mathrm{SO}_{4}$ ), As (50 and $100 \mu \mathrm{M} \mathrm{Na} \mathrm{NA}_{2} \mathrm{HA}$ $\mathrm{SO}_{4} \cdot 7 \mathrm{H}_{2} \mathrm{O}$ ) or a combination of those stressing agents in hydroponic culture until harvest. Arsenic speciation was determined by HPLC-HG-AFS. Iron excess increased As retention by the roots in relation to the development of the root Fe plaque but decreased As accumulation in the shoot. Arsenic concentration was lower in the grains than in the shoots. Iron stress reduced As accumulation in the husk but not in the dehusked grains. Iron excess decreased the proportion of extractable As ${ }^{\text {III }}$ and $\mathrm{As}^{\mathrm{V}}$ in the grain while it increased the proportion of extractable $\mathrm{As}^{\mathrm{III}}$ in the shoot. Combined stresses (Fe + As) affected plant nutrition and significantly reduced the plant yield by limiting the number of grains per plant and the grain filling. Fe excess had an antagonist impact on shoot As concentration but an additive negative impact on several yield-related parameters. Iron stress influences both As distribution and As speciation in rice. In a study of As speciation in a 185 rice samples from Thailand and Other Asian Countries, a simple extraction with water and digestion with alpha-amylase followed by analysis using ion-paring mode HPLC-ICP-MS was developed. ${ }^{82}$ The method showed good extraction efficiencies (generally $>80 \%$ ) and column efficiencies $(>90 \%)$ for all samples. The LOQ of $\mathrm{As}^{\mathrm{III}}, \mathrm{As}^{\mathrm{V}}$, MMA, and DMA that were calculated based on sample mass were 1.6, 2.0, 2.0, and $1.6 \mu \mathrm{g}$ $\mathrm{kg}^{-1}$ respectively. The total As and iAs in rice samples were in the ranges of $22.5-375$ and $13.9-233 \mu \mathrm{g} \mathrm{kg}^{-1}$, respectively. The estimated weekly intake of iAs from rice by Thai people accounted for 14-29\% of the provisional tolerable weekly intake. In an increasingly rare application of ET-AAS, the development of three different methods for the determination of total As, iAs, $\mathrm{As}^{\mathrm{III}}$ and $\mathrm{As}^{\mathrm{V}}$ in rice and rice flour food products have been described. ${ }^{83}$ The methods were based on the use of different selective extraction procedures and the optimisation of instrumental and methodological parameters to prevent the loss and transformation of analytes during the extraction and digestion steps. The calculated recoveries ranged between $92 \%$ and $105 \%$ and the RSD values were up to $15 \%$ for the concentration levels tested. The validated methods were applied successfully for the determination of total As and total iAs in a proficiency test organised by the International Measurement Evaluation Program - 107.

A continuous on-line leaching method using artificial gastrointestinal fluids has been used to determine the bio-accessible fraction of $\mathrm{As}, \mathrm{Cu}, \mathrm{Fe}, \mathrm{V}$ and $\mathrm{Zn}$ in brown and white rice from California. ${ }^{84}$ Arsenic speciation analysis was performed on the saliva and gastric juice leachates using IC-ICP-MS. As ${ }^{\text {III }}$, MMA, DMA and $\mathrm{As}^{\mathrm{V}}$, as well as $\mathrm{Cl}^{-}$in the gastric juice leachate, were successfully separated within 5.5 min using a simple nitric acid gradient. Saliva generally accounted for the largest percentage of total element leached in comparison to gastric and intestinal juices. While cooking rice had relatively little effect on total bioaccessibility, a change in species from $\mathrm{As}^{\mathrm{V}}$ and DMA to $\mathrm{As}^{\mathrm{III}}$ was observed for both types of rice. Washing the rice with doubly deionised water prior to cooking removed a large percentage of the total bio-accessible fraction of $\mathrm{As}, \mathrm{Cu}, \mathrm{Fe}, \mathrm{V}$ and $\mathrm{Zn}$.

The measurement of As species in rice, is normally accomplished by extraction followed by HPLC-ICP-MS analysis. This method is seldom compared to other methods having now become routinely established in many laboratories. However, in a recent study ${ }^{\mathbf{8 5}}$ As speciation data obtained using nitric acid extraction/HPLC-ICP-MS was compared with data produced using XANES, without extraction. The purpose of the study was to verify the efficacy of using $2 \% \mathrm{v} / \mathrm{v}$ nitric acid extraction and to measure iAs, DMA, and MMA in reference rice materials and common rice varieties obtainable in Australia. Total As and As individual species ( $\mathrm{As}^{\mathrm{III}}, \mathrm{As}^{\mathrm{V}}$, DMA, and MMA) concentrations were measured in 8 reference materials and were in agreement with published values. The XANES analysis was performed on 5 samples, having total As concentrations ranging from 0.198 to $6.34 \mu \mathrm{g} \mathrm{g}^{-1}$. The results were in agreement with those obtained using HPLC-ICP-MS, although XANES was also able to distinguish two forms of $\mathrm{As}^{\mathrm{III}}$ : $\mathrm{As}^{\mathrm{III}}$ and $\mathrm{As}^{\mathrm{III}} \mathrm{GSH}$.

The As accumulation in 96 rhizomes of Zingiberaceous plants from Thailand (Alpinia galanga (Khaa), Boesenbergia rotunda (Kra-chaai), Curcuma longa (Khamin-chan), Curcuma zedoaria (Khamin-oi), Zingiber cassumunar (Plai) and Zingiber officinale 
(Ginger) has been determined by HG-AAS). ${ }^{86}$ Concentrations of total As based on dry weight were $92.4 \pm 9.2,103.5 \pm 20.8$, $61.7 \pm 12.5,89.8 \pm 17.5,106.7 \pm 19.5$ and $69.3 \pm 11.8 \mathrm{ng} \mathrm{g}^{-1}$, respectively and iAs were $48.8 \pm 7.0,66.3 \pm 12.7,25.5 \pm 5.0$, $38.7 \pm 4.7,71.2 \pm 11.6$, and $38.5 \pm 5.5 \mathrm{ng} \mathrm{g}^{-1}$, respectively. All concentrations were much lower than limits recommended by Thai Food and Drug Administration.

Arsenic in seafood also continues to attract a lot of attention. A series of 350 food products, belonging to various food groups and bought on the Belgian market, were analysed for total As and 5 different As species (iAs, $\mathrm{As}^{\mathrm{III}}$ and $\mathrm{As}^{\mathrm{V}}$, MMA, DMA, and $\mathrm{AB}) .{ }^{87}$ In all samples $\mathrm{AB}$ was the dominant As species detected. DMA, MA, As ${ }^{\mathrm{III}}$ and $\mathrm{As}^{\mathrm{V}}$ were found in lower concentrations in some of the organisms under investigation. Mussel, shrimp and scampi were the only marine organisms in which iAs was present in quantifiable amounts, with concentrations generally in the range $0.005-0.022 \mathrm{mg} \mathrm{kg}^{-1}$ whole weight. These results are in agreement with several other literature data that also report very low concentrations of inorganic arsenic in these organisms, but they contradict some other studies reporting much higher values. The study therefore confirms the existing inconsistency among different studies regarding iAs concentrations in seafood, although the reasons for this remains unclear. A LC-ESI-MS-MS instrument has been used in parallel with AAS to survey of the concentrations of AsB, AC, MMA, and DMA in seafood from southern Italy ${ }^{88}$ Total As concentrations ranged from 1.38 to $12.8 \mathrm{mg} \mathrm{kg}^{-1}$. AB and DMA were detected in all samples (AB: 0.72 to $10.4 \mathrm{mg} \mathrm{kg}^{-1}$; DMA: 0.28 to $1.08 \mathrm{mg}$ $\mathrm{kg}^{-1}$ ), and concentrations of AC and MMA ranged from 0.20 to $1.53 \mathrm{mg} \mathrm{kg}^{-1}$.

Whaley-Martin et $a .^{89}$ have examined the As species in the tissues of the marine periwinkle (Littorina littorea) along an As concentration gradient in sediment using HPLC-ICP-MS and XAS. Total As concentrations in the periwinkle tissues ranged from 56 to $840 \mathrm{mg} \mathrm{kg}^{-1}$ dry weight (equivalent to 13 to $190 \mathrm{mg}$ $\mathrm{kg}^{-1}$ wet weight). The iAs were found to be positively correlated with total As concentrations $\left(R^{2}=0.993\right)$ and reached $600 \mathrm{mg}$ $\mathrm{kg}^{-1}$ dry weight, amongst the highest reported to date in marine organisms. These high iAs concentrations within this low trophic organism pose a potential toxicological risk to higher trophic consumers. An evaluation of microwave and ultrasound extraction procedures for As speciation in bivalve molluscs (Anomalocardia brasiliana sp. and Macoma constricta sp.) using LC-ICP-MS has been reported by Santos et al. ${ }^{90}$ Microwave and ultrasound radiation, combined with different extraction conditions (solvent, sample amount, time, and temperature), were evaluated for As-species extraction from the mollusc tissues. Accuracy, extraction efficiency with different solvents, sample amount, time, and temperature, and stability of As species were evaluated by analysing the CRMs DORM-2, dogfish muscle; BCR-627, tuna fish tissue; and SRM 1566b, oyster tissue. Recovery tests were also performed. The best conditions were found to be microwave-assisted extraction using $200 \mathrm{mg}$ of samples and water at $80{ }^{\circ} \mathrm{C}$ for $6 \mathrm{~min}$. Thus, $\mathrm{AB}$ was the main species present in bivalve mollusc tissues, while MMA and $\mathrm{As}^{\mathrm{V}}$ were below the LOQ (0.001 and $0.003 \mu \mathrm{g} \mathrm{g}^{-1}$, respectively). Two unidentified As species also were detected and quantified. The sum of the As-species concentration was in agreement (90 to $104 \%$ ), with the total As content determined by ICP-MS after sample digestion.

Whereas iAs is classified as a human carcinogen, risks to human health related to the presence of arsenosugars in marine food are still unclear. Since studies have indicated that human iAs metabolites contribute to iAs induced carcinogenicity, it can be argued that a risk assessment for arsenosugars should also include a toxicological characterisation of their respective metabolites. Leffers et al. ${ }^{91}$ have assessed intestinal bioavailability of the human arsenosugar metabolites oxo-DMAA ${ }^{\mathrm{V}}$, thio$\mathrm{DMAA}^{\mathrm{V}}$, oxo-DMAE ${ }^{\mathrm{V}}$, thio-DMAE ${ }^{\mathrm{V}}$ and thio-DMA ${ }^{\mathrm{V}}$ in relation to $\mathrm{As}^{\mathrm{III}}$ in the Caco-2 intestinal barrier model. Arsenic speciation by LC-ICP-MS based As speciation studies during the transfer experiments demonstrated transfer of thio-DMA ${ }^{\mathrm{V}}$ itself across the intestinal barrier and suggest metabolism of thio-DMA ${ }^{\mathrm{V}}$ using the in vitro intestinal barrier model to its oxygen-analogue $\mathrm{DMA}^{\mathrm{V}}$. In the case of $\mathrm{As}^{\mathrm{III}}$ no metabolism was observed. The author suggest that the presystemic metabolism of arsenosugars might strongly impact As intestinal bioavailability after arsenosugar intake and should therefore be considered when assessing the risks to human health related to the consumption of arsenosugar-containing food.

The potential of high temperature LC with detection by ICPMS for the determination of arsenosugars in marine organisms has been examined by Terol et al. ${ }^{92}$ The retention behaviour of four naturally occurring dimethylarsinoylribosides was studied on a graphite column using water as mobile phase. An aqueous solution of $\mathrm{pH} 8$, ionic strength $13.8 \mathrm{mM}$ and containing $2 \%$ (v/v) of methanol, along with a column temperature of $120{ }^{\circ} \mathrm{C}$ and a liquid flow rate of $1.0 \mathrm{~mL} \mathrm{~min}{ }^{-1}$, were selected as the optimal conditions, as they allowed the separation of the four arsenosugars in less than $18 \mathrm{~min}$, without any interferences due to other common As species ( $\mathrm{As}^{\mathrm{III}}, \mathrm{As}^{\mathrm{V}}$. MMA, DMA and $\left.\mathrm{AB}\right)$. The run time could be further decreased to $12 \mathrm{~min}$ by working at $1.5 \mathrm{~mL} \mathrm{~min}^{-1}$, although with a 3-4 times loss of sensitivity. The procedural LODs were $0.03-0.04 \mu \mathrm{g}$ As $\mathrm{g}^{-1}$ dry mass, and the precision of the procedure ranged from $4 \%$ for arsenosugar glycerol to $18 \%$ for arsenosugar sulfate (RSD\%, $n=5$ ). The developed method was applied to a number of representative biological samples, such as algae and crustaceans, providing results consistent with previous studies. In the red algae samples, most of extracted As was as arsenosugars (81-97\%), mainly arsenosugar phosphate (56-94\%). Lower concentrations of these compounds were found in the crustacean, accounting for about $15 \%$ of the extracted As.

Approaches for the identification of lipophilic As species in Saccharina latissima (sugar kelp) have been studied. ${ }^{93}$ Parallel use of ICP-MS and ESI-MS after separation revealed that Saccharina latissima contained three distinct classes of lipophilic As-species, a family of As containing phospholipids, all including As in the form of As sugar $\mathrm{PO}_{4}$, As-containing hydrocarbons, and As-containing polyunsaturated fatty acids. For detailed identification, the use of phospholipases, in particular phospholipase A2, was essential to define the fatty acid composition (determination of regioisomers) of the lipids without purification of the sample, while fragmentation of the 
molecules by $\mathrm{MS}^{2}$ measurements alone did not supply this information. Complete lipid hydrolysis showed that this alga did not contain As containing fatty acids bound to complex lipids. The study indicated that in addition to HPLC-ICP-MS and ES-MS a range of different derivatisation methods should be used for the comprehensive identification of unknown lipidsoluble As compounds.

Most edible seaweeds are ingested after a heat treatment and these thermal procedures could lead to a change in As speciation. The As species in four edible seaweeds (Kombu, Wakame, Nori and Sea Lettuce) were determined after cooking using anion-exchange HPLC-ICP-MS. ${ }^{94}$ The cooking waters were also analysed. The powdered cooked seaweed was subjected to an in vitro digestion procedure using piperasine- $N, N$-bis(2-ethanesulfonic acid)disodium, as a buffer solution at a pH of 7.0 and dialysis membranes of $10 \mathrm{kDa}$ molecular weight cut off. Dialysable fractions were analysed to identify the As species that become bioavailable for human body functions. Total As concentrations were found between 53 and $79.1 \mu \mathrm{g} \mathrm{g}^{-1}, 3.6-37.0$ $\mu \mathrm{g} \mathrm{g}^{-1}$ and $1.8-54.3 \mu \mathrm{g} \mathrm{g}^{-1}$ for raw and cooked seaweed, and cooking water, respectively. The total As bioavailability was $20 \%, 29 \%, 18 \%$ and $11 \%$ for cooked Kombu, Nod, Wakame and Sea lettuce, respectively. Results suggest that the heat treatment and the acidic environment and enzymes used in the in vitro gastrointestinal digestion are not sufficient to produce a change in the As species of the four seaweeds studied. Arsenosugars were the main As species found. As ${ }^{\mathrm{III}}$ species and $\mathrm{AB}$ were only found in the Sea Lettuce sample. Glycerol sugar and sulfonate sugar were the most bioavailable species for cooked Kombu and Wakame. Phosphate sugar showed to be in highest proportion in the dialysable fraction and $\mathrm{AB}$ and glycerol sugar became more bioavailable in the Sea Lettuce sample.

Dietary supplements composed of herbal plants and seaweed have also been studied. ${ }^{95}$ The total As was determined by dry ashing and HG-AAS, and iAs was determined by acid digestion, solvent extraction, and HG-AAS. The total and iAs in the supplements ranged from 0.07 to $8.31 \mathrm{mg} \mathrm{kg}^{-1}$ dry weight, which equates to a daily intake of total As between 0.05 to 12.5 $\mu \mathrm{g}$ per day. A solid-phase extraction procedure for the extraction of As-containing hydrocarbons from fish oil prior to analysis by GC-ICP-MS has been reported. ${ }^{96}$ The method was applied on a range of different commercial fish oils, including oils of anchovy (Engraulis ringens), Atlantic herring (Clupea harengus), sand eel (Ammodytes marinus), blue whiting (Micromesistius poutassou) and a commercial mixed fish oil (mix of oils of Atlantic herring, Atlantic cod (Gadus morhua) and saithe (Pollachius virens)). Total As concentrations (in the range 5.9 to $8.7 \mathrm{mg} \mathrm{kg}{ }^{-1}$ ) were determined by microwave-assisted acid digestion and ICP-MS. Three dominant As-containing hydrocarbons in addition to one minor unidentified compound were detected. The molecular structures of the As-containing hydrocarbons, dimethylarsinoyl hydrocarbons $\left(\mathrm{C}_{17} \mathrm{H}_{38} \mathrm{AsO}\right.$, $\mathrm{C}_{19} \mathrm{H}_{42} \mathrm{AsO}, \mathrm{C}_{23} \mathrm{H}_{38} \mathrm{AsO}$ ), were verified using GC-MS-MS, and verified using a Q-TOF-MS. Additionally, total As and the Ascontaining hydrocarbons were studied in decontaminated and in non-decontaminated fish oils, where a reduced As concentration was seen in the decontaminated fish oils. This provided an insight to how a decontamination procedure originally ascribed for the removal of persistent organic pollutants affects the level of arsenolipids present in fish oils.

Total As and iAs have been determined by ICP-MS following microwave-assisted wet digestion on fillet samples of Northeast Artic cod, herring, mackerel, Greenland halibut, tusk, saithe and Atlantic halibut from the coast of Norway. ${ }^{97}$ In total, 923 individual fish samples were analysed. The determination of iAs was carried out by HPLC-ICP-MS following microwave-assisted dissolution of the samples. The concentrations found for total As varied greatly between fish species, and ranged from 0.3 to $110 \mathrm{mg} \mathrm{kg}^{-1}$ wet weight. For iAs, the concentrations found were very low $\left(<0.006 \mathrm{mg} \mathrm{kg}^{-1}\right)$ in all cases. The obtained results question the assumptions made by the European Food Safety Authority (EFSA) on the iAs level in fish used in the recent EFSA opinion on arsenic in food. The As species in methanolic extracts of cod liver have been determined by RP-HPLC-ICP-MS coupled with ESI-Q-TOF-MS.98 ${ }^{98}$ The total concentration of As in the fresh cod liver was found to be $1.53 \pm 0.02 \mathrm{mgAs} \mathrm{kg}^{-1}$ w.w. and the extraction recovery was $c a .100 \%$ and column recovery $>93 \%$. Besides polar inorganic and methylated As species $(>70 \%)$ more hydrophobic As-containing fatty acids and hydrocarbons occurred. Based on mass spectrometric data, proposals for molecular structures were elaborated for 20 of the organic As species included 10 As-containing fatty acids and an As-containing hydrocarbon, described for the first time in fresh cod liver. Arsenobetaine was found as main water-soluble As compound in cod liver followed by higher molecular mass Ascontaining fatty acids and hydrocarbons.

Arsenic speciation has also been studied in foods of animal origin. Residual organoarsenical feed additives such as $p$-arsanilic acid, nitarsone and roxarsone (3-nitro-4-hydroxyphenylarsonic acid), have been studied by Cui et al. ${ }^{99}$ HPLC-UV-HG-AFS using a C-18 column with $50 \mathrm{mM} \mathrm{KH}_{2} \mathrm{PO}_{4}, 0.1 \% \mathrm{v} / \mathrm{v}$ trifluoroacetic acid at pH 2.43 as the mobile phase was employed for the study. Following optimisation of the extraction solvent, temperature, static extraction time, flush volume and cycle time, ASE was used to extract organoarsenic species The methodology developed facilitated a LOD and LOQ of 0.24, 0.74, 0.41 and $0.72,2.24,1.24 \mathrm{ng} \mathrm{mL}^{-1}$ for $p$-arsanilic acid, nitarsone and roxarsone, respectively The recovery rates and RSDs, were higher than 94\% and lower than 5\%, respectively. A method for the determination of roxarsone and $p$-arsanilic acid in environmental matrices has also been reported. ${ }^{\mathbf{1 0 0}}$ The method employed HPLC-ICP-MS with gradient elution to determine MMA, DMA, As ${ }^{\mathrm{III}}$ and $\mathrm{As}^{\mathrm{V}}$ in soils and sediments. The optimal extractions were obtained with $0.5 \mathrm{~mol} \mathrm{~L}^{-1} \mathrm{H}_{3} \mathrm{PO}_{4}$ under constant shaking for $16 \mathrm{~h}$. The study revealed that areas of the Pearl River Delta in southern China were already contaminated with organoarsenic feed additives.

Total and iAs was determined in 16 dietary supplements based on herbs, other botanicals and algae purchased on the Danish market. ${ }^{\mathbf{1 0 1}}$ The dietary supplements originated from various regions, including Asia, Europe and USA. The contents of total and iAs was determined by ICP-MS and anion exchange HPLCICP-MS, respectively, were in the range of 0.58 to $5.0 \mathrm{mg} \mathrm{kg}^{-1}$ and 0.03 to $3.2 \mathrm{mg} \mathrm{kg}^{-1}$, respectively, with a ratio between iAs 
and total As ranging between 5 and $100 \%$. Consumption of the recommended dose of the individual dietary supplement would lead to an exposure to iAs within the range of 0.07 to $13 \mu \mathrm{g}$ per day. Such exposure from dietary supplements would in worst case constitute $62.4 \%$ of the range of benchmark dose lower confidence limit values ( 01 at 0.3 to $8 \mu \mathrm{g}$ per $\mathrm{kg}$ bw per day) put down by European Food Safety Authority in 2009, for cancers of the lung, skin and bladder, as well as skin lesions. Hence, the results demonstrate that consumption of certain dietary supplements could contribute significantly to the dietary exposure to inorganic As at levels close to the toxicological limits established by EFSA.

Arsenic species in fruiting bodies of a fungi, Xerocomus badius, collected from selected Polish forests areas subjected to high anthropogenic pressure have been determined by HPLC-HGAAS. ${ }^{102}$ The results show high levels (up to 27.1, 40.5 and 88.3 $\mathrm{mg} \mathrm{kg}^{-1}$, for As ${ }^{\mathrm{III}}, \mathrm{As}^{\mathrm{V}}$ and DMAA respectively) For mushroom samples collected from areas not subjected to high anthropogenic pressure and for two commercially available samples from the Polish Sanitary Inspectorate, the As species level were below $0.5 \mathrm{mg} \mathrm{kg}^{-1}$ for each As form. The results As species levels should be monitored in mushroom foodstuffs.

Drinking water is another major source of As in the diet, and this has been the subject of several studies again this year. Groundwater in Cyprus is a valuable natural resource as approximately $50 \%$ of the total water needs come from underground water supplies. According to the Directive 118/2006/EC, groundwater should be protected from deterioration and chemical pollution. This is particularly important for groundwater dependent ecosystems and for the use of groundwater as a water supply for human consumption. During 2007 to 2009, as part of a national monitoring programme, 84 boreholes were sampled in Cyprus and subsequently analysed for total As by ICP-MS. ${ }^{103}$ The groundwater concentrations ranged from $<0.3$ to $41 \mu \mathrm{g} \mathrm{L}^{-1}$ As. Several boreholes had concentrations above the WHO Drinking Water Guideline limit of $10 \mu \mathrm{g} \mathrm{L}^{-1}$ As, the predominant species being $\mathrm{As}^{\mathrm{V}}$. In New Zealand, a study of geothermal water from 28 geothermal features has been conducted to determine the levels of $\mathrm{As}^{\mathrm{III}}, \mathrm{As}^{\mathrm{V}}$, MMA and DMA. ${ }^{104}$ Samples were collected for speciation analysis using SPE to facilitate separation, stabilisation and pre-concentration of the species at the time of sample collection in the field prior to later analysis by ICP-MS. Total As concentrations ranged from 0.008 to $9.08 \mathrm{mg} \mathrm{L}^{-1}$ As. Inorganic As species were predominant in the geothermal waters, with $\mathrm{As}^{\mathrm{III}}$ contributing to more than $70 \%$ of the total As in the majority of samples. Organic species were also determined in all samples, indicating the presence of microbial activity. A potential risk to human health was highlighted due to the high levels of $\mathrm{As}^{\mathrm{III}}$ in geothermal features linked to bathing pools. In the same context, $\mathrm{As}^{\mathrm{III}}$ and $\mathrm{As}^{\mathrm{V}}$ have been determined in 23 water samples have been collected from public wells in Hungary. ${ }^{105}$ Collection on SPE anion exchange in the field was used to retail sample integrity prior to analysis using SF-ICP-MS. Total As level in the samples was higher than the health limit value established by the European Union $(10 \mu \mathrm{g}$ $\mathrm{L}^{-1}$ ) for drinking water in 22 samples. The total As concentration in the samples ranged between 7.2 and $210 \mu \mathrm{g} \mathrm{L}^{-1}$ with $\mathrm{As}^{\mathrm{V}}$ being the dominant species in about $70 \%$ of the samples. Iron ${ }^{\text {III }}$ modified sodium alginate beads have also been adopted for use as a $\mu$ SPE for the selective iAs species extraction from water samples. ${ }^{106}$ A HG-AFS approach was then used to speciate As ${ }^{\text {III }}$ and $\mathrm{As}^{\mathrm{V}}$ in the samples. The pre-concentration of $\mathrm{DMA}^{\mathrm{V}}$ from water samples using a strong cation exchange (SCX) disk functionalised with sulfonic groups, before being analysis by WDXRF has also been reported. ${ }^{107}$ The adsorption of DMA ${ }^{\mathrm{V}}$ occurred preferentially on the surface of the SCX disk, regardless of $\mathrm{pH}$ levels, probably due to interactions with the sulfonic functional groups. However, no other As species, such as arsenate $\mathrm{As}^{\mathrm{V}}, \mathrm{As}^{\mathrm{III}}$, and $\mathrm{MMA}^{\mathrm{V}}$ were retained. The SCX-WDXRF method produced a strongly linear calibration curve $\left(R^{2}=\right.$ 0.9996) with its LOD at $0.218 \mu \mathrm{g} \mathrm{L}^{-1}$ when a $1 \mathrm{~L}$ water sample was used for pre-concentration. The As intensity of the system was sensitive to the $\mathrm{Pb}$ content retained on the SCX disk owing to the proximity of the As- $\mathrm{K}$ alpha and $\mathrm{Pb}-\mathrm{L}$ alpha lines. To compensate for this interference, a correction factor was developed by considering the calibration slope ratio between the X-ray intensity measured at a Bragg angle of 48.781 degrees and the $\mathrm{Pb}$ content of the SCX disks. The results of spike tests for $\mathrm{As}^{\mathrm{V}}, \mathrm{As}^{\mathrm{III}}, \mathrm{MMA}^{\mathrm{V}}$, and $\mathrm{DMA}^{\mathrm{V}}$ with and without the addition of $\mathrm{Pb}$ in synthetic landfil leachate exhibited reasonable recoveries (i.e., 98-105\%) after the spectral adjustment for the $\mathrm{Pb}$ interference.

The western part of the Chalkidiki peninsula in Northern Greece is a geothermally active area that contains high levels of naturally derived As in its alkaline groundwaters (up to $3760 \mu \mathrm{g}$ $\mathrm{L}^{-1}$ ). Near wells, equilibration of these groundwaters with atmospheric carbon dioxide leads to the precipitation of travertines that contain very high levels of As (up to $913 \mathrm{mg} \mathrm{kg}^{-1}$ ). Winkel et al. ${ }^{108}$ analysed two different types of travertine using both XAS and $\mu$ XAS together with $\mu$ XRF to determine the mechanism of As uptake. Bulk XAS showed that in all of the samples As is present as $\mathrm{As}^{\mathrm{V}}$. The $\mu \mathrm{XRF}$ analyses indicated that As was closely associated with the calcite matrix and that it generally did not correlate well with iron. The As K-edge XAS spectra of all samples closely matched each other and closely resembled a reference spectrum for $\mathrm{As}^{\mathrm{V}}$ co-precipitated with calcite (rather than adsorbed or pure calcium arsenate). Iron on the other hand was found to be mainly present as a constituent of clay minerals, of presumably detrital origin, suggesting that iron-(hydr)oxides were not sufficiently abundant to act as major scavengers for As in the Chalkidiki travertines. It was estimated that calcite in these travertines could sequester at least $25 \%$ of aqueous $\mathrm{As}$ in the form of $\mathrm{As}^{\mathrm{V}}$ and thus immobilise a substantial part of As present in the geothermal groundwaters. These results may also be relevant for other areas where geothermal groundwaters carry As to the surface and possibly as well for As geochemistry in other environments with $\mathrm{CO}_{2}$-enriched water.

Long-term As exposure is a major global health problem. However, few epidemiologic studies have evaluated the association of As with kidney measures. Zheng et al. ${ }^{109}$ have evaluated the association between iAs exposure and albuminuria in American Indian adults (aged 45-74) from rural areas of Arizona, Oklahoma, and North and South Dakota. Arsenic exposure was estimated by measuring total urine As and urine As 
species ICP-MS and HPLC-ICP-MS, respectively. Urine albumin was measured by automated nephelometric immunochemistry. The prevalence of albuminuria (albumin-creatinine ratio $\geq 30$ $\mathrm{mg} \mathrm{g}^{-1}$ ) was $30 \%$ and the median value for the sum of inorganic and methylated As species was 9.7 (interquartile range, 5.8-15.6) $\mu \mathrm{g} \mathrm{g}^{-1}$ of creatinine. The association between urine As and albuminuria was observed across all participant subgroups evaluated and was evident for both micro- and macroalbuminuria, however the cross-sectional design could not rule out reverse causation. The characteristics of As metabolites in human liver hepatocytes have been studied by Cao et al. ${ }^{\mathbf{1 1 0}}$ Thus, HPLC-ICP-MS was used for the determination of As metabolites in Chang liver cells after As incubation. The MMTA was characterised by standard addition using a synthesised MMTA standard. Quantitative analysis showed that MMTA increased when the incubated As concentration increased. The results from mass balance studies suggested that some As species were found as As-protein bonded forms beside low molecular As species in hepatocytes. Furthermore, MMTA, which was first found in human hepatocytes, was speculated as a metabolite after As incubation.

Potential occupational As exposure is a significant problem in smelting plants in some parts of the world. A study is to determine if methylation capacity, as measured by urinary As metabolites, differed in workers with skin lesions compared to workers without skin lesions has been reported from a study in China. ${ }^{111}$ Thus, HG-AAS was used to determine three As species in urine of workers who had been working in As plants, and primary and secondary methylation indexes were calculated. The mean concentrations of iAs, MMA and DMA in the urine of workers was significantly higher than those of the control group and there was more iAs, MMA, and DMA in urine, for workers with skin lesions. Workers with skin lesions had the lowest secondary methylation index $(3.50 \pm 1.21)$, and may be in danger. The report suggests that individuals who metabolise iAs to MMA easily, but metabolise MMA to DMA with difficulty have more risk of skin lesions.

In a study of As species in the plasma and red blood cells of

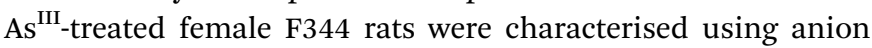
exchange and size exclusion chromatography separation with ICP-MS and ESI-MMS detection. ${ }^{112} \mathrm{As}^{\mathrm{III}}, \mathrm{As}^{\mathrm{V}}, \mathrm{MMA}^{\mathrm{V}}, \mathrm{DMA}^{\mathrm{V}}$, $\mathrm{TMAO}^{\mathrm{V}}$, monomethylmonothioarsonic acid $\left(\mathrm{MMMTA}^{\mathrm{V}}\right)$, and dimethylmonothioarsinic acid $\left(\mathrm{DMMTA}^{\mathrm{V}}\right)$ ) were detected in the plasma, with $\mathrm{DMA}^{\mathrm{V}}$ being the predominant metabolite. Upon oxidative pre-treatment with $5 \% \mathrm{H}_{2} \mathrm{O}_{2}$, plasma proteins released bound As in the form of $\mathrm{DMA}^{\mathrm{V}}$ as the major species and $\mathrm{MMA}^{\mathrm{V}}$ as the minor species. The ratio of protein-bound As to total As decreased with increasing dosage of iAs ${ }^{\mathrm{III}}$ administered to the rats, suggesting a possible saturation of the binding capacity of the plasma proteins. The proportion of the protein-bound As in the plasma varied among rats. In the $\mathrm{H}_{2} \mathrm{O}_{2}$-treated lysates of red blood cells of rats, $\mathrm{DMA}^{\mathrm{V}}$ was consistently found as the predominant As species, probably reflecting the preferential binding of $\mathrm{DMA}^{\mathrm{III}}$ to rat haemoglobin. $\mathrm{iAs}^{\mathrm{V}}, \mathrm{MMA}^{\mathrm{V}}$, and $\mathrm{TMAO}^{\mathrm{V}}$ were also detected in the $\mathrm{H}_{2} \mathrm{O}_{2}$-treated lysates of red blood cells. Importantly, DMMTA ${ }^{\mathrm{V}}$ and $\mathrm{MMMTA}^{\mathrm{V}}$ have not been reported in rat blood, and the present finding of DMMTA ${ }^{\mathrm{V}}$ and $\mathrm{MMMTA}^{\mathrm{V}}$ in the rat plasma is toxicologically relevant because these pentavalent thioarsenicals are more toxic than their counterparts $\mathrm{DMA}^{\mathrm{V}}$ and $\mathrm{MMA}^{\mathrm{V}}$. Identifying novel thiolated As species and determining protein-bound As species in the blood provide useful insights into the metabolism and toxicity of As in animals.

A less well studied chemical precursor, as well as a degradation product of As-containing chemical weapons, such as Clark 1 (diphenylarsine chloride) and Clark 2 (diphenylarsine cyanide) isDPAA $^{\mathrm{V}}$. Compared to iAs species, toxicological findings on $\mathrm{DPAA}^{\mathrm{V}}$ are limited. To elucidate the mechanism of $\mathrm{DPAA}^{\mathrm{V}}$ toxicity, Kobayashi and Hirano ${ }^{113}$ have investigated the metabolic behaviour of $\mathrm{DPAA}^{\mathrm{V}}$ in rats following an oral dose of $1.0 \mathrm{mg} \mathrm{As} \mathrm{\textrm {kg } ^ { - 1 } \text { body weight. DPAA }}{ }^{\mathrm{V}}$ was excreted in bile, either as the original DPAA ${ }^{\mathrm{V}}$ or as a DPAA-GSH complex as determined by HPLC-ICP-MS and HPLC-ESI-MS, with the DPAA-GSH complex being the main form. Approximately $1.7 \%$ and $2.4 \%$ of the dose was accumulated in erythrocytes three hours and three days after administration, respectively. Approximately $91 \%$ of the dose was excreted in urine and faeces as $\mathrm{DPAA}^{\mathrm{V}}$ in three days, mostly in the urine.

Arsenic speciation has also been investigated in algae and freshwater plants. The As speciation in two green algae species (Cladophora sp. and Chara sp.) and in five aquatic plants (Azolla sp., Myriophyllum aquaticum, Phylloscirpus cf. desserticola, Potamogeton pectinatus, Ruppia filifolia and Zannichellia palustris) from the Loa River Basin in northern Chile has been reported. ${ }^{114}$ HPLC-ICP-MS with both anionic and cationic chromatographic exchange systems was used. The main As species in the extracts were $\mathrm{As}^{\mathrm{III}}$ and $\mathrm{As}^{\mathrm{V}}$, whereas glycerolarsenosugar, DMA and MMA were present only as minor constituents. Of the samples studied, algae species accumulated more As than aquatic plants with total As content ranging from 182 to 11100 and from 20 to $248 \mathrm{mg} \mathrm{As} \mathrm{kg}^{-1}$ (dry weight) in algae and freshwater plants, respectively. The metabolic processes of incorporated $\mathrm{As}^{\mathrm{III}}$ in axenic cultures of the freshwater cyanobacteria Synechocystis sp. PCC 6803 and Nostoc (Anabaena) sp. PCC 7120 have also been examined. ${ }^{115}$ Analyses of the As compounds in cyanobacterial extracts using a HPLCICP-MS showed that both strains have an ability to biotransform $\mathrm{As}^{\mathrm{III}}$ into oxo-arsenosugar-glycerol within $20 \mathrm{~min}$ through (1) reduction of incorporated $\mathrm{As}^{\mathrm{V}}$ to $\mathrm{As}^{\mathrm{III}}$ and (2) methylation of produced $\mathrm{As}^{\mathrm{III}}$ to DMA by methylarsonic acid as a possible intermediate product. In addition, Synechocystis sp. PCC 6803 cells are able to biosynthesise oxoarsenosugar-phosphate from incorporated $\mathrm{As}^{\mathrm{V}}$. These findings suggest that arsenosugar formation as well as arsenic methylation in cyanobacteria possibly play a significant role in the global As cycle.

It has been known for over a hundred years that microorganisms can produce volatile As species. However, this topic has received relatively little attention compared to As behaviour in soils and biotransformation through the trophic level in the marine and terrestrial environment. Mestrot et al. ${ }^{\mathbf{1 1 6}}$ believe this is due to long-standing misconceptions regarding volatile As stability and transport as well as an absence, until recently, of appropriate sampling methods. They have produced a comprehensive review which considers the mechanisms, 
stability, transport and sampling of arsines and suggest that more research should be conducted on this important process. The stability of As species in environmental samples during sampling, storage and processing is crucial for speciation studies. Losses, interconversion and degradation of arsenocompounds can occur during these steps as a result of the interaction with the container material, microbial activity and temperature or light. In order to study the possible effects of storage and processing on As compounds in marine macroalgae, Pell et al. ${ }^{117}$ have studied subsamples of alga Cystoseira mediterranea Sauvageau stored under different conditions (nonfrozen; frozen at $-18{ }^{\circ} \mathrm{C}$ for $24 \mathrm{~h}$ and 45 days; frozen at $-80{ }^{\circ} \mathrm{C}$ for $24 \mathrm{~h}$ and 45 days). The samples were then subjected to one of the following processing methods: chopping into fine pieces with a knife; grinding by hand in a glass mortar under liquid $\mathrm{N}_{2}$; drying under an air current at room temperature $\left(25^{\circ} \mathrm{C}\right)$; drying in an oven at $40{ }^{\circ} \mathrm{C}$; lyophilisation. The total As and As compounds were then determined in these subsamples. The results indicated that freezing was an unsuitable storage method for macroalgae because losses of As may occur, and so the authors recommend a drying method for this purpose.

The inorganic forms of As together with MMA, DMA, TMAO, TMA and $\mathrm{AB}$ were measured in 95 marine sediment samples and 11 pore water samples from the Baltic Sea at depths of up to $100 \mathrm{~m} .{ }^{118}$ iAs and DMA were detected in the sediment and iAs was detected in the sediment pore water. Average total As concentration of $10.6 \pm 7.4 \mathrm{mg} \mathrm{kg}^{-1}$ dry matter in the sediment corresponds to previously reported values in the Baltic Sea and other parts of the world. Existing data for on-site measurements of sorption coefficients $\left(K_{\mathrm{d}}\right)$ of As compounds in marine and freshwater sediments show large variability from $<1$ to $>1000 \mathrm{~L}$ $\mathrm{kg}^{-1}$. It was concluded that, at locations with significant anthropogenic point sources or where the local geology contains volcanic rock and sulphide mineral deposits, there may be significantly elevated As concentrations, and it is recommended to determine on-site $K_{\mathrm{d}}$ values. The inter-conversion and sorption of iAs species in representative geological media has also been reported by $\mathrm{Hu}$ et al. ${ }^{119}$ Using HPLC-ICP-MS and integrated batch and column approaches, oxidation of $\mathrm{As}^{\mathrm{III}}$ to $\mathrm{As}^{\mathrm{V}}$ was shown in the sediment of the River Hanford, while reduction of $\mathrm{As}^{\mathrm{V}}$ to $\mathrm{As}^{\mathrm{III}}$ was shown for the surface soil of Savannah River Site. Overall, the sorption distribution coefficient of $\mathrm{As}^{\mathrm{V}}$ onto geological media was found to be much larger than that of $\mathrm{As}^{\mathrm{III}}$, and a reduction of the more sorptive $\mathrm{As}^{\mathrm{V}}$ to $\mathrm{As}^{\mathrm{III}}$ will lead to groundwater enrichment with As. Coupled with the different sorption behaviour of $\mathrm{As}^{\mathrm{III}}$ and $\mathrm{As}^{\mathrm{V}}$, the interconversion of these species will strongly affect the geochemical cycling of redox-sensitive As in the subsurface.

The biogeochemical reductive release of $A s^{V}$ from beudantite into solution in a crater area in northern Taiwan has been studied using XANES and AAS. ${ }^{120}$ Total As concentrations in the soil were more than $200 \mathrm{mg} \mathrm{kg}{ }^{-1}$. Over four months of laboratory experiments, less than $0.8 \%$ As was released into solution after reduction experiments. $71 \%$ to $83 \%$ As was chemically reduced to $\mathrm{As}^{\mathrm{III}}$ and partially weathering into the soluble phase. The kinetic dissolution and re-precipitation of $\mathrm{As}, \mathrm{Fe}, \mathrm{Pb}$ and sulfate in this area of paddy soils merits further study. As species in soil solution have been determined by microcartridges (both self-made and commercial) and ferrihydritebased diffusive gradient in thin films (DGT). ${ }^{121}$ The self-made microcartridge was effective in separating $\mathrm{As}^{\mathrm{III}}$ from $\mathrm{As}^{\mathrm{V}}$ in volumes of only $3 \mathrm{~mL}$ of solution. Detection was by ICP-OES. The DGT study also showed that the ferrihydrite-based gels are effective for $\mathrm{As}^{\mathrm{III}}$ and $\mathrm{As}^{\mathrm{V}}$ in solutions with As and $\mathrm{P}$ concentrations and ionic strength commonly found in soils. The ferrihydrite-based-DGT was tested on flooded and unflooded As spiked soils and recoveries of $\mathrm{As}^{\mathrm{III}}$ and $\mathrm{As}^{\mathrm{V}}$ were $85-104 \%$ of the total dissolved As.

Earthworms, Eisenia fetida, were exposed to soils spiked with $A s^{I I I}$ and $A s^{V}$ over a 28 day period to investigate their response in terms of both toxicity and accumulation using toxicokinetics. ${ }^{\mathbf{1 2 2}}$ $\mathrm{As}^{\mathrm{III}}$ showed higher toxicity than $\mathrm{As}^{\mathrm{V}}$, for all toxicity endpoints: burrowing time, survival, growth, and cocoon production. Bioconcentration occurred during both $\mathrm{As}^{\mathrm{III}}$ and $\mathrm{As}^{\mathrm{V}}$ treatments. Biotransformation of As was characterised using HPLC-ICP-MS and XANES, showing the reduction of As in worms regardless of the As species to which worms were exposed. Metabolism of As in worms that formed As-thiol complex is thought to limit the excretion of As, and thus induce bioconcentration. Uptake rates by one-compartment model indicated that pore water was the bioaccessible pool of As, and directly controlled the uptake of As by worms. The study suggests that higher uptake rate and bioaccumulation of $\mathrm{As}^{\mathrm{III}}$ than of $\mathrm{As}^{\mathrm{V}}$ are among the factors that make $\mathrm{As}^{\mathrm{III}}$ more toxic than $\mathrm{As}^{\mathrm{V}}$.

There have been a few miscellaneous studies of As in other samples of biological origin. Desorption electrospray ionisation mass spectrometry (DESI-MS) has been applied for the detection of $\mathrm{As}^{\mathrm{III}}, \mathrm{As}^{\mathrm{V}}$, DMA and disodium methyl $\mathrm{As}^{\mathrm{V}}$ hexahydrate: compounds in fern leaves. ${ }^{123}$ Operational conditions of DESIMS were optimised with DMA standard deposited on paper surfaces to improve ionisation efficiency and detection limits. Mass spectra data for all As species were acquired in both the positive and negative ion modes. The positive ion mode was shown to be useful in detecting both the organic and iAs compounds. The negative ion mode was shown only to be useful in detecting $\mathrm{As}^{\mathrm{V}}$ species. Moreover, MS-MS spectra were recorded to confirm the identity of each As compound by the characteristic fragmentation profiles. Optimised conditions of DESIMS were applied to the analysis of fern leaves. LC-ICP-MS was employed to confirm the results obtained by DESI-MS and to quantify the As species in fern leaves. The results confirmed the applicability of DESI-MS in detecting As compounds in complex matrices. The uptake of As in the fern Pteris vittata (commonly known as Chinese brake, Chinese ladder brake, or simply ladder brake) has been investigated following cultivation in quartz substrate with and without co-contamination with As and a contaminated soil for 7 weeks. ${ }^{124}$ Thus, HPLC-ICP-MS analysis detected $\mathrm{As}^{\mathrm{III}}$ and $\mathrm{As}^{\mathrm{V}}$ as the main species in aqueous extracts of roots and fronds. Adding increasing amounts of As to the quartz substrate resulted in increasing uptake of $\mathrm{Sb}$. In contrast to As, which is readily transferred to the fronds, $\mathrm{Sb}$ is primarily accumulated in the roots with $\mathrm{Sb}^{\mathrm{V}}$ being the dominant species (>90\% of $\mathrm{Sb}$ ). The addition of As does not result in enhanced translocation of $\mathrm{Sb}$ into the fronds. 
A method based on pressurised hot water extraction (PHWE) for the determination of total As and As species (mainly As ${ }^{\text {II }}$ and $\mathrm{As}^{\mathrm{V}}$ ) in human scalp hair has been developed. ${ }^{\mathbf{1 2 5}}$ The proposed PHWE method is said to be a "green", fast, highly efficient and automated leaching method for use prior to determining the As species by HPLC-ICP-MS. The operating parameters for PHWE including modifier concentration, extraction temperature, static time, extraction steps, pressure, mean particle size, diatomaceous earth mass/sample mass ratio and flush volume were studied using an experimental design of approach (Plackett-Burman design PBD). Following optimisation, the extraction was carried out at $100{ }^{\circ} \mathrm{C}$ and at an extraction pressure of 1500 psi for $5 \mathrm{~min}$ in four extraction steps. Under optimised LOQ values of 7.0, 6.3 and $50.3 \mathrm{ng} \mathrm{g}^{-1}$ for total $\mathrm{As}, \mathrm{As}^{\mathrm{III}}$ and $\mathrm{As}^{\mathrm{V}}$, respectively were achieved. The analysis of CRM GBW-07601 (human hair) was used for validation.

A method for the speciation of iAs species in coal samples by HPLC-HG-AFS after microwave-assisted extraction using $1.0 \mathrm{~mol} \mathrm{~L}^{-1} \mathrm{H}_{3} \mathrm{PO}_{4}$ and $0.1 \mathrm{~mol} \mathrm{~L}^{-1}$ ascorbic acid has been reported. ${ }^{126}$ Under the optimised conditions, the LODs were $0.01 \mu \mathrm{g} \mathrm{L}^{-1}$ and $0.02 \mu \mathrm{g} \mathrm{L}^{-1}$ for $\mathrm{As}^{\mathrm{III}}$ and $\mathrm{As}^{\mathrm{V}}$, with RSD values of $2.4 \%$ and $3.3 \%\left(10.0 \mu \mathrm{g} \mathrm{L}^{-1}, n=7\right)$, and recoveries of $103 \%$ and $96.5 \%$ respectively. The proposed method was successfully applied for the determination of speciation of iAs in coal samples and SRM GBW11117, a coal material with complex matrix.

Arsenic speciation methods have also been applied to the study of drug metabolites. Arsenic trioxide has been successfully used as a therapeutic in the treatment of acute promyelocytic leukemia (APL). Saliva samples were collected in a study by Chen et al. ${ }^{\mathbf{1 2 7}}$ from nine APL patients over three consecutive

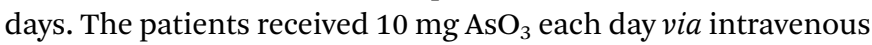
infusion. The saliva samples were analysed using HPLC-ICPMS. Monomethylarsonous acid and monomethylmonothioarsonic acid were identified along with As ${ }^{\mathrm{III}}$, DMA, MMA, and $\mathrm{As}^{\mathrm{V}}$. Arsenite was the predominant As species, accounting for $71.8 \%$ of total As in the saliva. Following the As infusion each day, the percentage of methylated As significantly decreased, possibly suggesting that the As methylation process was saturated by the high doses immediately after the As infusion. These results suggest that saliva can be used as an appropriate clinical biomarker for monitoring As species in APL patients. In a separate study, HPLC-ICP-MS was used to study As in the plasma of children with Leukemia. ${ }^{128}$ It was found that AC and $\mathrm{AB}, \mathrm{As}^{\mathrm{III}}$, DMA, MMA and $\mathrm{As}^{\mathrm{V}}$ were present, although $\mathrm{As}^{\mathrm{V}}$ was the predominant species. Melarsoprol is the only currently available drug for treatment of the late stage of African trypanosomiasis (sleeping sickness). Unfortunately, the Ascontaining drug causes serious side effects, for which the mechanisms have not been elucidated so far. A study to investigate the melarsoprol biotransformation processes has been reported by Baumann et al. ${ }^{129}$ Electrochemical techniques were used to study the potential oxidation reactions, whilst LC and ESI-MS were used to elucidate structure and HPLC-ICP-MS used for the detection of As containing metabolites. The results indicate that melarsen oxide, the active derivative of melarsoprol, strongly binds to human haemoglobin and forms different adducts via the free cysteinyl groups of the haemoglobin alphaand beta-chain.

Finally, the speciation and spatial distribution of As on rusted steel surfaces has been studied since it affects both measurement and removal approaches. The chemistry of As residing in the rust of Ton containers that held the chemical warfare agents bis(2-chloroethyl)sulfide (sulfur mustard) and 2-chlorovinyldichloroarsine (Lewisite) has been investigated by Groenewold et $a l .{ }^{\mathbf{1 3 0}}$ This is of particular interest, because while the agents may have been decontaminated, residual As could pose a health or environmental risk. The authors used SIMS, XPS, Auger electron spectroscopy, and SEM-EDX to probe the sample surface. iAs species were homogeneously distributed at the very topmost layer of the rust samples and were intimately associated with Fe. Sputter depth profiling followed by SIMS and XPS showed As at a depth of several nanometers, in some cases in a reduced form. The SEM-EDX experiments showed that As was present at a depth of several micrometers but was heterogeneously distributed; most locations contained oxidised As at concentrations of a few percent; however, several locations showed very high concentrations of As in the zerovalent form. The results indicated that the rust material must be removed if the steel containers are to be cleared of As.

\subsection{Cadmium}

Miszczak et $a l .{ }^{131}$ have used a combination of SEC-ICP-MS and CZE-ICP-MS to study the binding of Cd to sulphur containing ligands in plant material The stoichiometry of the low, medium and high molecular weight $\mathrm{Cd}$ complexes with glutathione and phytochelatin in vitro was shown to be in the ratio $1: 1$ using ESI-MS. Complimentary use of SEC-ICP-MS and CZE-ICP-MS confirmed the ability of thiopeptides to create medium and low molecular weight complexes with $\mathrm{Cd}$ and confirmed the presence of disulfide bridges to be one of the factors connected to their formation. Although the selectivity of the CZE method was considerably better in comparison with that of the SEC method, the resolution was insufficient to establish the stoichiometry of the complexes. The CZE method was more suitable for the high molecular weight complexes because its exclusion range was less narrow in comparison with the SEC method, but it was strongly sensitive to matrix effects. Hence, both SEC ICP MS and CZE ICP MS should be treated as complementary for studies of polymorphism of Cd-thiopeptide complexes. The speciation of Cd in scallop with high capacity for Cd accumulation, compared to species of clam with a low capability to accumulate $\mathrm{Cd}$ were studied using SEC-ICP-MS. ${ }^{132}$ The action of digestion fluids, such as saliva and the acidic nature of the stomach and intestinal environment, on the binding of Cd was also investigated. Three Cd containing species, metallothionein, glutathione and cysteine were detected in the scallop, whereas only metallothionein and glutathione were detected in the clams. One unidentified small molecular Cd species was detected in the gastric digest and four Cd species (mainly metallothionein-Cd) were detected in the intestinal digests extracts for the scallop. For the clam, the unknown Cd was predominant in both the gastric and intestinal extracts. 


\subsection{Chromium}

The determination of individual $\mathrm{Cr}$ species in water samples continues to be widely reported, although in many cases the focus of the work is the use of novel sorbents for SPE. A nanomaterial has been developed for speciation of $\mathrm{Cr}^{\mathrm{III}}$ and $\mathrm{Cr}^{\mathrm{VI}}$ in water and soil samples. Alumina-coated magnetite nanoparticles $\left(\mathrm{Fe}_{3} \mathrm{O}_{4} / \mathrm{Al}_{2} \mathrm{O}_{3}\right)$ modified by the surfactant Triton X-114 has been synthesised and used in a magnetic mixed hemimicelles solid-phase extraction procedure. ${ }^{\mathbf{1 3 3}}$ The procedure was based on the reaction of $\mathrm{Cr}^{\mathrm{III}}$ with 1-(2-pyridilazo)-2-naphtol as a ligand, yielding a complex, which was entrapped 'in situ' in the surfactant hemimicelles. The concentration of $\mathrm{Cr}^{\mathrm{III}}$ was determined using FAAS. After reduction of $\mathrm{Cr}^{\mathrm{VI}}$ to $\mathrm{Cr}^{\mathrm{III}}$ by ascorbic acid, the system was applied to the total $\mathrm{Cr} . \mathrm{Cr}^{\mathrm{VI}}$ was then calculated by difference. It is reported that the method could also be used for complicated matrices such as soil samples without any special pre-treatment. The recoveries of $\mathrm{Cr}^{\mathrm{III}}$ in spiked waters and soil samples were between 98.6 and $100.8 \%$ and between 96.5 and $100.7 \%$, respectively. Detection limits of $\mathrm{Cr}^{\mathrm{III}}$ were between 1.4 and $3.6 \mathrm{ng} \mathrm{mL}^{-1}$ for water samples and $5.6 \mathrm{ng} \mathrm{mg}^{-1}$ for soil samples. Poly(1,3-thiazol-2-yl methacrylamide-co-4-vinyl pyridine-co-divinylbenzene) has been prepared and used for the extraction of $\mathrm{Cr}^{\mathrm{VI}}$ ions from aqueous solution. ${ }^{\mathbf{1 3 4}}$ Two forms of Cr showed different exchange capacities at different $\mathrm{pH}$ values; $\mathrm{Cr}^{\mathrm{VI}}$ was selectively retained especially at $\mathrm{pH}$. The total Cr was determined after the oxidisation of $\mathrm{Cr}^{\mathrm{III}}$ to $\mathrm{Cr}^{\mathrm{VI}}$ using potassium permanganate. A preconcentration factor of 30 and a $3 \sigma$ LOD of $2.4 \mu \mathrm{g} \mathrm{L}^{-1}(n=20)$ was achieved for $\mathrm{Cr}^{\mathrm{VI}}$ ions. $\operatorname{Poly}\left(N, N^{\prime}\right.$-dipropionitrile methacrylamide-co-divinylbenzene-co-2-acrylamido-2-methyl-1-propanesulfonic acid) resin was also synthesised as chelating adsorbent for $\mathrm{Cr}$ species in water and food samples by FAAS. ${ }^{\mathbf{1 3 5}}$ The sorption capacity of the resin was found to be $12.1 \mu \mathrm{g} \mathrm{g}^{-1}$ for $\mathrm{Cr}^{\mathrm{III}}$. A preconcentration factor of 150 with a RSD of $2.0 \%$ $(n=10)$ were obtained. The LOD of the method was $1.11 \mu \mathrm{g} \mathrm{L}^{-1}$. Method validation was performed using CRM materials (TMDA70 lake water and SRM 1568a rice flour). A $\mathrm{Cr}^{\mathrm{III}}$-imprinted polymer has been prepared from $\mathrm{Cr}^{\mathrm{III}}$-pyrrolidinedithiocarbamate complex, acrylamide functional monomer and ethylene glycol methacrylate cross-linking agent. ${ }^{136}$ It was found that $\mathrm{Cr}^{\mathrm{III}}$ ions could be retained with reasonable efficiency and repeatability $(87 \%$, RSD $=3.2 \%)$ from a solution of $\mathrm{pH} 3.50-4.75$. Elution of analyte was achieved using $0.2 \mathrm{~mol} \mathrm{~L}^{-1}$ nitric acid solution. The selectivity of the sorbent towards $\mathrm{Cr}^{\mathrm{III}}$ ions was retained in the presence of $\mathrm{Cu}^{\mathrm{II}}$ and $\mathrm{Ni}^{\mathrm{II}}$ ions but degraded in the presence of $\mathrm{Fe}^{\mathrm{III}}$ ions at a concentration higher than $0.5 \mu \mathrm{g}$ $\mathrm{mL}^{-1}$. The LOD for $\mathrm{Cr}^{\mathrm{III}}$ obtained ETAAS after preconcentration of $40 \mathrm{~mL}$ of sample on the polymer was $0.018 \mathrm{ng} \mathrm{mL}{ }^{-1}$. The method was applied to the determination of trace amounts of $\mathrm{Cr}^{\mathrm{III}}$ in tap and river water and municipal sewage.

Multi-walled carbon nanotubes have been used as an adsorbent for the on-line separation and preconcentration $\mathrm{Cr}^{I I I}$ and $\mathrm{Cr}$ speciation. ${ }^{137}$ The surface functional groups and negative charges of the nanotubes are beneficial to the adsorption of $\mathrm{Cr}^{\mathrm{III}}$, and at $\mathrm{pH}$ 3.0-6.0, a discrimination of $\mathrm{Cr}^{\mathrm{III}}$ and $\mathrm{Cr}^{\mathrm{VI}}$ was achieved. The adsorbed $\mathrm{Cr}^{\mathrm{III}}$ was quantitatively eluted by $10 \%$ (v/v) nitric acid with detection by FAAS. By loading a $6.0 \mathrm{~mL}$ sample solution, an enrichment factor of 22 , a detection limit $(3 \sigma)$ of $1.15 \mu \mathrm{g} \mathrm{L}^{-1}$ and a precision of $1.7 \%$ RSD were achieved for $\mathrm{Cr}^{\mathrm{III}}$ within a linear range of $5-200 \mu \mathrm{g} \mathrm{L}^{-1}(r=0.9994)$. Following reduction of the $\mathrm{Cr}^{\mathrm{VI}}$ with hydroxylamine hydrochloride, the total amount of $\mathrm{Cr}$ was obtained, and the $\mathrm{Cr}^{\mathrm{VI}}$ calculated by difference.

A microextraction procedure called ultrasound-assisted emulsification-microextraction (USAEME) has been developed for $\mathrm{Cr}$ species separation and preconcentration from water samples. ${ }^{138}$ The procedure was based on forming an ion-pair between $\mathrm{Cr}^{\mathrm{VI}}$ species and hydrophobic ionic liquid trihexyl(tetradecyl) phosphonium chloride. Determination of $\mathrm{Cr}$ was performed by direct injection of the organic phase into an ETAAS. Parameters that affect the efficiency of the microextraction step were investigated using a Plackett-Burman screening design. For $10 \mathrm{~mL}$ of water sample, the optimised USAEME procedure used $40 \mu \mathrm{L}$ of tetrachloroethylene as extraction solvent, $5 \mathrm{~min}$ of extraction and $5 \mathrm{~min}$ of centrifugation at $1700 \mathrm{rpm}$. Selectivity among $\mathrm{Cr}$ species was obtained through $\mathrm{pH}$ selection. The concentration of $\mathrm{Cr}^{\mathrm{III}}$ species was calculated from the difference between total $\mathrm{Cr}$ and $\mathrm{Cr}^{\mathrm{VI}}$ concentrations. Under optimum conditions, the analyte extraction recovery was $>99 \%$ and yielded a preconcentration factor of 250 . The LOD obtained was $14.8 \mathrm{ng} \mathrm{\textrm {L } ^ { - 1 }}$ and the relative standard deviation for 10 replicate determinations at the $0.05 \mu \mathrm{g} \mathrm{L}^{-1} \mathrm{Cr}^{\mathrm{VI}}$ level was $3.8 \%$. A system employing DLLME using a microsample injection system coupled with FAAS has been used for $\mathrm{Cr}^{\mathrm{VI}}$ determinations. ${ }^{139} \mathrm{In}$ this method, APDC, carbon tetrachloride, and ethanol were used as chelating agent, extraction solvent, and disperser solvent, respectively. An LOD of $0.037 \mu \mathrm{g} \mathrm{\textrm {L } ^ { - 1 }}$ was achieved with an enrichment factor of 400 with $40 \mathrm{~mL}$ volumes. The RSD $(n=$ $6)$ was $<4 \%$. The proposed method was applied to the determination of $\mathrm{Cr}^{\mathrm{VI}}$ at ultratrace levels in natural drinking water and industrial effluents wastewater. Nano-strontium titanate coated glass fibre filters for Cr speciation in waters have been prepared by a sol-gel method and characterised using XRD and SEM. ${ }^{\mathbf{1 4 0}}$ At normal temperature, the adsorbent had strong adsorption capacity for $\mathrm{Cr}^{\mathrm{III}}$ and $\mathrm{Cr}^{\mathrm{VI}}$ but two forms of $\mathrm{Cr}$ showed different adsorption capacities at different $\mathrm{pH}$ values. Retained $\mathrm{Cr}^{\mathrm{III}}$ and $\mathrm{Cr}^{\mathrm{VI}}$ were eluted with $1 \mathrm{~mol} \mathrm{~L}^{-1} \mathrm{HCl}$ and $2 \mathrm{~mol} \mathrm{~L}^{-1} \mathrm{NaOH}$, respectively and determined by FAAS.

Two different widely-used methods for the determination of $\mathrm{Cr}^{V I}$ in water samples by ETAAS have been compared. ${ }^{\mathbf{1 4 1}}$ Both methods are based on the complexation - reaction of $\mathrm{Cr}^{\mathrm{VI}}$ with an organic complexation reagent, which is then extracted and preconcentrated in organic solvent. In the first method, APDC was used as complexation reagent, whereas 1,5-diphenylcarbazide (DPC) was used in the second method. The methods were applied to the determination of $\mathrm{Cr}^{\mathrm{VI}}$ in the same multi-level groundwater samples $\left(0.060-42 \mu \mathrm{g} \mathrm{L}^{-1}, n=13\right)$. In addition, the samples were also analysed by reagent free ion chromatography with a conductivity detector. The paired $t$-test was applied and the results indicated that there was no statistically significant difference between the three methods. The DPC method provided a lower LOD than that using APDC. However the APDC method was more robust than the DPC method. Both methods 
were found to be appropriate for the determination of $\mathrm{Cr}^{\mathrm{VI}}$ in different ground water samples at sub- $\mu \mathrm{g} \mathrm{L}^{-1}$ levels.

Fabregat-Cabello et al. ${ }^{142}$ reported a method utilising ID-MS for the determination of $\mathrm{Cr}^{V I}$ in solid samples. The quantitative extraction of $\mathrm{Cr}^{\mathrm{VI}}$ was achieved in 10 minutes using focused microwave assisted extraction with $50 \mathrm{mmol} \mathrm{L}^{-1}$ EDTA at $\mathrm{pH} 10$ as extractant. Separation of $\mathrm{Cr}$ species was achieved by anion exchange chromatography using a mobile phase of a $1: 10$ dilution of the extracting solution. Thus, neutralisation or acidification steps which are prone to cause interconversion of $\mathrm{Cr}$ species were not needed. Another benefit of using EDTA is that it allowed measurement of $\mathrm{Cr}^{\mathrm{III}}$-EDTA complex and $\mathrm{Cr}^{\mathrm{VI}}$ simultaneously in an alkaline extraction solution. The application of a 10 minutes focused microwave assisted extraction $(5$ min at $90{ }^{\circ} \mathrm{C}$ plus 5 min at $110^{\circ} \mathrm{C}$ ) was shown to quantitatively extract all forms of $\mathrm{Cr}^{\mathrm{VI}}$ from SRM NIST 2700 and NIST 2701. The ID-MS technique was then employed to study $\mathrm{Cr}$ interconversion reactions. It was observed that the formation of a $\mathrm{Cr}^{\mathrm{III}}-$ EDTA complex avoided $\mathrm{Cr}^{\mathrm{III}}$ oxidation for these two SRMs. Thus, the use of a double spiking strategy for quantification was not required and a single spike ID-MS procedure using isotopically enriched $\mathrm{Cr}^{\mathrm{VI}}$ provided accurate results.

A study has been conducted to determine $\mathrm{Cr}^{\mathrm{VI}}$ and $\mathrm{Cr}^{\mathrm{III}}$ in dietary supplements. ${ }^{143}$ Thus, EPA Method 3060A extraction protocol was performed to extract $\mathrm{Cr}^{\mathrm{VI}}$, and EPA Method 3052 was performed on the extracted residue to digest the remaining $\mathrm{Cr}^{\mathrm{III}}$. Isotope dilution MS, as described in the EPA Method 6800 (update V), was used with ion-exchange HPLC-ICP-MS. Method 6800 enabled tracking and correcting for the bidirectional $\mathrm{Cr}$ interspecies conversions that occur during extraction and sample handling prior to instrumental analysis. The mass balance results indicated that the off-the-shelf dietary supplements analysed during the study contained $\mathrm{Cr}^{\mathrm{VI}}$ ranging from $<$ DL (detection limit not given) to $122 \pm 13.0 \mu \mathrm{g} \mathrm{g}^{-1}$, which corresponds to concentrations up to $16 \%$ of the total $\mathrm{Cr}$ content. This type of variation in the final products raises public health issues and points to a need to use a robust method that can accurately and reliably make species measurements including correcting for species conversions.

Other more esoteric studies on Cr speciation reported this year include the speciation of migratory $\mathrm{Cr}^{\mathrm{VI}}$ in toys by HPLC-ICPMS. ${ }^{144}$ The $\mathrm{Cr}^{\mathrm{III}}$ and $\mathrm{Cr}^{\mathrm{VI}}$ were separated on an Dionex AS19 column using ammonium nitrate as the mobile phase with $\mathrm{pH}$ 7.4 at flow rate $1.0 \mathrm{~mL} \mathrm{~min}^{-1}$. The LOD was found to be $0.02 \mu \mathrm{g}$ $\mathrm{L}^{-1}$ for $\mathrm{Cr}^{\mathrm{VI}}$ for $100 \mu \mathrm{L}$ injection volume using a He collision cell. Spiked recoveries for both species were in the range 96.3$104.2 \%$ with an RSD of $<4.2 \%$. A method to determine $\mathrm{Cr}$ speciation in cigarette papers had also been developed using HPLC-ICP-MS. ${ }^{145}$ Separation of $\mathrm{Cr}^{\mathrm{III}}$ and $\mathrm{Cr}^{\mathrm{VI}}$ could be achieved in under 3 minutes with LODs of $0.54 \mu \mathrm{g} \mathrm{L}^{-1}$ and $1.1 \mu \mathrm{g} \mathrm{L}^{-1}$ for $\mathrm{Cr}^{\mathrm{III}}$ and $\mathrm{Cr}^{\mathrm{VI}}$ respectively. A sample preparation method based on PFA self-sealing bottles was also developed. Complete sample decomposition could be achieved with $2 \mathrm{~mL} \mathrm{HNO} 3$ at $120^{\circ} \mathrm{C}$ in 1 h. Organic bound $\mathrm{Cr}$ was extracted using ethyl acetate. It was reported that $85-95 \%$ of the $\mathrm{Cr}$ in the cigarette papers was in the immobilised organic form. The Cr speciation in 22 species of medicinal plants (anise, centaury, chamomile, fennel, flax, green tea, Indian hemp, laurel, liquorice, linden, marestail, melissa, nettle, oat, red clover, riesenfenchel, rosehip, rosemary, sage, senna tea, yam, yarrow) taken from five different local herbalists in Turkey has been reported. ${ }^{146}$ The $\mathrm{Cr}^{\mathrm{III}}$ and $\mathrm{Cr}^{\mathrm{VI}}$ concentrations in medicinal herbs were found in the range of $0.26-3.12 \mathrm{mg} \mathrm{kg}^{-1}$ and $0.07-1.09 \mathrm{mg} \mathrm{kg}^{-1}$, respectively.

\subsection{Cobalt}

Interest in the speciation of Co has increased in recent years as a result of its release into the human body from metal-on-metal hip-replacements. Being a toxic element Co has a wide range of potential health effects and so methods which can delineate the different species in human samples are of interest. Kerger et al. ${ }^{147}$ have developed a method to distinguish between different molecular size fractions containing Co using SEC-ICP-MS. The separation was performed using a Superdex Peptide 10/300 GL column, an eluent composed of hydrochloric acid $(50 \mathrm{mM})$ at a

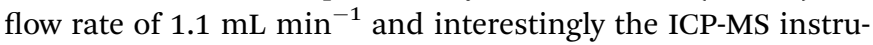
ment was operated in cell mode with He at a flow rate of $3 \mathrm{~mL}$ $\mathrm{min}^{-1}$. Whilst not truly elemental speciation because the actual molecular entity containing Co was not identified, it does represent a screening method when investigating the high levels of Co, found in some patients. However, the developed method seems to have little real applicability because it does not identify the quantity or type of organic ligand attached to Co in the large or small molecular fractions that were separated. Also the report showed cyanocobalamin (actually a related but artificial form of cobalamin) eluting as the unbound form, close to the peak for inorganic Co, when physiologically vitamin B12 is transported in the plasma associated with transcobalamin II and one would therefore expect it to elute in the large molecular peak. More importantly perhaps, quantification of the different size fractions was achieved indirectly by summing the large and small molecule-bound Co peaks and comparing this to the total Co measurement following digestion of the sample. However, this assumes that all of the Co containing compounds elute from the column and that none are irreversibly bound. It also assumes that all of the Co that is spiked into the standards is accounted for in the chromatogram and that none remains unbound as the inorganic ion, which could bind irreversibly to the column. Neither of these possibilities do not seem to have been thoroughly investigated in the paper. Clearly size exclusion has its place in the speciation of large metal-containing molecules, but as is shown in many other studies it needs to be used in conjunction with other, higher resolution, separation methods which are better able to isolate all the species present. In a second paper $^{148}$ the same authors apply the developed method to a cohort of individuals who are taking Co containing nutritional supplements and show that the large molecular Co fraction was the predominant Co species in both undiluted and diluted human serum over a broad range of in vivo Co concentrations, reflecting high albumin-Co binding capacity. It is interesting to speculate from a medico-legal perspective whether this method is specific enough to characterise the toxic and non-toxic forms of Co in samples from patients adversely affected by failing metal-on-metal hip-replacements. 


\subsection{Copper}

In two similar papers, Pesch et al. ${ }^{\mathbf{1 4 9 , 1 5 0}}$ have investigated the complexation of $\mathrm{Cu}$ by methanobactins, which are simple copperbinding molecules produced by many aerobic methane oxidising bacteria, with molecular mass of 1154 Da and composed of seven amino acids. Potentiometric and spectrophotometric titrations of the free ligand indicated the presence of four protonation sites consistent with the molecular structure of methanobactin. Metal titrations revealed a distinct $\mathrm{pH}$-dependence of $\mathrm{Cu}$ binding between $\mathrm{pH} 5$ and 8. Based on evidence from SEC-ICP-MS using a Superdex Peptide 10/300 GL column, the $\mathrm{Cu}$ binding was quantitatively described with three different types of copper methanobactin complexes which could additionally undergo protonation reactions. In the second paper the group used the same experimental set-up to study $\mathrm{Cu}$ mobilisation from humic acid to methanobactin, effectively demonstrating that these molecules can sequester $\mathrm{Cu}$ in organic-rich environments.

\subsection{Gadolinium}

The application of gadolinium (Gd)-based contrast agents for magnetic resonance imaging (MRI) and its potential impact on both human health and aqueous ecosystem has attracted the interest of several researchers (see also Section 1). In general, gadopentetate (Gd-DTPA), gadodiamide (Gd-DTPA-BMA), gadobenate (Gd-BOPTA), gadoterate (Gd-DOTA), and gadobutrol (Gd-BT-DO3A) are the target species. A method employing a solid core hydrophilic interaction liquid chromatography (HILIC) coupled to SF-ICP-MS was optimised for evaluating the impact of treated waste water effluent on receiving waters. ${ }^{151}$ Sample introduction system into the plasma as a dry aerosol allowed the authors to get a LOD as low as $0.10 \mathrm{nmol} \mathrm{L}^{-1}$. Thus, Gd-DTPA, Gd-DOTA and Gd-BT-DO3A were identified and quantified in the water at levels ranged from $0.59 \mathrm{nmol} \mathrm{L}^{-1}$ for Gd-DOTA to $3.55 \mathrm{nmol} \mathrm{L}^{-1}$ for Gd-BT-DO3A. Separation was accomplished in less than 15 minutes. Additionally, the sum of Gd-species concentration found by LC-ICP-MS accounted for $74-89 \%$ of the total Gd determined by IDA-ICP-MS, indicating the presence of non-detected Gd-species. Results were confirmed by performing rare earth elements (REE) patterns. The same authors ${ }^{152}$ investigated the fate of Gd compounds during sewage treatment by HILIC-ICP-MS and IDA-ICP-MS. The balancing of Gd input (237 g) and output (213) over seven days shown that only a $10 \%$ of the Gd is removed during treatment. Speciation analysis of the $24 \mathrm{~h}$ composite samples revealed that $80 \%$ of the Gd complexes are as Gd-BTDO3A. Transformation of Gd-complex during treatment was observed, however the resulting species could not be identified. Lindner et $a l .{ }^{153}$ has also utilised a zwitterionic HILIC $(250 \mathrm{~mm} \times 2.1$ $\mathrm{mm} 5 \mu \mathrm{m}$ )-ICP-MS to study Gd-based contrast agents in surface waters receiving the influx of a waste water treatment plant. The predominant forms in water samples were Gd-DOTA and GdBTDO3A. With the aim of evaluating the capability of water plants to accumulate gadolinium, Lepidium sativum (cress plants) was hydroponically grown in presence of Gd-based contrast agents, added individually. Speciation in aqueous extracts of plant tissues (root, stems and leaves) revealed that Gadolinium compounds are efficiently translocated from roots to leaves. Bio concentration factors were found to be, 1, 0.1 and 0.2 for leaves, stem and roots, respectively. No transformation of Gadolinium-complexes during the accumulation process was detected.

\subsection{Iron}

Iron is considered to be the limiting nutrient in the open oceans with its dissolved speciation being dominated by complexation with organic ligands. A method has been developed to determine the concentration of four Fe-ligand complexes (Fe-EDTA, ferrichrome, ferrioxamine $\mathrm{E}$ and Fe-heme), and one cobalt complex (cobalamine) by HPLC-ICP-MS in seawater and Synechococcus sp. culture extracts. ${ }^{154}$ Reverse phase PEEK columns were used for the separations with a gradient elution program of $100 \%$ $\mathrm{H}_{2} \mathrm{O}$ to $100 \% \mathrm{MeOH}$ over 20 minutes followed by a 10 minute hold at $100 \% \mathrm{MeOH}$. A MC-ICP-MS with a collision/reaction cell was employed to monitor the transient signals using ${ }^{56} \mathrm{Fe}$. Three different methods were employed simultaneously to increase plasma stability and reduce carbon build up Pt sampler and skimmer cones; the HPLC eluent flow was split so that the sample flow rate $0.05 \mathrm{~mL} \mathrm{~min}^{-1}$, a heated PTFE membrane desolvator was interfaced between the flow splitter and torch

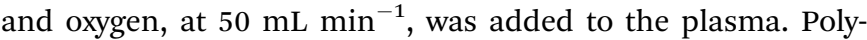
atomic interferences, such as ${ }^{40} \mathrm{Ar}^{16} \mathrm{O}$ and ${ }^{40} \mathrm{Ca}^{16} \mathrm{O}$, were negated using $\mathrm{Ar}$ and $\mathrm{H}_{2}$, flowing at 1.8 and $2.5 \mathrm{~mL} \mathrm{~min}^{-1}$ respectively, as the collision/reaction cell gases. Detection limits ranged from 30-250 femtomoles for the Fe and Co complexes. Instrumental sensitivity decreased with elution time suggesting that not all of the $\mathrm{MeOH}$ in the mobile phase was removed by the desolvation device. Different signal responses were not observed for each metal complex when separately aspirated. For the analysis of seawater a SPE procedure was employed to remove the salt matrix and concentrate the organic ligands present. A signal enhancement effect was observed for organic ligands spiked into seawater vs. $\mathrm{H}_{2} \mathrm{O}$. Therefore, calibration standards, which were prepared using the ligands under study, were matrix matched by the addition of a separate of organic ligand. Despite all of the precautions taken to ensure and accurate calibration the authors conclude that precise quantification is still hindered by instrumental sensitivity changes. Thus, the method is restricted in accuracy to within a factor of two.

The binding of Fe to proteins in human milk and milk formulas has been investigated. ${ }^{155}$ A SEC was used to separate protein fractions of differing molecular weight before introduction to a collision/reaction cell ICP-MS. Hydrogen, at $4 \mathrm{~mL} \mathrm{~min}^{-1}$, was used as the cell gas. The resultant chromatograms, obtained from colostrum, transitional, and mature human whey samples, showed five distinguishable peaks. Four of the peaks were assigned as follows, two immunoglobulins (IgA $430 \mathrm{kDa}$ and IgG $160 \mathrm{kDa})$, lactoferrin (78 kDa), transferrin (76 kDa) or serum albumin (66 kDa), $\alpha$-lactalbumin ( $14 \mathrm{kDa})$. The fifth peak $(<10 \mathrm{kDa})$ was assigned to low molecular weight compounds such as peptides, peptones, amino acids, orotic acid, lactose, 
enzymes and vitamins. The majority of the Fe detected, 76 to $93 \%$ of the total Fe content, was associated with high molecular mass proteins, 160-600 kDa. The Fe content obtained for human pre-term and full term milk was found not to be statistically different. In the milk formulas only $5 \%$ of Fe was bound to high molecular mass fractions, with $>75 \%$ found in fractions of $20-10 \mathrm{kDa}$ and b10 $\mathrm{kDa}$. The total Fe content was typically $0.5 \mu \mathrm{g} \mathrm{mL} \mathrm{m}^{-1}$ for human milk and $9.5 \mu \mathrm{g} \mathrm{mL} \mathrm{m}^{-1}$ for formula milk. The authors concluded that bioavailability is greater for Fe bound to higher molecular mass proteins than those of lower molecular mass. In turn, in order to avoid increased oxidative stress and the risk of respiratory tract infections, from high Fe intake in infants new milk formulas, which contain Fe bound to high molecular mass proteins, should be developed.

\subsection{Halogens}

Interest in the speciation of the halides, usually $\mathrm{Br}, \mathrm{Cl}$ or I, is less popular this year. Spolaor et al. ${ }^{156}$ have used ion chromatography coupled to ICP-MS to determine the levels of $\mathrm{IO}_{3}{ }^{-}, \mathrm{I}^{-}$, $\mathrm{BrO}_{3}{ }^{-}$and $\mathrm{Br}^{-}$at the $\mathrm{pg} \mathrm{g}^{-1}$ concentration level in Antarctic ice. An IonPac AS16 high-capacity column for the determination of polarisable anions, with a $\mathrm{NaOH}$ eluent was used to achieve detection limits of 5 and $9 \mathrm{pg} \mathrm{g}^{-1}$ for I and $\mathrm{Br}$ species respectively. Iodide and bromide were the most abundant species determined in the Antarctic ice cores.

\subsection{Mercury}

A non-chromatographic method has been developed for the determination of $\mathrm{Hg}$ species in biological materials with detection by ETV-AFS. ${ }^{157}$ Samples of three different bivalve molluscs were purchased locally and, after drying and homogenisation, $\mathrm{iHg}$ and $\mathrm{MeHg}$ were extracted with UAE and $10 \mathrm{~mL}$ of $6 \mathrm{~mol} \mathrm{~L}^{-1} \mathrm{HCl}$. Following centrifugation the supernatant was diluted to $25 \mathrm{~mL}$ with $2 \mathrm{~mol} \mathrm{~L}^{-1} \mathrm{COOH}_{2}$. The extracted mercury species were sequentially converted to $\mathrm{Hg}^{0}$ using immobilised $\mathrm{L}_{\text {-Cys }}$ on a graphite electrode. The anodic electrolyte was $0.5 \mathrm{~mol} \mathrm{~L}^{-1}$ $\mathrm{H}_{2} \mathrm{SO}_{4}$, and the catholyte either $1 \mathrm{~mL} \mathrm{~L}^{-1} \mathrm{COOH}_{2}$ or the sample, both of which were flowing at $5.5 \mathrm{~mL} \mathrm{~min}^{-1}$. At an applied current of $0.2 \mathrm{~A} \mathrm{iHg}$ was reduced to $\mathrm{Hg}^{0}$ and swept to a gas/ liquid separator prior to AFS detection. For the conversion of $\mathrm{MeHg}$ to $\mathrm{Hg}^{0}$ an applied current of $2.2 \mathrm{~A}$ was required. Potential Interferences from a wide range of potentially co-existing elements in sample extracts were evaluated. Signal suppression of up to $45 \%$ was observed from $\mathrm{Cu}^{2+}$ and $\mathrm{Pb}^{2+}$ and a standard additions approach was adopted to mitigate these effects. Limits of detection were 73 and $98 \mathrm{ng} \mathrm{L}^{-1}$ for $\mathrm{MeHg}$ and $\mathrm{iHg}$ respectively. The method was validated using DORM-2 CRM and recoveries of $>98 \%$ were obtained for both $\mathrm{iHg}$ and $\mathrm{MeHg}$. Finally, the $\mathrm{iHg}$ and $\mathrm{MeHg}$ content in three bivalve molluscs was determined. The $\mathrm{MeHg}$ content ranged from 23 to $35 \mu \mathrm{g} \mathrm{kg}$ whilst iHg was below the LOD. Sample throughput is stated to be $30 \mathrm{~h}^{-1}$ which would represent an advance on chromatographic base analyses for $\mathrm{Hg}$ species. One of the potential problems with new devices such as this is being able to fabricate them in a different laboratory. However, sufficient information would appear to given in this case to achieve this. A selective extraction procedure has also been developed to allow the isotopic composition of $\mathrm{MeHg}$ in biological materials to be determined by CV-MC-ICP-MS. ${ }^{158}$ The extraction procedure is based on acidic $\mathrm{HBr}-\mathrm{CuSO}_{4}$-toluene followed by back extraction into sodium thiosulfate. Recovery of the method was determined by two different methods, GC-ID-ICP-MS with ${ }^{199} \mathrm{iHg}$ and $\mathrm{Me}^{201} \mathrm{Hg}$ as the spike materials and propylation with sodium tetra- $n$-propylborate, and $\mathrm{CV}$-AFS with $\mathrm{BrCl}$ and $\mathrm{SnCl}_{2}$ as the oxidant and reductant respectively. Recoveries determined by the two different methods were not statistically different for each of the seven CRMs analysed, chosen to represent differing original preparation procedures, tissue types $\mathrm{Hg}$ concentrations and proportional differences between $\mathrm{iHg}$ and $\mathrm{MeHg}$ content, and ranged between 97 and $110 \%$. The found $\delta^{201} \mathrm{MeHg}$ values ranged from $0.65 \pm 0.03 \%$ for BCR 414 (plankton) and $4.95 \pm$ $0.03 \%$ for NIST SRM 1947 (trout tissue).

A simple, selective extraction procedure for $\mathrm{iHg}$ and $\mathrm{MeHg}$ in water and fish samples, using a sulfonic acid ion exchange resin packed into a glass column, has been described. ${ }^{159}$ Water samples were preserved by the addition of $\mathrm{HNO}_{3}$ whilst $\mathrm{Hg}$ in fish tissue was solubilised with UAE and $5 \mathrm{~mol} \mathrm{~L}^{-1} \mathrm{HCl}$ followed by centrifugation and supernatant removal. The $\mathrm{pH}$ of the sample solutions, $50 \mathrm{~mL}$ in volume, was adjusted to 4 before extraction of $\mathrm{Hg}$ species onto the resin column. The eluents used were $0.2 \mathrm{~mol} \mathrm{~L}^{-1}$ thiourea in $3 \mathrm{~mol} \mathrm{~L}^{-1} \mathrm{HCl}$ for iHg and $0.1 \mathrm{~mol} \mathrm{~L}^{-1} \mathrm{HCl}$ for $\mathrm{MeHg}$. The reductant used for sample analysis by CV-AAS was alkaline NaBH4. Potential interferences from a suite of alkaline, alkaline earth and transition metal were evaluated and no significant influence was observed at environmentally relevant concentrations. Limits of detection were calculated as $440 \mathrm{ng} \mathrm{L}{ }^{-1}$ for $\mathrm{iHg}$ and $560 \mathrm{ng} \mathrm{L}^{-1}$ for $\mathrm{MeHg}$. The method was validated using ERM CE464 (tuna fish) and no significant difference ( $t$ test 95\% confidence interval) between the found and certified values of $5.0 \pm 0.3$ and $5.5 \pm 0.17 \mathrm{mg}$ $\mathrm{kg}^{-1}$ respectively. The iHg content in ERM CE464, $0.26 \mathrm{mg} \mathrm{kg}^{-1}$, is below the LOD of the method. No $\mathrm{iHg}$ or $\mathrm{MeHg}$ was detected in the water or fish samples, although spike recoveries were $95 \%$ or greater. Magnetic NPs are now being used as catalysts to produce $\mathrm{OH}$ radicals from acidic $\mathrm{H}_{2} \mathrm{O}_{2}$ for the oxidation of organic compounds. A paper has been published detailing the use of magnetic $\mathrm{Fe}_{3} \mathrm{O}_{4}$ NPs for the post chromatographic oxidation of $\mathrm{MeHg}$ prior to reduction and detection by AFS. ${ }^{\mathbf{1 6 0}}$ Four $\mathrm{Hg}$ species, $\mathrm{iHg}, \mathrm{MeHg}, \mathrm{EtHg}$ and $\mathrm{PhHg}$ were separated in under 10 minutes using a RP C18 column with a mobile phase of $10 \% \mathrm{ACN}, 0.12 \% \mathrm{~L}-\mathrm{Cys}$ in $\mathrm{H}_{2} \mathrm{O}$ at $\mathrm{pH}$ 6.8. Online oxidation of the OMC was achieved using a mini column packed with $0.5 \mathrm{~g}$ of in-house prepared (details given) magnetic $\mathrm{Fe}_{3} \mathrm{O}_{4} \mathrm{NPs}$ in $0.6 \%$ $\mathrm{H}_{2} \mathrm{O}_{2}$ at $\mathrm{pH}$ 2. Subsequently, the $\mathrm{iHg}$ in the combined flow was reduced to $\mathrm{Hg}^{0}$ with alkaline $\mathrm{KBH}_{4}$ and, following gas/liquid separation, the transient signals were detected by AFS. The possible reaction mechanism for organomercurial oxidation is discussed in detail with the conclusion that it oxidation occurs on the NP surfaces rather than in the liquid phase. This theory was supported by observations that as the NP diameter decreased, and hence relative surface increased, oxidative efficiency for $\mathrm{PhHg}$ increased. Limits of detection were found to be 
0.7, 1.1, 0.8 and $0.90 \mu \mathrm{g} \mathrm{\textrm {L } ^ { - 1 }}$ (as $\mathrm{Hg}$ ) for $\mathrm{iHg}, \mathrm{MeHg}$, EtHg and $\mathrm{PhHg}$, respectively. Method validation was by analysis of DORM-2 CRM, after an $\mathrm{HCl} / \mathrm{UAE}$ extraction procedure, with the found value of $4.60 \pm 0.11 \mathrm{mg} \mathrm{kg}^{-1}$ in statistical agreement with the certified value of $4.47 \pm 0.32 \mathrm{mg} \mathrm{kg}^{-1}$.

A study has been undertaken to compare the performance of two different methods, HPLC-ICP-MS and ID-GC-MS, for the $\mathrm{MeHg}$ content in fish samples. ${ }^{\mathbf{1 6 1}}$ For HPLC-ICP-MS LOD was 2.0 $\mathrm{ng} \mathrm{Hg}$ per $\mathrm{g} \mathrm{iHg}$ and $5.0 \mathrm{ngHg}$ per $\mathrm{g}$ for $\mathrm{MeHg}$. In comparison, the LOD for MeHg by ID-GC-MS was $3.4 \mathrm{ngHg}$ per g. Method validation was undertaken using two CRMs with results in good agreement with the certified values for both methods. The mean recovery for analysis of CRM BCR 463 by HPLC-ICP-MS was 99\% for $\mathrm{MeHg}$ and $103 \%$ for total $\mathrm{Hg}$. For ID-GC-MS the mean recoveries for BCR 463 and NRCC DORM-2 were 87\% and 102\% respectively. The results obtained for $\mathrm{MeHg}$ for 73 fish samples analysed by both methods were generally in good agreement with each other. The authors conclude that HPLC-ICP-MS was the preferred method as it required a simpler sample preparation procedure and higher sample throughput than for the ID-GC-MS method.

Two papers report $\mathrm{Hg}$ measurements in human plasma. An HPLC-CV-ICP-MS method has been employed to measure $\mathrm{iHg}$, $\mathrm{MeHg}$ and EtHg in human plasma samples. ${ }^{162}$ The OMC were separated using a C8 column, with a mobile phase of $3 \% \mathrm{v} / \mathrm{v}$ methanol, 97\% v/v $\mathrm{H}_{2} \mathrm{O}$ which contained $0.5 \% \mathrm{v} / \mathrm{v}$ 2-mercaptoethanol and $0.05 \% \mathrm{v} / \mathrm{v}$ formic acid at a flow rate of $1.2 \mathrm{~mL}$ $\min ^{-1}$, in eight minutes. The reductant used, alkaline $\mathrm{NaBH}_{4}$ $(0.06 \% \mathrm{~m} / \mathrm{v})$ flowing at $0.65 \mathrm{~mL} \mathrm{~min}^{-1}$, was added post-column via low dead volume t-piece and the ICP-MS spray chamber was used as the GLS. Mercury species were extracted from plasma samples, $15 \mathrm{~mL}$, with $2.75 \mathrm{~mL}$ of a $0.10 \% \mathrm{v} / \mathrm{v} \mathrm{HCl}, 0.05 \% \mathrm{~m} / \mathrm{v} \mathrm{L}^{-}$ CYS and $0.10 \% \mathrm{v} / \mathrm{v} 2$-mercaptoethanol solution followed by UAE for 15 minutes. Subsequently the extracts were filtered, $0.2 \mu \mathrm{m}$, prior to injection onto the column. The LOD values were found to be 12,4 and $5 \mathrm{ng} \mathrm{\textrm {L } ^ { - 1 }}$ for $\mathrm{iHg}, \mathrm{MeHg}$ and EtHg respectively, which the authors suggest are the lowest values so far reported for these analytes in clinical samples. Only $\mathrm{iHg}\left(1.2-8.8 \mu \mathrm{g} \mathrm{L}^{-1}\right.$ range) and $\mathrm{MeHg}\left(0.6-3.9 \mu \mathrm{g} \mathrm{\textrm {L } ^ { - 1 }}\right.$ range) were detected in the eight human plasma samples analysed. In the second paper a 2D-HPLC method, comprising SEC and weak anion exchange, has been used, in conjunction with both ICP-MS and ion trap FT-ICR detection, to identify human serum albumin as a $\mathrm{Hg}$ containing protein in human plasma. The SEC mobile phase was a $50 \mathrm{mmol} \mathrm{L}{ }^{-1}$ Tris- $\mathrm{HCl}$ at $\mathrm{pH} 8.06$ whilst the weak anion exchange mobile phase comprised A: $10 \mathrm{mmol} \mathrm{L}^{-1}$ Tris- $\mathrm{HCl}$ at pH 8.06 and B: $10 \mathrm{mmol} \mathrm{L}^{-1}$ Tris- $\mathrm{HCl}+0.5 \mathrm{~mol} \mathrm{~L}^{-1} \mathrm{NaCl}$ at $\mathrm{pH}$ 8.06. A step gradient was used for this part of the separation with the eluent directly coupled, post UV detection, to an ICPMS instrument (20\% flow) and a fraction collector. Plasma samples were diluted four fold with $50 \mathrm{mmol} \mathrm{L}{ }^{-1}$ Tris- $\mathrm{HCl}$ buffer prior to analysis. For protein identification the collected $\mathrm{Hg}$ containing fraction was subjected to a tryptic digestion procedure (no details given) before analysis by HPLC-FT-ICR. In this case a RP C18 column was used with a mobile phase of A: $2 \% \mathrm{ACN}+98 \% \mathrm{H}_{2} \mathrm{O}+0.1 \%$ TFA and $\mathrm{B}: 80 \% \mathrm{ACN}+20 \% \mathrm{H}_{2} \mathrm{O}+$ $0.1 \%$ TFA in a gradient elution program of 150 minutes duration. The results of these analysis, after database matching of the resultant chromatograms identified the $\mathrm{Hg}$ containing protein as human serum albumin.

A fast AEC-ICP-MS method has been developed for the determination of four OMC, iHg, MeHg, EtHg and PhHg in fish samples. ${ }^{163}$ The separation was achieved in under five minutes by the use of a guard column, which gave broad but baseline separated peaks, instead of an analytical column. The mobile phase consisted of $1.0 \mathrm{mmol} \mathrm{\textrm {L } ^ { - 1 }}$ sodium 3-mercapto-1-pro-

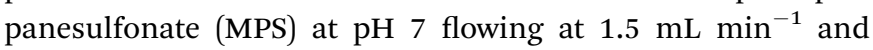
coupled directly to the nebuliser of the ICP-MS instrument used. The OMC in the fish samples were extracted using $1.0 \mathrm{~g}$ of fish (wet weight) with $10 \mathrm{~mL}$ of $5 \mathrm{~mol} \mathrm{~L}^{-1} \mathrm{HCl}$ containing $10 \mathrm{mmol} \mathrm{L}^{-1}$ MPS. After vigorous shaking for $1 \mathrm{~min}$, the resulting suspension was subjected to UAE for $15 \mathrm{~min}$ at $40{ }^{\circ} \mathrm{C}$ followed by centrifugation. The supernatant was filtered, 0.45 $\mu \mathrm{m}$, prior to injection of the extract onto the AEC. Detection limits of 8, 24, 29 and $34 \mathrm{ng} \mathrm{\textrm {L } ^ { - 1 }}$ were obtained for $\mathrm{iHg}, \mathrm{MeHg}$, EtHg and $\mathrm{PhHg}$ respectively. These values equate to approximately three orders of magnitude lower than the Chinese regulatory limit of $\mathrm{MeHg}$ in predatory fish of $1 \mathrm{mg} \mathrm{kg}^{-1}$ and non-predatory fish of $0.5 \mathrm{mg} \mathrm{kg}^{-1}$. All of the 11 fish samples analysed had $\mathrm{MeHg}$ concentrations, which ranged from 3.2 to $754 \mu \mathrm{g} \mathrm{kg}{ }^{-1}$, below these regulatory limits. A different paper by the same authors reported an even faster separation of the same four OMC in 2.5 minutes. ${ }^{164}$ In this case two CEC guard columns were connected in series and the mobile phase was either $2.0 \mathrm{mmol} \mathrm{L}^{-1}$ L-Cys or thiourea (both at $\mathrm{pH} 2.0$ ) In this work both seawater and marine fish samples were analysed. The LOD values for $\mathrm{iHg}, \mathrm{MeHg}$, EtHg and $\mathrm{PhHg}$ in seawater were 19, 27, 31 and $22 \mathrm{ng} \mathrm{L}^{-1}$ respectively and 1.9, 2.7, 3.1, $2.2 \mu \mathrm{g} \mathrm{kg}^{-1}$ respectively for marine fish.

\subsection{Phosphorus}

The determination of phosphite and phosphate in transgenic plants using HPLC coupling to ICP-MS has been reported. ${ }^{165}$ Separation of $\mathrm{P}$ compounds was carried out using a Hamilton PRP X100 column $(250 \times 4.6 \mathrm{~mm}, 5 \mu \mathrm{m})$. The use of nitric acid in the mobile phase $\left(5 \mathrm{mmol} \mathrm{L}^{-1}\right.$ potassium hydrogen phthalate/nitric acid ( $\mathrm{pH}=2.5)$ mixture) was found to enhance the formation of phosphorus oxide for P detection at $m / z$ 47, thus eliminating the need for oxygen introduction via a collision/reaction cell. The detection limits for phosphite and phosphate were reported to be as low as 1.58 and $1.74 \mu \mathrm{g} \mathrm{P} \mathrm{L}{ }^{-1}$ at $m / z 47$, respectively and 2.18 and $2.04 \mu \mathrm{g} \mathrm{P} \mathrm{L}{ }^{-1}$ at $m / z 31$, respectively. The method was applied to $\mathrm{P}$ speciation in transgenic tobacco plants engineered for phosphite metabolisation. For this purpose, $\mathrm{P}$ species were extracted by using a method based on using EDTA at $\mathrm{pH}=8$ as extracting agent. Speciation results confirm an efficient oxidation of $\mathrm{P}^{\mathrm{III}}$ to $\mathrm{P}^{\mathrm{V}}$ by plants growth in presence in phosphite as a sole $\mathrm{P}$ source. The results obtained in the analysis of transgenic plants using two detection modes $(\mathrm{m} / \mathrm{z} 31$ and 47) were in good agreement; however signal acquisition at $\mathrm{m} / \mathrm{z} 47$ enabled better precision without the use of a collision/reaction cell (RSD below $2 \%$ ) as compared to RSD around $4 \%$ obtained at $\mathrm{m} / \mathrm{z} 31$ using an He-pressurised cell. 


\subsection{Platinum}

The complexity and dynamics of cisplatin (CP) adduct formation has been studied using HPLC-ICP-MS and ES-FT-ICR-MS. ${ }^{166}$ This work revealed a complex array of different DNA-adducts after treatment of the sample with 3 different digestion enzymes. The kinetics of CP-DNA adduct formation was studied using species-unspecific IDA HPLC-ICP-MS measurements, although unfortunately the quantification of the specific adducts themselves was not reported. Two different DNA systems were examined: the traditional calf thymus DNA (3 g) was reacted with $\mathrm{CP}(2 \mathrm{mM})$; and mice were intraperitoneally injected with CP $\left(10 \mathrm{mg} \mathrm{kg}^{-1} \mathrm{bw}\right)$. The DNA was then recovered from the CT-DNA and the mouse liver, using conventional DNA extraction and isolation methods. The DNA was digested with three enzymes: HS nuclease; calf-intestinal alkaline phosphatise; and nuclease S1, in a similar way to previous work in the area. The digests were qualitatively characterised using HPLCICP-MS and ES-FT-ICR-MS, with a recovery for the enzymatic digestion of $87 \%$ and for the chromatographic separation of $70 \%$. The results showed a range of inter- and intra-strand crosslinks, but that no one particular adduct predominated, which is notable because the majority of work in the area (see the Kelland review [L. Kelland, Nat. Rev., 2007, 7, 573-584]) shows that the intrastrand GG-CP adduct is the major adduct formed with DNA, with the intrastrand AG-CP and the GG-CP interstrand crosslink the minor adducts, with some work also showing the mono-adduct G-CP. There are a number of possible explanations for the differences between this and earlier work: the use of $\mathrm{a}_{18}$ column in the current study as opposed to a $\mathrm{C}_{8}$ column as usually used may be the cause of the $30 \%$ loss in Pt adducts reported; the scale of the reaction between CP and the CT-DNA is considerably larger than in other studies and does not reflect clinical practice, where a $1000 \times$ lower amount of CP is used; and the route of exposure of the drug in the mouse model is considerably different to the intravenous administration of the drug used clinically, this is important because CP is activated in the body by the change in chloride concentration, which may be different with intraperitoneal injection. Unfortunately the authors did not apply any clean-up method to their samples so could not show that the smaller number of adduct types found previously was due to this step, as they infer in their report. Previous studies have in general used a much lower concentration of $\mathrm{CP}$, but also employed methods appropriate to use in the clinical setting, where DNA levels obtainable from leukocytes, the most accessible source of DNA in a clinical setting, are considerably lower than used in the current work by a factor of 30000 . It will be interesting to see further work using such highly sensitive instrumentation, particularly if focused on more realistic in vivo systems such as real patient samples, where adduct formation has been shown to be mainly as the GG-CP adduct.

A study ${ }^{167,168}$ on a new pharmaceutical delivery system for cisplatin involving liposomal formulations has used CE-ICP-MS to assess liposome stability and CP release in vitro. Free CP, CP encapsulated with a PEGylated liposomal formation and CP bound to "plasma components", which were not identified but postulated to be albumin-CP conjugates, were qualitatively measured. The developed methodology used Pt, I and P isotopes to identify the presence of $\mathrm{CP}$, neutrally charged species and the CP-liposome complex, respectively. The methodology was further applied to other liposomal systems and platinum containing drugs, specifically oxaliplatin. The rather poor LOD of 42 ug Pt $\mathrm{L}^{-1}$ for $\mathrm{CP}$, compared to what has been achieved in other hyphenated systems probably reflects the small sample size that can be injected onto a CE system. However, even with such a poor LOD the developed method would still be sufficient to measure the CP formulation in the circulation, but not the cellular and active forms of CP bound to DNA.

The mechanism of electrodissolution of a Pt electrode in $0.5 \mathrm{M}$ aqueous $\mathrm{H}_{2} \mathrm{SO}_{4}$ solution has been studied by ion-exchange chromatography "on line" coupled to ICP-MS. The Pt species generated by electro-dissolution were first transformed to the corresponding chloro-complexes and then separated by AEC. ${ }^{\mathbf{1 6 9}}$ $\mathrm{PtCl}_{4}{ }^{2-}$ and $\mathrm{PtCl}_{6}{ }^{2-}$ were the predominant species found. A detection limit as low as $0.1 \mu \mathrm{g} \mathrm{L}^{-1}$ was reported for $\mathrm{Pt}^{\mathrm{II}}$ and $\mathrm{Pt}^{\mathrm{IV}}$. Additionally, the sum of platinum species concentration found by LC-ICP-MS was in agreement with the total Pt concentration. The method was applied to selectively determinate platinum species generated during potential cycling using cyclic voltammetry $(\mathrm{CV})$. The results revealed that $\mathrm{Pt}^{\mathrm{IV}}$ was the main specie, accounted for the $80 \%$ of total Pt. This is reported by the authors to be the first report of the determination of Pt species during Pt-electrochemical dissolution by LC-ICP-MS.

\subsection{Selenium}

During the past year, two reviews have appeared. A comprehensive review of Se metabolism in cancer cells by Weekley et al. ${ }^{\mathbf{1 7 0}}$ summarised recently published data on selenium speciation in cells and rat tissues with a range of techniques including X-ray absorption spectroscopy (XAS), X-ray fluorescence microscopy (XFM), HPLC-ICP-MS and ESI-MS-MS. Ogra et al. ${ }^{171}$ focused on some selenometabolites recently identified in biological samples by speciation analysis. The paper is divided into two parts. Firstly, it presented the techniques employed to detect selenometabolites, such as: HPLC-ICP-MS and HPLC-MS-MS, and finally the paper describes some of selenometabolites of interest such as, selenosugars, selenoamino acids in Se-accumulating plants and SeMet derivates.

Many studies have examined the metabolic pathway of selenium compounds when plants and yeast are exposed to selenium. The concentration of total selenium and selenoamino acids was evaluated in Agaricus bispours cultivated in compost irrigated with $\mathrm{Se}^{\mathrm{IV}}$ (up to $40 \mathrm{mg} \mathrm{L}^{-1}$ ). ${ }^{172}$ Determination of selenoamino acids was achieved by reversed-phase LC-ESI-MS $\left(\mathrm{C}_{18}\right.$ column, $2.1 \times 50 \mathrm{~mm}, 1.8 \mu \mathrm{m}$ ) before enzymatic hydrolysis with protease and derivatisation of the resulting amino acids with aminoquinolyl- $N$-hydroxysuccinimidyl carbamate. The maximum selenoamino acids concentration was found in caps and stalks with values of $9.65 \mathrm{mg} \mathrm{g}^{-1}$ for SeCys, $0.58 \mathrm{mg} \mathrm{g}^{-1}$ for SeMet, and $0.10 \mathrm{mg} \mathrm{g}^{-1}$ for MeSeCys. The most notable result obtained in the present study was the much higher levels of SeCys (detected as $\mathrm{SeCys}_{2}$ ), accumulated by A. bisporus, compared to SeMet and 
MeSeCys which is in discrepancy with the results reported in the literature. The authors attributed these differences to the yield of the different methods used for extracting selenoamino acids. An in vitro simulated gastro intestinal digestion method was applied by Bhatia et al. ${ }^{173}$ to establish Se bioaccessibility of Sebiofortified edible mushroom growth on wheat straw from a seleniferous area of India. The Se concentration in biofortified mushrooms was found to be 800 times higher compared with control samples (141 vs. $0.17 \mathrm{mg} \mathrm{g}^{-1}$ ). Selenium species liberated by simulated gastrointestinal digestion were characterised by SEC-ICP-MS and AEC (PRP-X100 column, $250 \mathrm{~mm} \times 4.1 \mathrm{~mm}$, $5 \mu \mathrm{m})$-ICP-MS. It was found that Se in the bioaccessible fraction was mainly present as SeMet, which accounted for $73 \%$ of the sum of the detected species. In a study by Srikanth Lavu et al., ${ }^{174}$ Se speciation and Se bioaccessibility in Se-enriched leek (Allium ampeloprasum) was studied. Speciation was performed by using two separation mechanisms: a Hamilton PRP-X100 anion exchange column and an Altima $\mathrm{C}_{8}$ reversed phase column $(250 \mathrm{~mm} \times 4.6 \mathrm{~mm}, 5 \mu \mathrm{m})$ coupled to ICP-MS after enzymatic hydrolysis with protease. In the plants grown on soils treated with $3.8 \mathrm{mg} \mathrm{kg}^{-1}$ as $\mathrm{Na}_{2} \mathrm{SeO}_{4}$, approximately $53.6 \pm 8.0 \%$ was found to be $\mathrm{Se}^{\mathrm{VI}}$, and the most abundant organic species were SeMet $(12.3 \pm 0.8 \%)$, followed by MeSeCys $(4.3 \pm 1.6 \%)$. When $\mathrm{Se}^{\mathrm{VI}}$-enriched soil was applied, the main observed Se species in the plants were $\mathrm{Se}^{\mathrm{VI}}(21.6 \pm 7.9 \%)$, SeMet $(16.7 \pm 14.1 \%)$, and MeSeCys $(6.8 \pm 0.2 \%)$. Concentrations of MeSeCys and $\gamma$-GluMeSeCys were lower as compared to other Allium species (garlic and onion). The majority of the Se in the leek was found to be bioaccessible in the stomach (around 60\%) and small intestine (around 80\%). An HPLC-ICP-MS method utilising a reversed phase column $(\mathrm{C} 18,250 \times 4.6 \mathrm{~mm} 5 \mu \mathrm{m})$ was employed to study Se metabolisms in Se-enriched Kale (Brassica oleracea var. alboglabra L.) grown under hydroponic conditions in presence of $5,10,5,30$ and $45 \mu \mathrm{g} \mathrm{L} \mathrm{L}^{-1}$ of Se ${ }^{\mathrm{VI}}$ during 15 days. ${ }^{175}$ The highest Se concentration accumulated by kale was approximately $400 \mu \mathrm{g} \mathrm{g}^{-1}$. Selenium speciation in the $0.1 \mathrm{M} \mathrm{HCl}$ in $10 \%$ methanol extracts revealed SeMet, SeMetCys and two unknown Se-peaks as the predominant forms of organic selenium, accounting of around $80 \%$ of the total selenium present in the Se-enriched kale samples. It was suggested that the two unknown Se-peaks were intermediate compounds in the pathway from SeMet to SeCys.

Two papers have been published covering the topic of $S e$ determination in Se-enriched rice. The first focused on screening of Se-containing proteins in Se-enriched rice by SEC-HPLC-ICPMS. ${ }^{176}$ Several sample treatment procedures for extracting Se were compared: $\mathrm{NaCl}$ extraction, $\mathrm{NaOH}$ extraction and ethanol extraction, being $\mathrm{NaOH}$ the extracting medium that provides the best recoveries values (48.2\% of total selenium). The SECHPLC-ICP-MS analysis shown Se is mainly incorporated to glutelin and globulin, and in less extension to albumin and prolamin. Selenium speciation in Se-rich rice by cloud point extraction (CPE)-GF-AAS is described in the second paper. ${ }^{177}$ Selenium biofortification of rice was carried out by foliar spraying of a nutrient solution containing organic selenium (not specified by the authors). Separation of organic and inorganic Se was achieved by sequentially extraction with water and cyclohexane. Then CPE was carried out by using $2 \%$ (v/v) Triton $\mathrm{X}-114,2 \mathrm{mmol} \mathrm{L}^{-1}$ dithizone at $\mathrm{pH}=1.0$. This approach offered a LOD of $0.08 \mu \mathrm{g} \mathrm{L}^{-1}$, a linear range up to100 $\mu \mathrm{g} \mathrm{L}^{-1}$, and an enrichment factor of 82 . Organic selenium was the dominant species in selenium-enriched rice and content ranged from 94.6 to $116 \mu \mathrm{g} \mathrm{L}^{-1}$, which was significantly higher than inorganic selenium $\left(18.2-29.6 \mu \mathrm{g} \mathrm{L}^{-1}\right)$.

Speciation of Se in a plankton CRM (BCR-414) and Brazil nuts samples has been reported by utilising HPLC (PRPX100 column, $6 \times 250 \mathrm{~mm}, 7 \mu \mathrm{m})$-ICP-MS. The only Se form detected in the water extract of the CRM was $\mathrm{Se}^{\mathrm{IV}}$ while SeMet and SeCyst were identified in Brazil nut water extracts. After applying a simulated gastro-intestinal digestion test, only SeMet was found to be bioaccessible in Brazil nuts, corresponding to the $74 \%$ of total selenium $\left(54.8 \pm 4.6 \mathrm{mg} \mathrm{g}^{-1}\right)$ present in the sample. Surprisingly, SeCyst ${ }_{2}$ was found in urine of male and female volunteers after consumption of one Brazil nut per day during 15 days.

Three papers have appeared addressing the topic Se-metabolites identification in plants. The first covers low molecular weight Seleno-metabolites detection in seeds of Brassica nigra cultivated in Se-rich soil by using a multi-technique approach. ${ }^{178}$ Over 30 Se species were detected and characterised by using complementary cation exchange/HILIC/ES-MS. Selenoglucosinolates accounted over $50 \%$ of all metabolites found. These compounds were found to be unstable since production of Se volatile compounds such as, methylselenonitriles and methylselenoisothiocyanates was detected and identified using a parallel coupling of GC-ICP-MS and APCI-MS/MS. Selenoamino acids, selenosugars, selenosinapine and selenourea derivatives were also detected in the samples. The authors suggest different mechanisms as responsible of metabolites formation: (1) Se-S substitution in the metabolic pathway, (2) oxidative reactions of - $\mathrm{SeH}$ groups with endogenous biomolecules and (3) chemical reactions of Se-containing molecules and other biomolecules through functional groups not involving. In the second paper, se incorporation into wheat proteins was evaluated by a multi-technique approach combining IEF/SDSPAGE-LA-ICP-MS for S containing protein mapping, and capillary HPLC-electrospray Orbitrap MS/MS for the protein identification. ${ }^{179}$ The identified Se-rich proteins belong to two groups: glutenins and a gamma-gliadin. SeMet and SeCyst were the predominant Se species found. Qualitative studied of Se-S substitution was undertaken, in a peptide produced by tryptic digestion of gi121102 protein, containing both methionine and cysteine residues in its structure (VFLQQQCSPVAMPQR) and further analysis by HPLC in parallel with ICP-MS and ES-MSMS. It was the first evidence of the substitution of $S$ by Se in cysteine in plants. Finally, Ogra et al. ${ }^{\mathbf{1 8 0}}$ evaluated Se metabolism in Brasica rapa hydroponically grown in presence of selenometabolites such as, methyl-2-acetamido-2-deoxy-1seleno- $b$-D-galactopyranoside (selenosugar, SeSug) $\mathrm{TMSe}^{+}$, SeMet, and MeSeCys. Two selenometabolites were detected in the roots when the plant was exposed to SeMet, MeSeCys, and SeSug: $S$-(methylseleno)-glutathione and MeSeCys. Assignment of $S$-(methylseleno)-glutathione structure was performed by mixing methylseleninic acid and GSH, and later confirmation of its structure by ESI-MS-MS. In contrast, TMSe was not 
metabolised by the roots. The authors proposed that the organic Se compounds were assimilated as MeSeCys via $S$-(methylseleno)-GS in the plant root.

Several papers under the topic Se and yeast have appeared during the present review period. Rampler et al. ${ }^{181}$ applied an analytical methodology based on LC-ICP-MS for selecting the optimum fermentation conditions for preparing selenised yeast using three Saccharomyces cerevisiae strains. For this purpose, $\mathrm{Se}^{\mathrm{IV}}, \mathrm{Se}^{\mathrm{VI}}$, SeMet, Met, Cys and $\mathrm{S}$ levels were monitored in yeast cells at different fermentation times. For S-containing amino acids, LC-ICP-MS was applied after acid hydrolysis of the samples with $6 \mathrm{M} \mathrm{HCl}$ whereas for SeMet determination pronase digestion followed by IDA-reversed phase-ICP-MS was employed. The $\mathrm{Se}^{\mathrm{IV}}$ and $\mathrm{Se}^{\mathrm{VI}}$ levels were evaluated by breaking cell walls with glass beads followed by PRPX AEC-ICP-MS measurement. The results revealed a maximum production of SeMet after $42 \mathrm{~h}$ of fermentation. Afterwards cell viability was found to decrease as a consequence of sulfur limitation or/and excess of SeMet. As expected, a decrease of molar S/Se and Met/ SeMet ratios were observed during fermentation due to selenium accumulation, with strain specific threshold levels with the range of $2-3$ and 1 , respectively. Lobinski's group ${ }^{\mathbf{1 8 2}}$ have evaluated an porous graphite stationary phase for the high resolution large scale separation of Se metabolites in yeast. Electrospray hybrid quadrupole trap/Orbitrap mass spectrometry was used for identification and detection of 64 metabolites. The method allowed the detection of 64 metabolites. It was shown that metabolome of Se in Selenised yeast consists of selenoethers (14 compounds), conjugates of SeCys containing di- and tri-peptides (28 species) and occasionally selenols and selenoxides. Quantitative analysis of the metabolites was performed by on-line ICP-MS equipped with a frequency-matching rf generator which allowed maintenance of a quasi-uniform response within a $10-90 \%$ acetonitrile concentration range.

Methods for the determination of Se in cancer cells and body fluids have also been developed in the period covered by this Update. The chromatographic behaviour of two mayor selenoproteins (extracellular gluthatione peroxidise and selenoprotein P) in serum of four rodent species HPLC (multi gel permeation column, $7.5 \mathrm{id} \times 300 \mathrm{~mm}$ ) coupled to ICP-MS and ICP-MS-MS have been compared. ${ }^{\mathbf{1 8 3}}$ Although the amino acid sequences in the rodent species is identical, different chromatographic behaviour was noted for selenoproteins derived from rat serum. Two well-separated Se-peaks were detected in rat serum whereas in mouse, hamster and guinea pig serum only one broad Sepeak was detected. The differences observed were attributed to differences in the tertiary and quaternary structure of the proteins. The use of ICP-MS-MS with $\mathrm{O}_{2}$ as reaction/collision cell to allow removal of interferences from plasma gases and the biological sample matrix. Serum-selenoproteins status as a potential biomarker for colorectal cancer (CRC) has been evaluated by Roman et al. ${ }^{184}$ A 2D chromatography approach (2-D AEC-affinity-ICP-MS) and predictive data mining techniques (logistic regression analysis, classification trees and artificial neural networks) were employed. Measurement of GPx3, SelP and selenoalbumin (SeAlb) levels in human serum of 42 patients affected by CRC and 20 controls followed by data analysis revealed that early stage CRC could be associated to a variation of serum Se-proteins concentration, in particular SeAlb. Although more studies need to be performed, speciation analysis in combination with data mining tools is an interesting approach specially when applying to clinical studies. Similarly, Sanz-Medel and co-workers ${ }^{\mathbf{1 7 9}}$ evaluated GPx expression as potential indicator for oxidation status. Different combinations of chromatography techniques and mass spectrometry were used for identifying and quantifying GPx in red blood cells. Samples were first treated from haemoglobin precipitation and then fractionated by SEC-ICP-MS. The Se-containing SEC fraction was tryptically digested and subsequently purified by reversed phased and then analysed by capillary RP-ICP-MS and ESI-MS-MS. A single Se-containing peptide belong to GPX 1 was detected. The GPx was quantified by post column isotopic dilution analysis after SEC separation. Good correlation between GPx concentration obtained by ICP-MS and activity measurements of the enzyme was reported. A similar metallomic approach $^{\mathbf{1 8 5}}$ combining two dimensional chromatography (2-D SEC-RP-ICP-MS) and nano-HPLC-ESI-MS-MS was applied to identify seleno-containing proteins in HEK 293 kidney cells raised with SeMet. Proteins were screening by SEC column (SKGel3000SW $7.5 \times 300 \mathrm{~mm}$ ) and a capillary RPLC column $(\mathrm{C}-4,150 \times 0.50 \mathrm{~mm}, 5 \mu \mathrm{m})$. Twelve Se-containing RP fractions were digested with trypsin for analysing by peptide mapping with HPLC-Chip-ESI-MS-MS and Mascot database search. Identification of Se-containing peptides was achieved by assuming their co-existence with the corresponding $\mathrm{S}$ analogues. Thus, evidence was provided that SeMet incorporation into the HEK proteins is non-specific. An analytical method based on two 2D chromatography approaches (2-D SEC-SAX-ICPDRC-MS) and 2-D (SAX-CE-ICP-DRC-MS) was applied for selenium speciation in paired serum and cerebrospinal fluid (CSF) samples ${ }^{\mathbf{1 8 6}}$ The method was validated by analysing urine and serum control materials from 24 neurologically healthy persons. The LOD values obtained ranged from 0.026 to $0.031 \mu \mathrm{g} \mathrm{L}^{-1}$ for all the detected species (Seleno protein P, (SePP), SeMet, GPx, SeCis, thioredoxin reductase (TrxR), $\mathrm{Se}^{\mathrm{IV}}, \mathrm{Se}-\mathrm{HAS}$ and $\mathrm{Se}^{\mathrm{VI}}$ ). Model-fitting with linear regression evidenced strong correlation between Se in serum and SePP in serum but not with SePP in CSF. In contrast, a positive linear relationship between serum and CFS was found for GPx, Se-HAS and TrxR, indicating the capability of these compounds for crossing the neural barriers. Prigol et al. ${ }^{187}$ applied methods based on HPLC-ESI-MS-MS and HPLC-ICP-MS for "in vitro" study of dyphenyl diselenide (SePh)2 metabolism in rat liver fractions. Interaction of $(\mathrm{SePh})_{2}$ with GSH and NaC (mercapturic acid S-conjugate) shows the formation of two adducts. The results suggest that liver selenol-GSH adducts are excreted in urine as the corresponding mercapturic acids. It was also found that the presence of $(\mathrm{SePh})_{2}$ reduces microsomal activity of cytochrome P450 enzymes.

A method to determine nine Se species in human urine under three different LC conditions and ICP-MS detection has been reported. ${ }^{\mathbf{1 8 8}}$ Separation of SeMet, selenoethionine (SeEt), methylselenoglutathione (SeMeG), methyl-2-acetamido-2deoxy-1-seleno- $b$-D-galactopyranoside (SeSug1) and methyl-2amino-2-deoxy-1-seleno- $b$-D-galactopyranoside (SeSug3) was 
achieved by using a reversed phase (C18 $4.6 \times 150 \mathrm{~mm}, 3 \mu \mathrm{m})$ column. Anion exchange chromatography (Hamilton PRP-X100, $4.6 \times 150 \mathrm{~mm}, 5 \mu \mathrm{m})$ was applied for $\mathrm{Se}^{\mathrm{IV}}$ and $\mathrm{Se}^{\mathrm{VI}}$ separation, whereas CEC (Hamilton PRP-X200 $(250 \times 4.6 \mathrm{~mm}, 10 \mu \mathrm{m}))$ was used for $\mathrm{TMSe}^{+}$and SeMCys determination. The LOD values were $0.16 \mu \mathrm{g} \mathrm{L}^{-1}$ for $\mathrm{TMSe}^{+}, 0.18 \mu \mathrm{g} \mathrm{L}^{-1}$ for SeMeG, $0.19 \mu \mathrm{g} \mathrm{L}^{-1}$ for $\mathrm{Se}^{\mathrm{IV}}, 0.13 \mu \mathrm{g} \mathrm{L}^{-1}$ for SeSug1, $0.11 \mu \mathrm{g} \mathrm{\textrm {L } ^ { - 1 }}$ for SeEt and $0.10 \mu \mathrm{g}$ $\mathrm{L}^{-1}$ for $\mathrm{Se}^{\mathrm{VI}}$, MeSeCys, SeSug3 and SeMet. Analysis of 45 urine samples of individuals of the general population showed that selenosugars were the dominating species. A study has been conducted of Se metabolism in mice. ${ }^{189}$ For this purpose ${ }^{82} \mathrm{Se}-$ enriched SeMet was injected intravenously, into Se-deficient and Se-adequate mice and endogenous and exogenous ${ }^{82} \mathrm{Se}$ levels were quantified in 13 solid tissues, 3 body fluids (red blood cells [RBCs], plasma, and urine), and faeces. In addition selenium species and selenoproteins were evaluated in urine, plasma, liver and kidney by HPLC-ICP-MS. It was found that exogenous ${ }^{82} \mathrm{Se}$ was accumulated mainly in liver followed by muscle. The SeMet was completely transformed to selenoproteins (GPx and SelP) within $1 \mathrm{~h}$ after injection. No differences were found when comparing GPx levels between Se-deficient and Se-adequate mice. In contrast, Sel-P levels in plasma increased 1.5 times more in Se-deficient mice than in Seadequate mice. The results suggest that SelP plays an important role in selenium transport under Se-deficiency nutritional status. Finally, the characteristics of a new selenoamino acid, selenohomolanthionine (4, $4^{\prime}$-selenobis[2-aminobutanoic acid], SeHLan) isolated in selenised Japanese pungent radish, were compared with those of SeMet and $\mathrm{Se}^{\mathrm{IV}}$ when injecting in mice at the dose of $0.1,1.0$, and $10 \mathrm{mg} \mathrm{Se} \mathrm{kg}{ }^{-1}$ body weight. ${ }^{190}$ Selenium determination in urine and organ samples by HPLC (gel filtration column, $7.5 \mathrm{~mm}$ i.d. $\times 300 \mathrm{~mm}$ )-ICP-MS revealed that SeMet was preferably distributed to the liver than to the kidneys, whereas SeHLan was equally distributed to the liver and the kidneys. It was found that most of the ingested SeHLan was excreted into urine without being metabolised. Comparison of toxic effect among Se compounds shows that SeMet and SeHLan induced hepatic and pancreatic toxicities and only hepatic toxicity, respectively at the highest dose.

Speciation of Se in fish and mammal tissues has been the subject of a number of papers. The efficiency of three Se additives ( $\mathrm{Se}^{\mathrm{IV}}, 2$-hydroxy-4-methylselenobutanoic acid (SO), and Seyeast) in chicken broiler feed has been assessed by Briens et al. ${ }^{191}$ After a 21 day experiment, supplementing with organic Se increased the Se concentration in muscle with the highest accumulation values. Speciation by HPLC-ICP-MS showed that Se was only present, for all additives tested, as SeMet and SeCys in the muscle. In addition, Se digestibility measurements from day 20 to 23 reported values of 24,46 and $49 \%$ for selenite, selenised yeast and SO, respectively, corroborating the advantages of Se-organic sources as Se-enriched feed. The Se speciation in the post-mortem tissues of female pheasants (Phasianus Colchicus Torquator) ${ }^{\mathbf{1 9 2}}$ supplemented with varying proportions of Se-yeast or $\mathrm{Se}^{\mathrm{IV}}$ was performed in a study involving 216 animals. An enhancement of Se level in both tissues and blood was only observed when using selenised-yeast as supplement. In addition, Se-yeast and selenite supplementation increased erythrocyte GSH-peroxidase activity whereas tissue GSH-peroxidase activity remained unaltered, compared to the control samples. Kristan et al. ${ }^{193}$ also utilized HPLC-ICP-MS to study selenium species distribution in muscle and tissues of five different species of freshwater fishes from lakes of Argentina. The level of total Se in muscle varied from 0.66 to $1.61 \mu \mathrm{g} \mathrm{g}^{-1}$, while Se concentrations in liver were higher and ranged from 4.46 to $73.7 \mu \mathrm{g} \mathrm{g}^{-1}$. Separation of Se species in proteolytic extracts was carried out by using two separation columns: a Hamilton PRPX 100 anion exchange $(4.1 \mathrm{~mm} \times 250 \mathrm{~mm} \times$ $5 \mu \mathrm{m})$ and a Zorbax 300-SCX cation exchange $(4.6 \mathrm{~mm} \times 250 \mathrm{~mm}$ $\times 5 \mu \mathrm{m})$. The predominant Se form in all samples of fish muscle was SeMet, which represented around $80 \%$ of soluble Se, while in the liver, the percentage of species identified (SeMet and SeCys2) was very low and ranged from 8 to $17 \%$ of soluble Se. Finally, the in vitro bioavailability of Se from seafood (white fish, cold water fish and mollusc) using a simulated gastric and intestinal/dialysis method followed by HPLC-ICP-MS analysis has been studied. ${ }^{194}$ The bio-availability of selenium, calculated as the ratio between se concentration in dialysate extract and acid digestion extract, was ranged from $4.0 \%$ to $13 \%$ of total Se. The Se species detected in the dialysates were SeMet and SeMetO + SeCys at levels of 9.0 to 58 and 9 to $23 \mathrm{ng} \mathrm{g}^{-1}$, respectively. Additionally, the sum of Se species concentration found was in agreement with the total Se concentration determined in dialysates.

The studies previously described are focused on Se essentiality, however studies related to its potential toxicity and environmental impact has been also performed during this year. The potential use of the aquatic moss Fontinalis antipyretica as an indicator of Se pollution of watercourses was evaluated by HPLC-ICP-MS. ${ }^{195}$ Mosses collected from waters of nine locations of Slovenia were analysed by Hamilton PRP-X 100 anionexchange column and a Zorbax 300-SCX cation-exchange column coupled to ICP-MS. The highest selenium concentration (2250 $\mathrm{ng} \mathrm{g}^{-1}$ ) was found in mosses sampled in farming areas, reporting FBC values over 103. Selenium in mosses was mainly found as inorganic $\mathrm{Se}^{\mathrm{IV}}$ and $\mathrm{Se}^{\mathrm{VI}}$ species. The recovery values (sum of $\mathrm{Se}^{\mathrm{IV}}$ and $\mathrm{Se}^{\mathrm{VI}}$ concentration) were very low, ranging from 4 to $54 \%$ of the total Se content. Following a similar approach, ${ }^{\mathbf{1 9 6}}$ the ability of Macrophytes (Myriophyllum spicatum, Ceratophyllum demersum and Potamogeton perfoliatus) to absorb Se when cultivated outdoors in water solution containing $\mathrm{Se}^{\mathrm{IV}}\left(20 \mu \mathrm{g} \mathrm{L}^{-1}\right.$ and $\left.10 \mathrm{mg} \mathrm{L}^{-1}\right)$ was evaluated. It was shown that Se negatively affected biochemical parameters such as, the photochemical efficiency of PSII and the electron transport system activity in $M$. spicatum and $C$. demersum. The concentration of Se in plants cultured in $10 \mathrm{mg} \mathrm{L}^{-1}$ ranged from 436 to $839 \mu \mathrm{g} \mathrm{g}^{-1}$ in M. spicatum, 319 to $988 \mu \mathrm{g} \mathrm{g}^{-1}$ in C. demersum and 310 to $661 \mu \mathrm{g} \mathrm{g}^{-1}$ in P. perfoliatus. SeMet and MeSeCys were the organic forms of Se found in the Macrophytes after measurement by Hamilton PRP-X 100 AEC-ICP-MS. Freeman et al. ${ }^{197}$ report a nice demonstration of the usefulness of $\mu$ XANES and $\mu$ XRF for establishing Se resistance mechanisms of insects (seed chalcids and seed beetles) fed with seeds of Sehyperaccumulator species such as Astragalus bisulcatus and Stanleya pinnata. Data revealed that Se in seeds was mostly 
present as organic $\mathrm{C}-\mathrm{Se}-\mathrm{C}$ forms, later identified as Se-cystathionine by LC-ES-MS. Once seeds were ingested by the insects, Se was biotransformed into SeCys, selenodiglutathione, $\mathrm{Se}^{\mathrm{VI}}$ and $\mathrm{Se}^{\mathrm{IV}}$. The concentration of Se found in insects was much lower than Se levels found in seeds of Astragalus bisulcatus (4-6 $\mathrm{mg} \mathrm{g}^{-1}$ versus $5750 \mathrm{mg} \mathrm{g}^{-1}$ ). The results suggest a Se resistance mechanism based on the ability of insects to exclude Se from bioaccumulating in their tissues. The application of SRXRF and SR-XAS has also been reported to study the distribution and speciation of $\mathrm{Se}^{198}$ in situ using hydrated roots Cowpea roots (Vigna unguiculata) exposed to $20 \mu \mathrm{M}$ of $\mathrm{Se}^{\mathrm{IV}}$ and $\mathrm{Se}^{\mathrm{VI}}$. Root tissue imaging by $\mu$-XRF revealed the highest Se levels in the endodermis and cortex, and in the meristem when exposed to $\mathrm{Se}^{\mathrm{IV}}$ and $\mathrm{Se}^{\mathrm{VI}}$, respectively. Selenium speciation by XANES indicated that most Se was converted to the organic forms SeMet and SeCys in $\mathrm{Se}^{\mathrm{VI}}$-treated roots, but only $26 \%$ was converted to organoselenium when exposed to $\mathrm{Se}^{\mathrm{IV}}$. An evaluation of the influence of soils properties and selenium compound on fungal biomethylation of selenium and isotope ratios of methylselenides has been undertaken. ${ }^{199}$ The fungus Alternaria alternata was used as a model species and grown in soils spiked with $\mathrm{Se}^{\mathrm{IV}}$ and $\mathrm{Se}^{\mathrm{VI}}$. The determination of Se concentration and isotope ratios $\left(\delta^{82 / 76} \mathrm{Se}\right)$ were carried out using a multi-collector ICP-MS. It was found that in two of the incubated soil samples (pH 6.4-6), between 9.1 and $30 \%$ of the supplied $\mathrm{Se}^{\mathrm{IV}}$ and $1.7 \%$ of the supplied $\mathrm{Se}^{\mathrm{VI}}$ were methylated while in a strongly acidic forest soil ( $\mathrm{pH}$ 3.9) no Se methylation occurred. It was also noted that methylselenides produced from $\mathrm{Se}^{\mathrm{IV}}$ were strongly depleted in ${ }^{82} \mathrm{Se}\left(\delta^{82 / 76} \mathrm{Se}=-3.3\right.$ to $-4.5 \%$ oo $)$ compared with the soil $(0.16-$ $0.45 \%)$ and the added $\mathrm{Se}^{\mathrm{IV}}(0.20 \%)$. The speciation of ultratrace concentrations of $\mathrm{Se}^{\mathrm{IV}}$ and $\mathrm{Se}^{\mathrm{VI}}$ on leachates of freshly deposited volcanic ashes has been reported. ${ }^{200}$ The species were detected by IC-ICP-MS following preconcentration on an anion trap column. The on-line set up consists of a trap column, integration in the IC chromatographic system, for preconcentration and software controlled injection of the samples. Using this procedure, $\mathrm{Se}^{\mathrm{IV}}$ and $\mathrm{Se}^{\mathrm{VI}}$ were separated in $420 \mathrm{~s}$ with LOD and LOQ values of 2.3 and $7.3 \mathrm{pg}$ for $\mathrm{Se}^{\mathrm{IV}}, 3.0$ and $8.3 \mathrm{pg}$ for $\mathrm{Se}^{\mathrm{VI}}$, respectively. It was concluded that Se mobility was very low as only 2 out of 12 samples showed a mobilisation of more than $10 \%$ of the total Se. Finally, the combination of dispersive liquid-liquid microextraction (DLLME) to isolate se prior to determination by TXRF has been reported. ${ }^{201}$ The method was applied to evaluate the effect of anion content in rain water on Se mobility in volcanic ashes. The level of released Se was higher in presence of sulfuric acid rain compared to hydrochloric acid rain. Additionally, $\mathrm{Se}^{\mathrm{VI}}$ was the predominant form in sample leachates. Based on these results, it was concluded that Se mobility depends on competition with sulfate. The authors point out the potential of TXRF analysis for evaluating metal mobility in geochemical studies.

There have been a few studies published related to the separation and determination of multiple analytes in biological and environmental samples. Accumulation and distribution of Se and $\mathrm{Hg}$ in garlic tissues exposed to $\mathrm{Se}^{\mathrm{IV}}$ and $\mathrm{Se}^{\mathrm{VI}}$ and inorganic mercury was evaluated by ICP-MS, $\mu \mathrm{XRF}$ and XANES. ${ }^{202}$ It was concluded that selenium decreased mercury absorption and translocation when plants were exposed to high levels of selenium (>1 $\left.\mathrm{mg} \mathrm{L}^{-1}\right)$ and mercury $\left(>1 \mathrm{mg} \mathrm{L}^{-1}\right)$, simultaneously. However the influence of Se on of mercury phytotoxicity appeared to be dose-dependent. It was also noted that the Se lowered $\mathrm{Hg}$ accumulation in the pericycle of the roots and therefore its transportation upwards through the vessel of roots. This observation coincided with the presence of flocculates precipitates in the culture media. Speciation of $\mathrm{Hg}$ in garlic tissues with $\mu$ XANES indicated that the metal is present as $\mathrm{Hg}(\mathrm{GSH})_{2}$ and $\mathrm{Hg}(\mathrm{Met})_{2}$. The presence of Se decreased the formation of $\mathrm{Hg}(\mathrm{GSH})_{2}$, thus reducing the availability of mercury for further methylation. Moreno et al. ${ }^{203}$ described a method for the simultaneous extraction and determination of $\mathrm{iHg}, \mathrm{MeHg}$ and $\mathrm{Se}^{\mathrm{IV}}$ by hollow fibre extraction followed by HPLC $\left(\mathrm{C}_{18}\right.$ column, $\left.250 \mathrm{~mm} \times 4.60 \mathrm{~mm}, 5 \mu \mathrm{m}\right)$ coupled to ICP-MS. Samples were derivatised with $o$-phenylendiamine, collected on a hollow fibre during $20 \mathrm{~min}$ and finally injected in the HPLC system for analysis. Parameters affecting extraction were optimised by using a univariate approach. The enrichment factors were between 27 and 49-fold. The LOD were estimated to be 110, 230 and $131 \mathrm{ng} \mathrm{L}^{-1}$ for $\mathrm{iHg}, \mathrm{MeHg}$ and $\mathrm{Se}^{\mathrm{IV}}$, respectively. The method was applied to fortified samples of tap water, estuarine water and human blood with recovery values ranged from 79 to 99\%. Another study ${ }^{\mathbf{2 0 4}}$ determined mercury and selenium species in aqueous solution after subcritical water treatment of fish tissue (tuna and mackerel). Selenium and $\mathrm{Hg}$ were quantitatively extracted after autoclaving at $220{ }^{\circ} \mathrm{C}$ during 120 minutes. Monitoring of sample treatment process over 120 minutes by SEC-ICP-MS showed that selenoproteins require $120 \mathrm{~min}$ treatment to be completely hydrolysed to lower molecular hydrophilic species, and, dissolved in the aqueous phase. $\mathrm{MeHg}$ was found to be the predominant mercury specie in aqueous solution after analysing by HPLC-UV-CV-AFS. Subcritical water treatment is presented by the authors as an useful procedure for extracting selenium species from animal tissues.

There were further reports of the use of AFS and GF-AASmethodologies for Se speciation in the period under review. A method based on on-line coupling anion exchange HPCL-thermoreduction-HG-AFS was optimised for determining $\mathrm{Se}^{\mathrm{IV}}, \mathrm{Se}^{\mathrm{VI}}$, SeMet, SeCys and MeSeCys. ${ }^{\mathbf{2 0 5}}$ Selenium species transformation was achieved by adding $\mathrm{KBr}$ dissolved during the heating step $\left(150{ }^{\circ} \mathrm{C}\right)$, avoiding the use of UV irradiation. Under optimised conditions ( $6 \mathrm{M} \mathrm{HCl}, 1.5 \% \mathrm{NaBH}_{4}$ and $150{ }^{\circ} \mathrm{C}$ ), the method provided detection limits in the low ppb range, with the lowest one for SeCyst $\left(0.4 \mu \mathrm{g} \mathrm{Se} \mathrm{\textrm {L } ^ { - 1 } )}\right.$ and the highest for SeMet $(4.6 \mu \mathrm{g}$ Se $\mathrm{L}^{-1}$ ). The method was validated using SELM-1 CRM (selenised yeast, certified for SeMet), and good agreement was obtained between the found $\left(3283 \pm 216 \mathrm{mg}\right.$ SeMet $\left.\mathrm{kg}^{-1}\right)$ and the certified value $\left(3389 \pm 173 \mathrm{mg}\right.$ SeMet $\left.\mathrm{kg}^{-1}\right)$. The approach was also applied to Se speciation in Se-rich algae after feeding with $\mathrm{Se}^{\mathrm{VI}}$. SeMet was the main specie found $\left(3.4 \mathrm{mg} \mathrm{kg}^{-1}\right)$, followed by SeCys $\left(1.8 \mathrm{mg} \mathrm{kg}^{-1}\right)$ and MetSeCys $\left(1.0 \mathrm{mg} \mathrm{kg}^{-1}\right)$. The development of a multisyringe flow injection analysis (MSFIA) system coupled to AFS for determining $\mathrm{Se}^{\mathrm{IV}}, \mathrm{Se}^{\mathrm{VI}}$ and SeMet, using a non-chromatographic technique has been described. ${ }^{206}$ The method consists of three consecutive steps: (1) $\mathrm{Se}^{\mathrm{IV}}$ analysis 
by using $\mathrm{HCl} 1.2 \mathrm{M}$ and $\mathrm{NaBH}_{4} 1 \%(\mathrm{w} / \mathrm{v}),(2) \mathrm{Se}^{\mathrm{VI}}$ and SeMet analysis, as in (1) but using UV light irradiation and (3) Total Se determination, as in (1) but before reduction of $\mathrm{Se}^{\mathrm{VI}}$ to $\mathrm{Se}^{\mathrm{IV}}$ with $\mathrm{KI}(2.4 \mathrm{M})$ and $\mathrm{NaOH}(0.6 \mathrm{M})$ solution and using UV-light. The LODs for $\mathrm{Se}^{\mathrm{IV}}, \mathrm{Se}^{\mathrm{VI}}$ and SeMet were reported to be as low as 0.11, 0.12 , and $0.13 \mu \mathrm{g} \mathrm{L}^{-1}$, respectively. The method was applied to spiked water samples with recovery values close to $100 \%$. A third paper, ${ }^{207}$ detailed a non-chromatographic method for iSe and total selenium determination in edible oils based on dispersive liquid-liquid microextraction followed by ETAAS determination. The optimum DLLME conditions for extracting iSe, SeMet, SeCys 2 and SeCM in $10 \mathrm{~g}$ of oil were achieved by using $300 \mu \mathrm{L}$ of a mixture containing diluted nitric acid and isopropyl alcohol as aqueous phase meanwhile for extracting selectively the Se organic compounds the acidified aqueous solution was replaced by an ionic liquid [C12min][Tf2N]. The enrichment factor was reported to be 140 . Detection limits as low as $0.03 \mu \mathrm{g} \mathrm{kg}^{-1}$ were achieved in the original oil sample. Variations in Se concentration were reported depending on the sample precedence. It was found that oils of vegetal origin were Se-free (at the detection limit of $5 \mu \mathrm{g} \mathrm{kg}^{-1}$ ) or contained low levels of the element, while oils from fish or used in canned fish showed the highest selenium concentrations, with iSe as the predominant species.

\subsection{Silver}

The rapid increase in the use of $A g$ nanoparticles (NPS)I $n$ consumer products due to its antimicrobial activity has necessitated the development of methods for the speciation of the metal in different matrices. The simultaneous determination of $\mathrm{Ag}$ nanoparticles and ions via HPLC-ICP-MS has been reported. ${ }^{208} \mathrm{~A} \mathrm{C}_{18}$ column was used $(250 \times 4.6 \mathrm{~mm}, 7 \mu \mathrm{m})$ in conjunction with a mobile phase of $10 \mathrm{mmol} \mathrm{L}^{-1}$ ammonium acetate, in $10 \mathrm{mmol} \mathrm{L}^{-1} \mathrm{SDS}$ and $1 \mathrm{mmol} \mathrm{L}^{-1}$ sodium thiosulfate at $\mathrm{pH}=6.8$. Under these conditions $10 \mathrm{~nm} \mathrm{Ag-NPs}$ and $\mathrm{Ag}^{\mathrm{I}}$ were baseline-separated in one chromatographic run in less than 10 minutes. The reported LODs were in the order of 0.12, 0.08 and $0.40 \mathrm{ng} \mathrm{L^{-1 }}$ for $\mathrm{Ag}^{\mathrm{I}}, 10 \mathrm{~nm}$ AgNPs and $20 \mathrm{~nm} \mathrm{NPs}$, respectively. The method was then used in the determination of $\mathrm{Ag}$ species released from Sport Socks. Samples were treated during 2 hours with a buffer consisting of $10 \mathrm{mmol} \mathrm{L}^{-1}$ ammonium acetate at $\mathrm{pH} 6.8$ and $10 \mathrm{mmol} \mathrm{L}{ }^{-1}$ SDS. Subsequently, the resulting extracts were analysed by HPLC-ICP-MS. Although the chromatographic method offered repeatable results (RSD $<2 \%$ ) for three consecutive injections of the same extraction process, quantification was affected by the extraction conditions. The optimised chromatographic method was applied to speciate $\mathrm{Ag}$ in foetal bovine serum (FBS) incubated with $10 \mathrm{~nm}$ Ag NPs during $1 \mathrm{~h}$. The presence of FBS modified the retention time of $\mathrm{Ag}$ NPs: to 4.25 minutes compared with 5.0 minutes for FBS and SDS media, respectively.

\subsection{Tellurium}

Research publications on the speciation of tellurium are few and far between, so research work in this area is bound to receive attention. Anan et al. ${ }^{209}$ have used HPLC-ICP-MS and HPLC-ESI-
MS to study hydroponically cultivated garlic exposed to sodium tellurate. A multi-mode size exclusion column and a mobile phase containing ammonium acetate $\left(10 \mathrm{mmol} \mathrm{L}^{-1}\right) \mathrm{pH} 6.5$ at a flow rate of $0.6 \mathrm{~mL} \mathrm{~min}{ }^{-1}$ was used for the speciation analysis of Te in water extracts from freeze dried garlic leaves. Tellurium isotopes at $\mathrm{m} / \mathrm{z} 125,128$ and 130 were monitored and at least 4 Te-containing metabolites were detected. The major metabolites were identified after partial purification using an anionexchange cellulose material to remove interferences, followed by LC-MS/MS analysis using a capillary version $(2.0 \mathrm{~mm}$ id $\times$ $200 \mathrm{~mm}$ ) of the multimode column and the same eluent as before. The same separation conditions were used this time with the column coupled to a high resolution Orbitrap MS instrument to give accurate masses for the Te-containing metabolites. In this way three of the Te-containing peaks were identified as tellurate, Te-methyltellurocysteine oxide and cysteine $S$-methyltellurosulfide, but the final compound remained unidentified. Although the world-wide environmental impact of Te on garlic must be rather limited, it is interesting to see how this element is metabolised in vitro.

\subsection{Tin}

Since the ban on the use of organotin based antifouling systems under the IMO 'International convention on the control of harmful anti-fouling systems in ships' came into force in 2008, the number of studies on tin speciation has gradually declined. We are now at a point where there is just the occasional paper published each year. This year no novel work appeared in the primary literature, although the accumulation of TBT in selected organisms is still determined using well established techniques and reported in national/regional chemical society journals.

\subsection{Uranium}

Two papers have appeared on uranium speciation using different approaches. A study to elucidate uranium accumulation patters in gills and hepatopancreas of crayfish Procambarus clarkia has been published by Frelon et al. ${ }^{210}$ An ICP-MS and SEC-ICP-MS methodology was followed for subcellular fractionation and chemical speciation, respectively. The sub-cellular $\mathrm{U}$ distribution for U-treated crayfish during 4 and 10 days at 0, 30, 600 and $4000 \mu \mathrm{g} \mathrm{L}^{-1}$ was shown to be as follows: $13-30 \%$ and $35-75 \%$ of the total $U$ localised in the cytosol in gills and in hepatopancreas, respectively, suggesting an organ-dependent fractionation patterns. Results from SEC-ICP-MS revealed the existence of potential interactions between $\mathrm{U}$ and $\mathrm{Cu}$ and $\mathrm{Fe}$, and therefore competition for the same macromolecules. In the second paper, ${ }^{211}$ the application of X-ray based techniques to investigate $\mathrm{U}$ speciation and elemental distribution in fluid inclusions from unconformity-related $\mathrm{U}$ deposits was presented. The XRF measurements on 12 homogenised NaCl-rich fluid inclusions indicated the presence of elevated concentrations of $\mathrm{Br}, \mathrm{Fe}, \mathrm{Sr}$, transition metals $(\mathrm{Cu}, \mathrm{Mn}, \mathrm{Ni}, \mathrm{Zn}), \mathrm{Pb}, \mathrm{U}$ and rare earth elements (REE) (Ce, La), with concentrations being relatively homogeneous among fluid inclusions. The XANES results revealed $\mathrm{U}^{\mathrm{VI}}$ as the predominant form of $\mathrm{U}$ in the fluid inclusions. 


\subsection{Vanadium}

A fast chromatographic method, coupled with ICP-MS, was developed to determine $\mathrm{VO}^{2+}$ and $\mathrm{VO}_{4}{ }^{3-}$ ions in lake waters with separation of the two species taking less than a minute. ${ }^{212}$ The $\mathrm{V}$ ions were separated using a $\mathrm{C}_{18}$ column and an isocratic ion pair eluent comprising $18 \mathrm{mM}$ EDTA, $0.5 \mathrm{mM}$ tetrabutyl ammonium hydroxide, $20 \mathrm{mM}$ phosphoric acid and 5\% methanol adjusted to pH. 7 and flowing at $0.6 \mathrm{~mL} \mathrm{~min}^{-1}$. The outlet of the UPLC system was directly coupled to a SF-ICP-MS which was operated in both 'low' and 'medium' resolution. This was to show the effect of added $\mathrm{Cl}$ and the resulting ${ }^{35} \mathrm{Cl}^{16} \mathrm{O}^{+}$polyatomic interference on ${ }^{51} \mathrm{~V}^{+}$. It would appear though that the chromatograms are wrongly labelled. The chromatogram acquired in 'medium' resolution mode shows three peaks, whereas only two would be expected, as ${ }^{35} \mathrm{Cl}^{16} \mathrm{O}^{+}$would not be monitored. Conversely, the 'low' resolution mode chromatogram only contains two peaks, whereas three would be expected, due to the additional signal from the added chloride forming ${ }^{35} \mathrm{Cl}^{16} \mathrm{O}^{+}$. Detection limits were calculated to be 8 and $13 \mathrm{ng} \mathrm{L}{ }^{-1}$ for $\mathrm{VO}^{2+}$ and $\mathrm{VO}_{4}{ }^{3-}$ respectively. When the method was applied to lake waters only $\mathrm{VO}_{4}{ }^{3-}$ was detected, at a concentration of approximately $1 \mu \mathrm{g} \mathrm{L^{-1 }}$.

\subsection{Zinc}

Following on from work reported in this ASU last year, Blindauer ${ }^{213}$ has produced another excellent review, this time covering work on the critical interplay between zinc binding, protein structure and dynamics, once again giving a master class on how to approach the study of metalloproteins using a variety of speciation methods, which researchers in the field would do well to consult. It is clear from her discussion that $\mathrm{Zn}$ it has been mostly overlooked, when in fact it is an element with a nutritional and physiological importance as great as Fe. A combination of biophysical techniques, such as, NMR, isothermal titration calorimetry, XAFS and site-directed mutagenesis are required for the investigation of metal-binding in proteins, along with the use of more readily recognisable speciation methods such as ESI-MS/MS, ICP-OES and ICP-MS. A combination of ESI-MS with a second technique, usually elemental analysis by ICP-OES can be used to establish which metal ions are present, to provide an independent confirmation of metal-to-protein stoichiometry and to obtain an exact protein concentration through the sulfur content.

\section{Macromolecular analysis}

The quantitation of DNA by measurement of $P$ content is now possible due to the availability of magnetic sector and collision/ reaction cell instrumentation, which allow for the interferencefree determination of the element. The measurement of $\mathrm{S}$ is now also possible, which is important for the quantitation of proteins. Thus the extended capability for the determination of both $\mathrm{P}$ and $\mathrm{S}$ determination opens up important biological molecules for high accuracy measurement. Leclerc et al. ${ }^{\mathbf{2 1 4}}$ have developed a method for the quantitation of Legionella pneumophila genomic DNA. The method is based on the use of SF-ICP-
MS to measure the mass fraction of ${ }^{31} \mathrm{P}$, stoichiometrically present in the DNA molecules. After DNA sequencing the ICPMS results were converted into DNA genome units. Spectrophotometric measurements of the absorbance at $260 \mathrm{~nm}$ and real-time PCR techniques were used to independently confirm the ICP-MS measurement of DNA. Comparison of the methods showed that ICP-MS provided better accuracy compared to UV spectrophotometry, fluorescent dye methods, or real-time PCR. More importantly perhaps, the use of inorganic-MS with elemental rather than molecular calibration standards allows for the development of measurements traceable to SI units and the possibility of evaluating the contribution to the overall uncertainty of each step of the measurement procedure. These advantages make the ICP-MS method suitable for nucleic acid investigation, from nucleotides to genomic DNA, as well as for the certification of RM containing nucleic acids. The use of GE coupled to ICP-MS ${ }^{215}$ for the determination of DNA with different base pair lengths has also used the measurement of

${ }^{31} \mathrm{P}$ but this time a quadrupole instrument was employed. Interestingly no cell gas was used to remove the $\mathrm{NO}$ and $\mathrm{NOH}$ polyatomic interferences often present for this isotope. The coupling was achieved by developing a modified high performance concentric nebuliser (HPCN), which produced the liquid jet by the flow focusing effect. The HPCN effectively nebulised the highly viscous gel buffer solution even at a low flow rate of $0.010 \mathrm{~mL} \mathrm{~min}^{-1}$ and a nebuliser gas flow rate of $1 \mathrm{~L} \mathrm{~min}^{-1}$. After the electrophoretic separation at atmospheric pressure, the species were transferred to the ICP-MS through the interface by applying additional gas pressure. The LOD and absolute detection limit for $\mathrm{P}$ was $3.7 \mathrm{mg} \mathrm{kg}^{-1}$ and $0.6 \mathrm{pg}$ (equivalent to 6 pg of DNA), respectively. Unfortunately the system was not applied to real world samples to see what effect the matrix might have on the resolution of the 25 base pair (bp) dsDNA ladder sample with fragments between 25 and $2652 \mathrm{bp}$.

\subsection{Metalloproteins, metalloproteomics and metallomics}

The recent literature in this area indicates that chromatography rather than detection is the key developmental endeavour in metallomics and metalloproteomics at the current time. The use of a $2 \mathrm{D}$ or orthogonal separation is clearly the paramount consideration, whether that be SEC followed by planar GE or CE, IEC followed by RP chromatography, the difficulty of resolving metal-containing macromolecules without loss of the metal of interest is still a significant challenge for the current commercially available chromatographic systems. If metallomics is to develop in a similar manner to proteomics, then it requires development of common platforms to allow for protocols that can be used generically and whilst this has been achieved in proteomics, it is not possible to apply the same enzymatic techniques to metallomics without losing the metal centre so a different approach is required. A recent review ${ }^{216}$ has covered some of these issues and also proposed an explanation of the overlapping use of the terms metallomics and metalloproteomics, which is starting to enter the literature-metalloproteomics generally being regarded as part of metallomics in their view. However, in a perspectives article Lothian et al. ${ }^{\mathbf{2 1 7}}$ 
seem to offer a different interpretation of the two areas, considering metalloproteomics to amalgamate proteomic and metallomic approaches, believing that the term metalloproteomics is more suited to the field than metallomics alone, as it recognises the important relationship between biometals and proteins, rather than focusing solely on the presence of an individual metal species. These definitions seem to be at odds and so there is a current need for some consensus on these relatively new terms.

The investigation of metallodrugs and their interaction with physiologically important biomolecules has been the subject of two recent reviews by Hartinger et al. ${ }^{218,219}$ The clinical success of CP and newer platinum-based drugs has stimulated interest in other metallodrugs as therapeutic agents. The interaction of chemotherapeutic agents containing Pt and those more recently developed containing $\mathrm{Ru}$, with proteins, enzymes or DNA have been of particular interest due to their potential for systematic target optimisation. A wide range of techniques including: HPLC-ICP-MS, CE-ICP-MS, LC-ESI-MS/MS, LA-ICP-MS, nanoSIMS, XRF, XRD, fluorescence microscopy as well as gene expression analysis were reviewed, along with specific metallodrug binding applications and their use for the investigation of metallodrug binding sites.

The use of CE-ICP-MS is a promising tool for the investigation of metallodrug interactions, providing conditions in which the species are stable, with good tolerance to biological samples, and high resolving power, along with the capacity for multielemental detection. The application of CE-ICP-MS to various metallodrug-protein systems have been summarised in a review $^{220}$ focusing on: experimental approaches to the assessment of binding, reactivity and affinity; the monitoring of in vitro cellular transformations and serum binding profiles; and ex vivo metallodrug-proteomic analysis. This hyphenated technique's specific merits for metallodrug studies include: an ability to separate rapidly and efficiently the parent drug and protein-bound drug form(s), with no alteration of original speciation in the sample; to measure the binding parameters (e.g. rate and equilibrium constants); and to quantify the metalprotein adducts in real-world samples. A method ${ }^{221}$ based on combining $\mathrm{CE}$ or an ultrafiltration step with ICP-MS was developed to study the speciation of the serum protein adducts of a Ru anticancer drug under in vitro intracellular conditions. The capillary was conditioned prior to use with $0.1 \mathrm{M} \mathrm{NaOH}$, a mixture of $0.1 \mathrm{M} \mathrm{NaOH}$, methanol, and water $(25 / 50 / 25, \mathrm{v} / \mathrm{v} / \mathrm{v})$, water, and the background electrolyte. Samples were introduced into the capillary hydrodynamically by applying a pressure of 30 mbar for $10 \mathrm{~s}$ (injection volume $25.5 \mathrm{~nL}$ ). A voltage of $25 \mathrm{kV}$ was applied, with a positive polarity placed at the inlet end of the capillary, to generate the separation and acetone was used as a marker of electroosmotic flow via UV detection. Prior to analysis, the $\mathrm{Ru}$-protein adducts were separated from the unbound $\mathrm{Ru}$ species, as well as from high chloride, using ultrafiltration through a $10 \mathrm{kDa}$ cut-off filter. The high molecular mass fraction was reconstituted in $10 \mathrm{mM}$ phosphate buffer $\mathrm{pH} 6.0$ containing $4 \mathrm{mM} \mathrm{NaCl}$ and reverse centrifugation used to remove it from the membrane filter. The main adducts identified were with albumin and transferrin and the transferrin adducts were affected by both glutathione and ascorbic acid at concentrations found in the cytosol of cancer cells.

Investigations into the speciation of trace elements in the brain and their relation to neurodegenerative diseases have been the focus of considerable research efforts in the past year. McCormick et al. ${ }^{222}$ have characterised the low-molecular mass (LMM), (defined as $<10 \mathrm{kDa}$ ) complexes from mouse brain. Supernatant fractions of fresh mouse brain homogenates were passed through a $10 \mathrm{kDa}$ cut-off membrane and then subjected to SEC ICP-MS using two Superdex peptide GL 10/300 columns in series, with a mobile phase containing $20 \mathrm{mM}$ Tris buffer $\mathrm{pH}$ 7.4. Significantly the sample preparation and HPLC separation were carried out in a box under anaerobic refrigerated conditions. Post-separation a $100 \mu \mathrm{g} \mathrm{L}^{-1}$ In internal standard in $4 \%$ v/v nitric acid was added via a T-piece and Co, Cu, Fe, Mn, Mo, P, $\mathrm{S}$ and $\mathrm{Zn}$ were monitored using ICP-MS with $\mathrm{He}$ at $4.3 \mathrm{~mL} \mathrm{~min}^{-1}$ as collision gas. At least 30 different LMM metal complexes were detected along with numerous P-and S-containing species. The percentage of the metals that eluted from the column, normalised to the amount loaded, was determined and the averages of three runs were: $\mathrm{Co}, 93$; Cu, 84; Fe, 89; Mn, 93; Mo, 74; P, 91; S, 92; and $\mathrm{Zn}, 92$, indicating that the metal-containing species were not retained on the column. The $\mathrm{S}$ and $\mathrm{P}$ chromatograms were used to align the metal-based chromatograms and correct for any small differences in elution times between runs. Potential speciation changes during sample were investigated by leaving a sample for 13 days in a refrigerated box prior to passage through the column. The resulting chromatograms, compared to those obtained using fresh samples, revealed virtually no change in relative peak areas and distributions, indicating that degradation was not a problem over the much shorter time scale of the investigation. Unfortunately none of the species were fully identified as the authors only used the retention volume from the column to assign the molecular weight by comparison with a calibration plot and molecular mass spectrometry was not employed. The use of a second chromatographic step rather than just SEC on its own would also have helped to resolve any co-eluting species which were clearly present in the chromatograms presented. A similar study $^{223}$ on paired serum and CSF patient samples but looking only at Mn used an orthogonal approach involving SEC-ICP-MS, but also analysis of fractions from the SEC separation using CEICP-MS and ESI-FT-ICR-MS to fully identify the species, based on matching retention times to standards and structural elucidation. The aim of the study was to achieve a sufficient separation of various $\mathrm{Mn}$-proteins from different LMM Mn compounds, particularly Mn-citrate, in serum and CSF samples. Two SEC columns in series: a Biobasic 300 mesh column $(300 \times 8 \mathrm{~mm}$ ID, separation range $700-5 \mathrm{kDa})$ and a Kronlab TSK-HW40S $(550 \times 10 \mathrm{~mm}$ ID, separation range 100$2000 \mathrm{Da}$ ) and an eluent containing $10 \mathrm{mM}$ Tris $\mathrm{pH} 7.4$ and 250 $\mathrm{mM}$ ammonium acetate at a flow-rate of $0.75 \mathrm{~mL} \mathrm{~min}^{-1}$ were used for the separations. Absorption of the Mn compounds to the columns was checked by purging after each run with $10 \mathrm{mM}$ Tris- $\mathrm{HCl} \mathrm{pH} 2$ and analysis of the eluate gave the following recoveries: $\alpha$-2-macroglobulin, 91\%; Mn-transferrin, 98\%; Mnalbumin, 105\%; Mn-citrate, 108\%; inorganic Mn, 102\%. 


\subsection{Tagging and labelling of molecules}

Elemental labelling is an expanding area of research and encompasses the indirect determination of biomolecules by labelling with metals, NPs or quantum dots. Recent reviews ${ }^{224-226}$ highlight novel quantification approaches where elemental labelling is combined with FI-ICP-MS or HPLC-ICP-MS, and employed for quantification of biomolecules such as proteins. The ICP-MS as detector provides high sensitivity, selectivity and robustness in biological samples and the capability for multiplexing and ID-MS. The reviews highlighted the fundamental methodology of elemental labelling and recent analytical, as well as biomedical applications were presented.

Studies on labelling using different lanthanide elements have continued and been applied to the measurement of different peptides and the differentiation of human cancer cells. A research group from the Chemical Metrology Group of the NNRCC have used a species-specific ID GC-MS approach to validate the absolute quantitation of bradykinin by suID-MS using HPLC-ICP-MS. ${ }^{27}$ The HPLC-ICP-MS method involved the quantitative labelling of the peptide using the macrocyclic bifunctional chemical chelator DOTA (1,4,7,10-tetraazacyclododecane-1,4,7,10-tetraacetic acid), followed by addition of $\mathrm{Eu}$ as the metal tag. Both of these steps were monitored by ES-MS/ MS, which showed that a 10-fold molar excess of the DOTANHS-ester in a pH 8 triethylammonium acetate buffer produced a $100 \%$ labelling efficiency. Quantitation of the peptide using suID-MS was performed by post-column infusion of a spike solution enriched in ${ }^{151} \mathrm{Eu}$ and measurement of the ${ }^{151} \mathrm{Eu} /{ }^{153} \mathrm{Eu}$ signal ratios. The LOD using suID-MS evaluated from procedural blanks based on a $10 \mu \mathrm{L}$ injection was calculated to be 7.2 fmol. The method was validated using microwave hydrolysis and SSID-MS using GC-MS for the quantification of the constituent amino acid content of bradykinin and the subsequent peptide amount fraction. This GC-MS based determination is considered to be the current state of the art by the measurement science community for peptide quantitation. Concentrations obtained for five test solutions were in good agreement, demonstrating the accuracy of the proposed method. A recent technical note ${ }^{228}$ describes an on-line precleaning procedure for the analysis of peptides from tryptic digests again using a DOTA chelator tagged with a lanthanide. A set of labelled model peptides and a protein digest were analysed using an ion-pair nano-RP-HPLC-ICP-MS. Peptides were labelled with lanthanide metals using bifunctional DOTA-based (1,4,7,10-tetraazacyclododecane-1,4,7,10-tetraacetic acid) reagents. The resulting metal excess was removed online during nano-HPLC, by trapping the labelled peptides on a $\mathrm{C}_{18}$ precolumn and washing them prior to their elution to the analytical column. A 6 min washing time was determined to be the best parameter for lowering the lanthanide metal background while maintaining maximum peptide recovery. Alternative precleaning setups using EDTA to enhance the removal of free metal or an off-line approach using SPE did not show promising results. The application of the optimised method to labelled peptides in a lysozyme digest showed results comparable to those obtained with model peptides. A trifunctional probe for visualising and counting cancer cells ${ }^{229}$ using both fluorescence imaging and ICP-MS has been synthesised. The tagging probe consisted of 3 parts: (1) a dye (5-amino-fluorescein) for fluorescence imaging; (2) 2-aminoethyl-monoamide-DOTA (MMADOTA) for loading Eu for subsequent quantification using ICPMS; and (3) a guiding cyclic Arg-Gly-Asp peptide c(RGDfK(Mpa)) (cRGD) to target integrin $\alpha \mathrm{v} \beta 3$ overexpressed on the surface of cancer cells. The LOD $(3 \sigma)$ of the $\alpha v \beta 3$ integrin was 69.2-309.4 amol per cell depending on the type of $\alpha v \beta 3$-positive cancer cell.

The combined use of lanthanide labelled tags and DNA replication and hybridisation techniques is a new tagging application area and has been applied in a clinically relevant setting. The use of ICP-MS in virology to measure viral DNA levels ${ }^{\mathbf{2 3 0}}$ is truly novel and as a result of using techniques prevalent in molecular biology, such as rolling circle replication to amplify the DNA being measured, the LODs reported in this proof of concept work are impressively low. The ICP-MS-based multiplex assay for viral DNA with lanthanide-coded oligonucleotide hybridisation and replication strategies, used single-stranded capture DNA-functionalised magnetic nanoparticles (MNPs) with a diameter of $320 \mathrm{~nm}$, to recognise and enrich target DNAs and single-stranded report DNA coded by the lanthanide-DOTA complex hybridised with the targeted DNA, for the measurement of human immunodeficiency virus (HIV) (28 amol), hepatitis A virus (HAV) (48 amol), and hepatitis B virus (HBV) (19 amol). When utilising the replication technique in association with the design and synthesis of a "bridge" DNA and a corresponding ss-Rep-DNA-DOTA-Ho, HBV as low as $90 \mathrm{zmol}$ could be detected. Preliminary applications to the determination of the viral DNAs in 4T1 cell lysates and in serum confirmed the feasibility of the assay for clinical use. In another clinical study $^{231}$ a similar approach but using DNA-functionalised magnetic microparticles (MMP) with a diameter of $2.8 \mu \mathrm{m}$, multiplexed a larger number of DNA targets associated with clinical diseases including: HAV; HBV; hepatitis C virus; HIV; human papillomavirus; treponema pallidum; variola virus; ebola virus; bacillus anthracis (BA); francisella tularensis; severe acute respiratory syndrome (SARS); coronavirus; breast cancer; prostate cancer; Alzheimer's disease; as well as sickle cell disease. These were simultaneously detected by using elemental labelling tags of Ce, Dy, Er, Eu, Gd, Ho, La, Lu, Nd, Pr, Sm, Tb, $\mathrm{Tm}, \mathrm{Y}, \mathrm{Yb}$. The relative quantification was carried out by using internal calibration curves and employing In as an internal standard. The study went on to develop the absolute quantification with chromatography-free hybridisation isotope dilution analysis (HIDA). The HIDA system was composed of four parts: capture probes, report probes, isotope dilution probes, and analyte DNA targets. The capture probes had two DNA regions: the MMP region directly hybridised with the isotope dilution probe containing the enriched isotope, and an end region sequenced so as to form a sandwich hybridisation with the analyte DNA target and also the report probe containing the naturally abundant isotope. To demonstrate the feasibility of the HIDA method for a multiplex DNA assay, a two-strand system was designed where two sequence-specific capture probes were used for simultaneous hybridisation with BA and SARS targets. The natural Dy and Er labelled the reporting 
probes, while ${ }^{161}$ Dy-enriched and ${ }^{168}$ Er-enriched isotopes labelled the detection probes for BA and SARS respectively. To validate the accuracy of the HIDA method, UV absorption spectroscopy was used to quantify the amount of BA and SARS targets in the samples by measuring optical density at $260 \mathrm{~nm}$. These results could be considered as reference values and the results obtained by the HIDA method were in good agreement showing a recovery of 93.7-106.5\%, which indicates the accuracy of the developed method.

\subsection{Elemental imaging}

Elemental species imaging using LA-ICP-MS involves spatial analysis to provide an image of a planar GE separation, and comparison to molecular standards for identification of the species in the band. A method ${ }^{232}$ to screen for $\mathrm{Cu}$ and $\mathrm{Zn}$-containing proteins in plankton based on the use of Blue-Native PAGE gels, used a non-denaturing tris(hydroxymethyl)aminomethane(Tris)-tricine system and detection of the proteins by LA-ICP-MS. For comparison, denaturing PAGE gels based on Tris-glycine and Tris-tricine systems and Anodic-Native PAGE gels were also investigated. A large number of protein bands with MW between 20 and75 kDa were obtained by use of Trisglycine PAGE but detection by LA-ICP-MS was unsuccessful because of loss of metals from the proteins during the separation process. Different protein extraction, purification, and preconcentration methods were evaluated, focussing on achieving the best extraction and characterisation of the proteins, while maintaining the integrity of metal-protein binding. Use of 25 mmol L ${ }^{-1}$ Tris- $\mathrm{HCl}$ and a protease inhibitor as extraction buffer with subsequent ultrafiltration and acetone precipitation was the most efficient means of sample preparation. Two $\mathrm{Cu}$ and $\mathrm{Zn}$ proteins were detected, a protein band corresponding to a MW of $60 \mathrm{kDa}$ and another poorly resolved band with a MW between 15 and $35 \mathrm{kDa}$. Neither was identified.

Measurement of the native form of different metalloproteins using synchrotron radiation excited $X$-ray fluorescence (SPAX) has recently been developed and compared to LA-ICP-MS. ${ }^{233}$ X-ray based spectroscopies are able to determine the local structural environment, such as geometry, coordination number and ligand binding, around selected elements. As such they are therefore excellent methods for the identification of metalcontaining biomolecules in planar GE. Initially a pre-fabricated isoelectric focusing gel was used, however due to X-ray backscattering that adversely affected the LOD using this approach, a thinner native-gel film was prepared on a polyimide support. Once freeze dried the gel was about one-fourth the thickness of the isoelectric focusing gel and was suitable for both SPAX and LA-ICP-MS analysis. A number of metalloproteins were run on the gels including: Cu-SOD; Zn-SOD; Mn-SOD; metallothionein; along with commercially available bovine serum. All the model proteins were clearly visible in the gels however no bands were present in the horse serum lane. In a further experiment CP was reacted with commercially available BSA and run on the native-gel film followed by SPAX and LA-ICP-MS analysis. The SPAX results showed the presence of Pt up to a concentration of $150 \mathrm{ng}$ of added Pt and there was a curvilinear

calibration plot, indicating that the method had some promise as a semi-quantitative method. The advantages of SPAX were seen as: a non-invasive approach; giving an indication of the ligand environment around the metal; and giving $2 \mathrm{D}$ information.

\section{Abbreviations}

$2 \mathrm{D}$

AAS

$\mathrm{AB}$

$\mathrm{AC}$

AEC

AFS

APCI

APDC

APL

ASE

ASU

BA

$\mathrm{BH}$

$\mathrm{CE}$

$\mathrm{CP}$

CPE

CRC

CRM

CSF

$\mathrm{CT}$

CV-AFS

Cys

CZE

DDTC

DESI

DGT

DLLME

DMA

DMAE

DMMTA

DNA

DOTA

DPAA

DPP

EDTA

EI

ESI

ETAAS

EtHg

EXAFS

FAAS

FBS

FTIR

GC

Gd-BOPTA

Gd-BT-

DO3A
Two dimensional

Atomic absorption spectrometry

Arsenobetaine

Arsenocholine

Anion exchange chromatography

Atomic fluorescence spectrometry

Atmospheric pressure chemical ionisation

Ammonium pyrrolidine dithiocarbamate

Acute promyelocytic leukemia

Accelerated solvent extraction

Atomic Spectrometry Update

Bacillus anthracis

Borohydride

Capillary electrophoresis

Cisplatin

Cloud point extraction

Colorectal cancer

Certified reference material

Cerebrospinal fluid

Computer tomography

Cold vapour atomic fluorescence spectrometry

Cysteine

Capillary zone electrophoresis

Diethyldithiocarbamate

Desorption electrospray ionisation mass

spectrometry

Diffusive gradient in thin film

Dispersive liquid-liquid microextraction

Dimethylarsenic (include oxidation state if

known)

Dimethylarsenoethanol

Dimethylmonothioarsinic acid

Deoxyribonucleic acid

1,4,7,10-Tetraazacyclododecane-1.4.7.10-

tetraacetic acid

Diphenylarsinic acid

Differential pulse polarography

Ethylenediaminetetraacetic acid

Electron ionisation

Electrospray ionisation

Electrothermal atomic absorption spectrometry

Ethylmercury

Extended X-ray absorption fine structure

Flame atomic absorption spectrometry

Foetal bovine serum

Fourier transform infrared

Gas chromatography

Gadobenate

Gadobutrol 


$\begin{array}{ll}\text { Gd-DOTA } & \text { Gadoterate } \\ \text { Gd-DTPA } & \text { Gadopentetate } \\ \text { Gd-DTPA- } & \text { Gadodiamide } \\ \text { BMA } & \\ \text { GE } & \text { Gas electrophoresis } \\ \text { GF-AAS } & \text { Graphite furnace atomic absorption spectrometry } \\ \text { GPx } & \text { Glutathione peroxidase } \\ \text { GSH } & \text { Glutathione } \\ \text { HSA } & \text { Human serum albumin } \\ \text { HAV } & \text { Hepatitis A virus } \\ \text { HBV } & \text { Hepatitis B virus } \\ \text { HG } & \text { Hydride generation } \\ \text { HIDA } & \text { Hybridisation isotope dilution analysis } \\ \text { HILIC } & \text { Hydrophilic interaction liquid } \\ \text { HIV } & \text { Human immunodeficiency virus } \\ \text { HPCN } & \text { High performance concentric nebuliser } \\ \text { HPLC } & \text { High performance liquid chromatography } \\ \text { iAs } & \text { Inorganic arsenic } \\ \text { IC } & \text { Ion chromatography } \\ \text { ICP } & \text { Inductively coupled plasma } \\ \text { ICP-MS } & \text { Inductively coupled plasma mass spectrometry } \\ \text { ICP-OES } & \text { Inductively coupled plasma optical emission } \\ \text { ICR } & \text { spectrometry } \\ \text { id } & \text { Ion cyclotron resonance } \\ \text { IDA } & \text { Internal diameter } \\ \text { Isotope dilution analysis }\end{array}$

ID-ICP-MS Isotope dilution inductively coupled plasma mass spectrometry

$\begin{array}{ll}\text { ID-MS } & \text { Isotope dilution mass spectrometry } \\ \text { IEC } & \text { Ion exchange chromatography } \\ \mathrm{iHg} & \text { Inorganic mercury } \\ \mathrm{IR} & \text { Infrared } \\ \text { LA } & \text { Laser ablation }\end{array}$

LA-MC-ICP- Laser ablation multicollector inductively coupled MS plasma mass spectrometry

LC Liquid chromatography

LLE Liquid-liquid extraction

LLLME Liquid-liquid-liquid microextraction

LMM Low-molecular mass

LOD Limit of detection

LOQ Limit of quantification

MAE Microwave assisted extraction

MALDI Matrix-assisted laser desorption ionisation

MC-ICP-MS Multicollector inductively coupled plasma mass spectrometry

MeHg Methyl mercury

MeSeCys Methylselenocysteine

Met Methionine

MIP Microwave induced plasma

MMA Monomethylarsenic

MMMTA Monomethylmonothioarsonic acid

MMP Magnetic microparticles

MMTA Monomethylthioarsonic acid

MRI Magnetic resonance imaging

MRT Molecular recognition technology

MS Mass spectrometry

$\mathrm{m} / \mathrm{z} \quad$ Mass to charge ratio

MW Molecular weight

NIST National Institute of Standards and Technology

\begin{tabular}{|c|c|}
\hline NMG & $N$-Methylglucamine \\
\hline NRCC & National Research Council of Canada \\
\hline OMC & Organomercury compounds \\
\hline OTC & Organotin compounds \\
\hline PAGE & Polyacrylamide gel electrophoresis \\
\hline PCR & Polymerase chain reaction \\
\hline PDMS & Polydimethylsiloxane \\
\hline PEEK & Polyetheretherketone \\
\hline PEG & Polyethylene glycol \\
\hline PFA & Perfluoroalkyl \\
\hline $\mathrm{PhHg}$ & Phenylmercury \\
\hline PHWE & Pressurised hot water extraction \\
\hline PLS & Partial least squares \\
\hline PM & Particulate matter \\
\hline PTFE & Poly(tetrafluoroethylene) \\
\hline $\mathrm{Q}$ & Quadrupole \\
\hline QC & Quality control \\
\hline $\mathrm{RP}$ & Reversed phase \\
\hline RSD & Relative standard deviation \\
\hline SARS & Severe acute respiratory syndrome \\
\hline SAX & Strong anion exchange \\
\hline SCX & Strong cation exchange \\
\hline SDS & Sodium dodecylsulfate \\
\hline SeAlb & Selenoalbumin \\
\hline SEC & Size exclusion chromatography \\
\hline SeCys & Selenocysteine \\
\hline $\mathrm{SeCys}_{2}$ & Selenocystine \\
\hline SeEt & Selenoethionine \\
\hline SeHLan & 4,4'-Selenobis[2-aminobutanoic acid] \\
\hline SEM & Scanning electron microscopy \\
\hline SeMeG & Methylselenoglutathione \\
\hline SeMet & Selenomethionein \\
\hline SeMetSeCys & Selenomethioneinselonocysteine \\
\hline$(\mathrm{SePh})_{2}$ & Dyphenyl diselenide \\
\hline SePP & Seleno protein $\mathrm{P}$ \\
\hline SeSug1 & $\begin{array}{l}\text { Methyl-2-acetamido-2-deoxy-1-seleno- } b \text {-D- } \\
\text { galactopyranoside }\end{array}$ \\
\hline $\operatorname{SeSug}_{3}$ & $\begin{array}{l}\text { Methyl-2-amino-2-deoxy-1-seleno- } b \text {-D- } \\
\text { galactopyranoside }\end{array}$ \\
\hline SF-ICP-MS & $\begin{array}{l}\text { Sector field inductively coupled plasma mass } \\
\text { spectrometry }\end{array}$ \\
\hline SIMS & Secondary ion mass spectrometry \\
\hline SO & 2-Hydroxy-4-methylselenobutanoic acid \\
\hline SOD & Superoxide dismutase \\
\hline SPAX & Synchrotron radiation excited X-ray fluorescence \\
\hline SPE & Solid phase extraction \\
\hline SPME & Solid phase microextraction \\
\hline SRM & Standard reference material \\
\hline SR-XAS & $\begin{array}{l}\text { Synchrotron radiation X-ray absorption } \\
\text { spectroscopy }\end{array}$ \\
\hline SR-XRF & Synchrotron radiation X-ray fluorescence \\
\hline SSIDMS & $\begin{array}{l}\text { Species specific isotope dilution mass } \\
\text { spectrometry }\end{array}$ \\
\hline suIDMS & $\begin{array}{l}\text { Species unspecific isotope dilution mass } \\
\text { spectrometry }\end{array}$ \\
\hline TLC & Thin layer chromatography \\
\hline TMAH & Tetramethylammonium hydroxide \\
\hline TMAO & Trimethylarsine oxide \\
\hline TMSb & Trimethylantimony \\
\hline
\end{tabular}


TMSe

TOF-MS

TRIS

TrxR

TXRF

UAE

UPLC

USAEME

UV

WDXRF

WHO

XANES

XAS

XAFS

XRD
Trimethylselenium

Time-of-flight mass spectrometry

Tris(hydroxymethyl)aminomethane

Thioredoxin reductase

Total reflection X-ray fluorescence

Ultrasound-assisted extraction

Ultra high performance liquid chromatography

Ultrasound-assisted emulsification-

microextraction

Ultraviolet

Wavelength dispersive X-ray fluorescence

World Health Organisation

$\mathrm{X}$-ray absorption near-edge structure

X-ray absorption spectroscopy

X-ray absorption fine structure spectrometry

$\mathrm{X}$-ray diffraction

\section{References}

1 O. T. Butler, W. R. L. Cairns, J. M. Cook and C. M. Davidson, J. Anal. At. Spectrom., 2014, 29(1), 17-50.

2 A. Taylor, M. P. Day, S. Hill, J. Marshall, M. Patriarca and M. White, J. Anal. At. Spectrom., 2014, 29(3), 386-426.

3 E. H. Evans, J. Pisonero, C. M. M. Smith and R. N. Taylor, J. Anal. At. Spectrom., 2014, 29(5), 773-794.

4 M. West, A. T. Ellis, P. J. Potts, C. Streli, C. Vanhoof, D. Wegrzynek and P. Wobrauschek, J. Anal. At. Spectrom., 2013, 28(10), 1544-1590.

5 S. Carter, A. S. Fisher, M. W. Hinds, S. Lancaster and J. Marshall, J. Anal. At. Spectrom., 2013, 28(12), 1814-1869.

6 Speciation Studies in Soil, Sediment and Environmental Samples, ed. S. Bakirdere, CRC Press, Boca Raton, 2013, p. 612.

7 Analytical Techniques for Clinical Chemistry: Methods and Applications, ed. S. C. a. G. Záray, John Wiley \& Sons, New York, 2012, p. 838.

8 C. Bresson, F. Chartier, E. Ansoborlo and R. Ortega, Radiochim. Acta, 2013, 101(6), 349-357.

9 C. Bresson, F. Chartier and E. Ansoborlo, Actual. Chim., 2012, 367, 26-33.

10 K. Kleparnik, Electrophoresis, 2013, 34(1), 70-85.

11 A. R. Timerbaev, Chem. Rev., 2013, 113(1), 778-812.

12 L. Bertrand, M. Cotte, M. Stampanoni, M. Thoury, F. Marone and S. Schoder, Phys. Rep., 2012, 519(2), 51-96.

13 S. Majumdar, J. R. Peralta-Videa, H. Castillo-Michel, J. Hong, C. M. Rico and J. L. Gardea-Torresdey, Anal. Chim. Acta, 2012, 755, 1-16.

14 L. Telgmann, M. Sperling and U. Karst, Anal. Chim. Acta, 2013, 764, 1-16.

15 L. N. Suvarapu, Y. K. Seo and S. O. Baek, Rev. Anal. Chem., 2013, 32(3), 225-245.

16 K. Bierla, J. Szpunar, A. Yiannikouris and R. Lobinski, TrAC, Trends Anal. Chem., 2012, 41, 122-132.

17 N. R. Jyothi, N. A. M. Farook, M. Cho and J. Shim, Asian J. Chem., 2013, 25(8), 4125-4136.

18 P. A. Mello, J. S. Barin, F. A. Duarte, C. A. Bizzi, L. O. Diehl, E. I. Muller and E. M. M. Flores, Anal. Bioanal. Chem., 2013, 405(24), 7615-7642.

19 E. Beceiro-Gonzalez, M. J. Gonzalez-Castro, S. MuniateguiLorenzo, P. Lopez-Mahia and D. Prada-Rodriguez, J. AOAC Int., 2012, 95(5), 1291-1310.

20 A. O. Sunday, B. A. Alafara and O. G. Oladele, Chem. Speciation Bioavailability, 2012, 24(4), 216-226.

21 K. Dubalska, M. Rutkowska, G. Bajger-Nowak, P. Konieczka and J. Namiesnik, Crit. Rev. Anal. Chem., 2013, 43(1), 35-54.

22 J. Tyson, ISRN Anal. Chem., 2013, 2013, 24.

23 C. Giesen, L. Waentig, U. Panne and N. Jakubowski, Spectrochim. Acta, Part B, 2012, 76, 27-39.

24 S. D. Tanner, V. I. Baranov, O. I. Ornatsky, D. R. Bandura and T. C. George, Cancer Immunol. Immunother., 2013, 62(5), 955-965.

25 W. Maher, F. Krikowa, M. Ellwood, S. Foster, R. Jagtap and G. Raber, Microchem. J., 2012, 105, 15-31.

26 K. Malisova and O. Mestek, Chem. Listy, 2012, 106(11), 1034-1041.

27 A. N. Anthemidis and C. Mitani, Curr. Anal. Chem., 2013, 9(2), 250-278.

28 V. Andruch, I. S. Balogh, L. Kocurova and J. Sandrejova, J. Anal. At. Spectrom., 2013, 28(1), 19-32.

29 B. Hu, M. He, B. B. Chen and L. B. Xia, Spectrochim. Acta, Part B, 2013, 86, 14-30.

30 P. J. Zhang, L. Hu, R. H. Lu, W. F. Zhou and H. X. Gao, Anal. Methods, 2013, 5(20), 5376-5385.

31 L. B. Escudero, A. C. Grijalba, E. M. Martinis and R. G. Wuilloud, Anal. Bioanal. Chem., 2013, 405(24), 75977613.

32 D. S. Urgast and J. Feldmann, J. Anal. At. Spectrom., 2013, 28(9), 1367-1371.

33 M. Slachcinski, Appl. Spectrosc. Rev., 2014, 49(4), 271-321.

34 Y. Gao, R. Liu and L. Yang, Chin. Sci. Bull., 2013, 58(17), 1980-1991.

35 G. A. Zachariadis, J. Chromatogr. A, 2013, 1296, 47-69.

36 Y. G. Yin, J. F. Liu and G. B. Jiang, Chin. Sci. Bull., 2013, 58(2), 150-161.

37 V. Romaris-Hortas, P. Bermejo-Barrera and A. MoredaPineiro, J. Chromatogr. A, 2013, 1309, 33-40.

38 Z. F. Ge and C. Y. Wei, J. Chromatogr. Sci., 2013, 51(5), 391399.

39 C. D. B. Amaral, A. G. G. Dionisio, M. C. Santos, G. L. Donati, J. A. Nobrega and A. R. A. Nogueira, J. Anal. At. Spectrom., 2013, 28(8), 1303-1310.

40 X. Q. Guo, B. B. Chen, M. He, B. Hu and X. Q. Zhou, J. Anal. At. Spectrom., 2013, 28(10), 1638-1647.

41 C. J. Zeng, Y. Lin, N. Zhou, J. T. Zheng and W. Zhang, J. Hazard. Mater., 2012, 237, 365-370.

42 J. Moreda-Pineiro, E. Alonso-Rodriguez, A. Moreda-Pineiro, C. Moscoso-Perez, P. Lopez-Mahia, S. Muniategui-Lorenzo and D. Prada-Rodriguez, Talanta, 2012, 101, 283-291.

43 B. B. Chen, B. Hu, M. He, Q. Huang, Y. Zhang and X. Zhang, J. Anal. At. Spectrom., 2013, 28(3), 334-343.

44 S. Arpadjan, K. Tsekova, P. Petrova and J. Knutsson, Bulg. Chem. Commun., 2012, 44(4), 299-306. 
45 H. R. Badiei, J. McEnaney and V. Karanassios, Spectrochim. Acta, Part B, 2012, 78, 42-49.

46 K. C. Hsu, C. C. Sun, Y. C. Ling, S. J. Jiang and Y. L. Huang, J. Anal. At. Spectrom., 2013, 28(8), 1320-1326.

47 L. H. Liu, B. He, Z. J. Yun, J. Sun and G. B. Jiang, J. Chromatogr. A, 2013, 1304, 227-233.

48 Z. F. Liu, Z. L. Zhu, H. T. Zheng and S. H. Hu, Anal. Chem., 2012, 84(23), 10170-10174.

49 Y. L. Yu, F. Gao, M. L. Chen and J. H. Wang, Acta Chim. Sin., 2013, 71(8), 1121-1124.

50 T. Nakagama, K. Shinohara, S. Ughiyama, J. Tsunokawa, H. L. Zeng, H. Nakajima and K. Uchiyama, Bunseki Kagaku, 2013, 62(3), 199-206.

51 J. Knoll and A. Seubert, J. Chromatogr. A, 2012, 1270, 219224.

52 T. Pfeifer, R. Janzen, T. Steingrobe, M. Sperling, B. Franze, C. Engelhard and W. Buscher, Spectrochim. Acta, Part B, 2012, 76, 48-55.

53 C. S. K. Raju, L. L. Yu, J. E. Schiel and S. E. Long, J. Anal. At. Spectrom., 2013, 28(6), 901-907.

54 E. R. McKenzie and T. M. Young, Water Sci. Technol., 2013, 67(5), 1075-1082.

55 T. T. Shih, I. H. Hsu, J. F. Wu, C. H. Lin and Y. C. Sun, J. Chromatogr. A, 2013, 1304, 101-108.

56 T. T. Shih, C. H. Lin, I. H. Hsu, J. Y. Chen and Y. C. Sun, Anal. Chem., 2013, 85(21), 10091-10098.

57 B. Y. Deng, X. D. Qin, Y. Xiao, Y. Z. Wang, H. H. Yin, X. S. Xu and C. Y. Shen, Talanta, 2013, 109, 128-132.

58 J. M. Currier, R. J. Saunders, L. Ding, W. Bodnar, P. Cable, T. Matousek, J. T. Creed and M. Styblo, J. Anal. At. Spectrom., 2013, 28(6), 843-852.

59 R. Ortega, A. Carmona, I. Llorens and P. L. Solari, J. Anal. At. Spectrom., 2012, 27(12), 2054-2065.

60 A. Manceau and K. L. Nagy, Geochim. Cosmochim. Acta, 2012, 99, 206-223.

61 G. S. A. Wright, H. C. Lee, C. Schulze-Briese, J. G. Grossmann, R. W. Strange and S. S. Hasnain, J. Synchrotron Radiat., 2013, 20, 383-385.

62 J. Malherbe and F. Claverie, Anal. Chim. Acta, 2013, 773, 3744.

63 C. Frank, O. Rienitz, C. Swart and D. Schiel, Anal. Bioanal. Chem., 2013, 405(6), 1913-1919.

64 F. Kolbe, J. Mattusch, R. Wennrich, H. Weiss, E. Sorkau, W. Lorenz and B. Daus, Fresenius Environ. Bull., 2012, 21(11C), 3453-3458.

65 E. Margui, M. Sague, I. Queralt and M. Hidalgo, Anal. Chim. Acta, 2013, 786, 8-15.

66 A. G. Ilgen, A. L. Foster and T. P. Trainor, Geochim. Cosmochim. Acta, 2012, 94, 128-145.

67 D. Varrica, F. Bardelli, G. Dongarra and E. Tamburo, Atmos. Environ., 2013, 64, 18-24.

68 F. Seby, C. Gleyzes, O. Grosso, B. Plau and O. F. X. Donard, Anal. Bioanal. Chem., 2012, 404(10), 2939-2948.

69 M. Grotti, F. Ardini, A. Terol, E. Magi and J. L. Todoli, J. Anal. At. Spectrom., 2013, 28(11), 1718-1724.

70 M. L. Chen, Y. M. Lin, C. B. Gu and J. H. Wang, Talanta, 2013, 104, 53-57.
71 L. Elci, A. Elci, T. A. Berg and J. F. Tyson, Int. J. Environ. Anal. Chem., 2013, 93(10), 1065-1073.

72 S. Rabieh, M. Bagheri and B. Planer-Friedrich, Microchim. Acta, 2013, 180(5-6), 415-421.

73 I. M. M. Rahman, Z. A. Begum, Y. Furusho, S. Mizutani, T. Maki and H. Hasegawa, Water, Air, Soil Pollut., 2013, $224(5), 11$.

74 S. Doker, L. Uzun and A. Denizli, Talanta, 2013, 103, 123129.

75 E. Boyaci, N. Horzum, A. Cagir, M. M. Demir and A. E. Eroglu, RSC Adv., 2013, 3(44), 22261-22268.

76 T. Matousek, J. M. Currier, N. Trojankova, R. J. Saunders, M. C. Ishida, C. Gonzalez-Horta, S. Musil, Z. Mester, M. Styblo and J. Dedina, J. Anal. At. Spectrom., 2013, 28(9), 1456-1465.

77 G. Norton, C. Deacon, A. Mestrot, J. Feldmann, P. Jenkins, C. Baskaran and A. A. Meharg, Environ. Sci. Technol., 2013, 47(12), 6164-6172.

78 J. Tyson, Speciation Analysis: A Critical Look at Methods Involving HPLC With ICP-MS Detection, With a Focus On Rice, http://www.spectroscopyonline.com/ArsenicRice Webinar2013.

79 M. Z. Zheng, G. Li, G. X. Sun, H. Shim and C. Cai, Plant Soil, 2013, 365(1-2), 227-238.

80 R. R. Rasmussen, Y. T. Qian and J. J. Sloth, Anal. Bioanal. Chem., 2013, 405(24), 7851-7857.

81 D. Vromman, S. Lutts, I. Lefevre, L. Somer, O. De Vreese, Z. Slejkovec and M. Quinet, Plant Soil, 2013, 371(1-2), 199-217.

82 S. Nookabkaew, N. Rangkadilok, C. Mahidol, G. Promsuk and J. Satayavivad, J. Agric. Food Chem., 2013, 61(28), 6991-6998.

83 I. N. Pasias, N. S. Thomaidis and E. A. Piperaki, Microchem. J., 2013, 108, 1-6.

84 N. S. Horner and D. Beauchemin, Anal. Chim. Acta, 2013, 758, 28-35.

85 W. Maher, S. Foster, F. Krikowa, E. Donner and E. Lombi, Environ. Sci. Technol., 2013, 47(11), 5821-5827.

86 C. Ubonnuch, S. Ruangwises, W. Gritsanapan and N. Ruangwises, J. Evidence-Based Complementary Altern. Med., 2013, 7.

87 A. Ruttens, A. C. Blanpain, L. De Temmerman and N. Waegeneers, J. Geochem. Explor., 2012, 121, 55-61.

88 F. P. Serpe, R. Russo, P. Gallo and L. Severino, J. Food Prot., 2013, 76(7), 1293-1299.

89 K. J. Whaley-Martin, I. Koch and K. J. Reimer, Sci. Total Environ., 2013, 456, 148-153.

90 C. M. M. Santos, M. A. G. Nunes, I. S. Barbosa, G. L. Santos, M. C. Peso-Aguiar, M. G. A. Korn, E. M. M. Flores and V. L. Dressler, Spectrochim. Acta, Part B, 2013, 86, 108-114. 91 L. Leffers, C. A. Wehe, S. Huewel, M. Bartel, F. Ebert, M. S. Taleshi, H. J. Galla, U. Karst, K. A. Francesconi and T. Schwerdtle, Metallomics, 2013, 5(8), 1031-1042.

92 A. Terol, F. Ardini, M. Grotti and J. L. Todoli, J. Chromatogr. A, 2012, 1262, 70-76.

93 A. Raab, C. Newcombe, D. Pitton, R. Ebel and J. Feldmann, Anal. Chem., 2013, 85(5), 2817-2824. 
94 C. G. Sartal, M. D. Barciela-Alonso and P. Bermejo-Barrera, Microchem. J., 2012, 105, 65-71.

95 L. Garcia-Rico and L. Tejeda-Valenzuela, Environ. Monit. Assess., 2013, 185(7), 6111-6117.

96 V. Sele, H. Amlund, M. H. G. Berntssen, J. A. Berntsen, K. Skov and J. J. Sloth, Anal. Bioanal. Chem., 2013, 405(15), 5179-5190.

97 K. Julshamn, B. M. Nilsen, S. Frantzen, S. Valdersnes, A. Maage, K. Nedreaas and J. J. Sloth, Food Addit. Contam., Part B, 2012, 5(4), 229-235.

98 U. Arroyo-Abad, S. Lischka, C. Piechotta, J. Mattusch and T. Reemtsma, Food Chem., 2013, 141(3), 3093-3102.

99 J. Cui, Y. B. Xiao, L. Dai, X. H. Zhao and Y. Wang, Food Anal. Methods, 2013, 6(2), 370-379.

100 X. P. Liu, W. F. Zhang, Y. N. Hu and H. F. Cheng, Microchem. J., 2013, 108, 38-45.

101 R. V. Hedegaard, I. Rokkjaer and J. J. Sloth, Anal. Bioanal. Chem., 2013, 405(13), 4429-4435.

102 P. Niedzielski, M. Mleczek, Z. Magdziak, M. Siwulski and L. Kozak, Food Chem., 2013, 141(4), 3571-3577.

103 M. Christodoulidou, C. Charalambous, M. Aletrari, P. N. Kanari, A. Petronda and N. I. Ward, J. Hydrol., 2012, 468, 94-100.

104 G. Lord, N. Kim and N. I. Ward, J. Environ. Monit., 2012, 14(12), 3192-3201.

105 E. Sugar, E. Tatar, G. Zaray and V. G. Mihucz, Microchem. J., 2013, 107, 131-135.

106 X. L. Peng, F. Xu, J. Bian, W. Z. Zhang and Y. Wu, Spectrosc. Spect. Anal., 2013, 33(6), 1689-1692.

107 J. An, K. H. Kim, J. A. Kim, H. Jung, H. O. Yoon and J. Seo, J. Hazard. Mater., 2013, 260, 24-31.

108 L. H. E. Winkel, B. Casentini, F. Bardelli, A. Voegelin, N. P. Nikolaidis and L. Charlet, Geochim. Cosmochim. Acta, 2013, 106, 99-110.

109 L. Y. Zheng, J. G. Umans, M. Tellez-Plaza, F. Yeh, K. A. Francesconi, W. Goessler, E. K. Silbergeld, E. Guallar, B. V. Howard, V. M. Weaver and A. NavasAcien, Am. J. Kidney Dis., 2013, 61(3), 385-394.

110 X. Cao, J. J. Yu, Y. Gao, J. C. Sun, Y. Liu, Y. Y. Xu, G. F. Sun and X. R. Wang, Chin. J. Anal. Chem., 2012, 40(1), 83-88.

111 J. H. Wen, W. H. Wen, L. Li and H. Liu, Environ. Toxicol. Pharmacol., 2012, 34(2), 624-630.

112 B. W. Chen, X. F. Lu, S. W. Shen, L. L. Arnold, S. M. Cohen and X. C. Le, Chem. Res. Toxicol., 2013, 26(6), 952962.

113 Y. Kobayashi and S. Hirano, Metallomics, 2013, 5(5), 469478.

114 A. Pell, A. Marquez, J. F. Lopez-Sanchez, R. Rubio, M. Barbero, S. Stegen, F. Queirolo and P. Diaz-Palma, Chemosphere, 2013, 90(2), 556-564.

115 S. Miyashita, S. Fujiwara, M. Tsuzuki and T. Kaise, Environ. Chem., 2012, 9(5), 474-484.

116 A. Mestrot, B. Planer-Friedrich and J. Feldmann, Environ. Sci.: Processes Impacts, 2013, 15(9), 1639-1651.

117 A. Pell, A. Marquez, R. Rubio and J. F. Lopez-Sanchez, Anal. Methods, 2013, 5(10), 2543-2550.
118 P. Fauser, H. Sanderson, R. V. Hedegaard, J. J. Sloth, M. M. Larsen, T. Krongaard, R. Bossi and J. B. Larsen, Environ. Monit. Assess., 2013, 185(6), 4679-4691.

119 Q. H. Hu, G. X. Sun, X. B. Gao and Y. G. Zhu, Appl. Geochem., 2012, 27(11), 2197-2203.

120 K. Y. Chiang, T. Y. Chen, C. H. Lee, T. L. Lin, M. K. Wang, L. Y. Jang and J. F. Lee, J. Environ. Sci., 2013, 25(3), 626-636.

121 E. Moreno-Jimenez, L. Six, P. N. Williams and E. Smolders, Talanta, 2013, 104, 83-89.

122 B. T. Lee and K. W. Kim, Hum. Ecol. Risk Assess., 2013, 19(3), 792-806.

123 L. B. de Abreu, R. Augusti, L. Schmidt, V. L. Dressler, E. M. D. Flores and C. C. Nascentes, Anal. Bioanal. Chem., 2013, 405(24), 7643-7651.

124 K. Mullner, B. Daus, J. Mattusch, D. Vetterlein, I. Merbach and R. Wennrich, Environ. Pollut., 2013, 174, 128-133.

125 A. Pineiro, J. Moreda-Pineiro, E. Alonso-Rodriguez, P. Lopez-Mahia, S. Muniategui-Lorenzo and D. PradaRodriguez, Talanta, 2013, 105, 422-428.

126 M. Sun, G. J. Liu, Q. H. Wu and W. Q. Liu, Talanta, 2013, 106, 8-13.

127 B. W. Chen, F. L. Cao, C. G. Yuan, X. F. Lu, S. W. Shen, J. Zhou and X. C. Le, Anal. Bioanal. Chem., 2013, 405(6), 1903-1911.

128 X. L. Shu, J. X. Zhong, X. M. Li, K. Kang, X. L. Liu and D. L. Cai, Chin. J. Anal. Chem., 2013, 41(4), 606-607.

129 A. Baumann, T. Pfeifer, D. Melles and U. Karst, Anal. Bioanal. Chem., 2013, 405(15), 5249-5258.

130 G. S. Groenewold, R. Avci, R. V. Fox, M. Deliorman, Z. Y. Suo and L. Kellerman, Ind. Eng. Chem. Res., 2013, 52(4), 13961404.

131 A. Miszczak, M. Roslon, G. Zbroja, K. Brama, E. Szalacha, H. Gawronska and K. Pawlak, Anal. Bioanal. Chem., 2013, 405(14), 4667-4678.

132 Y. F. Zhao, D. R. Shang, J. S. Ning and Y. X. Zhai, Chin. J. Anal. Chem., 2012, 40(5), 681-686.

133 H. Tavallali, G. Deilamy-Rad and P. Peykarimah, Environ. Monit. Assess., 2013, 185(9), 7723-7738.

134 O. Hazer and D. Demir, Anal. Sci., 2013, 29(7), 729-734.

135 G. Cimen, S. Tokalioglu, I. Ozenturk and C. Soykan, J. Braz. Chem. Soc., 2013, 24(5), 856-864.

136 B. Lesniewska, B. Godlewska-Zylkiewicz and A. Z. Wilczewska, Microchem. J., 2012, 105, 88-93.

137 H. M. Yu, W. Sun, X. H. Zhu, X. M. Zhu and J. J. Wei, Anal. Sci., 2012, 28(12), 1219-1224.

138 P. Berton, L. Vera-Candioti, H. C. Goicoechea and R. G. Wuilloud, Anal. Methods, 2013, 5(19), 5065-5073.

139 J. A. Baig, T. G. Kazi, L. Elci, H. I. Afridi, M. I. Khan and H. M. Naseer, J. Anal. Methods Chem., 2013, 8.

140 D. Zhang and Y. J. Sun, Asian J. Chem., 2013, 25(6), 31953198.

141 M. G. Kostakis, I. N. Pasias, V. L. Borova, A. K. Panara and N. S. Thomaidis, Curr. Anal. Chem., 2013, 9(2), 288-295.

142 N. Fabregat-Cabello, P. Rodriguez-Gonzalez, A. Castillo, J. Malherbe, A. F. Roig-Navarro, S. E. Long and J. I. G. Alonso, Environ. Sci. Technol., 2012, 46(22), 1254212549 . 
143 N. Martone, G. M. M. Rahman, M. Pamuku and H. M. S. Kingston, J. Agric. Food Chem., 2013, 61(41), 9966-9976.

144 X. Wang, Y. N. Xing, Z. Y. Chen, J. Y. Huo and L. Q. Chen, Chin. J. Anal. Chem., 2013, 41(1), 123-127.

145 J. J. Niu, F. Li, L. F. Chen, B. Han, J. Hu and Y. Y. Jiang, Chin. J. Anal. Chem., 2013, 41(8), 1283-1286.

146 S. Sungur, Y. Kilboz and M. M. Atan, Int. J. Food Prop., 2013, 16(8), 1711-1716.

147 B. D. Kerger, R. Gerads, H. Gurleyuk, K. A. Thuett, B. L. Finley and D. J. Paustenbach, Toxicol. Environ. Chem., 2013, 95(4), 687-708.

148 B. D. Kerger, B. E. Tvermoes, K. M. Unice, B. L. Finley, D. J. Paustenbach and D. A. Galbraith, Toxicol. Environ. Chem., 2013, 95(4), 709-718.

149 M. L. Pesch, I. Christl, M. Hoffmann, S. M. Kraemer and R. Kretzschmar, J. Inorg. Biochem., 2012, 116, 55-62.

150 M. L. Pesch, M. Hoffmann, I. Christl, S. M. Kraemer and R. Kretzschmar, Geobiology, 2013, 11(1), 44-54.

151 M. Birka, C. A. Wehe, L. Telgmann, M. Sperling and U. Karst, J. Chromatogr. A, 2013, 1308, 125-131.

152 L. Telgmann, C. A. Wehe, M. Birka, J. Kunnemeyer, S. Nowak, M. Sperling and U. Karst, Environ. Sci. Technol., 2012, 46(21), 11929-11936.

153 U. Lindner, J. Lingott, S. Richter, N. Jakubowski and U. Panne, Anal. Bioanal. Chem., 2013, 405(6), 1865-1873.

154 R. M. Boiteau, J. N. Fitzsimmons, D. J. Repeta and E. A. Boyle, Anal. Chem., 2013, 85(9), 4357-4362.

155 M. L. Fernandez-Sanchez, R. R. D. St Remy, H. G. Iglesias, J. B. Lopez-Sastre, B. Fernandez-Colomer, D. Perez-Solis and A. Sanz-Medel, Microchem. J., 2012, 105, 108-114.

156 A. Spolaor, P. Vallelonga, J. Gabrieli, N. Kehrwald, C. Turetta, G. Cozzi, L. Poto, J. M. C. Plane, C. Boutron and C. Barbante, Anal. Bioanal. Chem., 2013, 405(2-3), 647-654.

157 W. B. Zhang, X. A. Yang, Y. P. Dong and J. J. Xue, Anal. Chem., 2012, 84(21), 9199-9207.

158 J. Masbou, D. Point and J. E. Sonke, J. Anal. At. Spectrom., 2013, 28(10), 1620-1628.

159 A. R. Turker, D. Cabuk and O. Yalcinkaya, Anal. Lett., 2013, 46(7), 1155-1170.

160 X. Ai, Y. Wang, X. D. Hou, L. Yang, C. B. Zheng and L. Wu, Analyst, 2013, 138(12), 3494-3501.

161 Z. W. Wang, D. Forsyth, S. Belisle, F. Beraldin, M. Sparling, R. A. Trudelle, P. Lapointe and P. Bellon-Gagnon, Food Anal. Methods, 2013, 6(1), 157-163.

162 S. S. de Souza, A. D. Campiglia and F. Barbosa, Anal. Chim. Acta, 2013, 761, 11-17.

163 X. P. Chen, C. Han, H. Y. Cheng, J. H. Liu, Z. G. Xu and X. F. Yin, Anal. Chim. Acta, 2013, 796, 7-13.

164 X. P. Chen, C. Han, H. Y. Cheng, Y. C. Wang, J. H. Liu, Z. G. Xu and L. Hu, J. Chromatogr. A, 2013, 1314, 86-93.

165 J. C. T. Elguera, E. Y. Barrientos and K. Wrobel, J. Agric. Food Chem., 2013, 61(27), 6622-6628.

166 M. Ziehe, D. Esteban-Fernandez, U. Hochkirch, J. Thomale and M. W. Linscheid, Metallomics, 2012, 4(10), 1098-1104.

167 T. Nguyen, J. Ostergaard, S. Sturup and B. Gammelgaard, Int. J. Pharm., 2013, 449(1-2), 95-102.
168 T. Nguyen, J. Ostergaard, S. Sturup and B. Gammelgaard, Anal. Bioanal. Chem., 2013, 405(6), 1845-1854.

169 L. Y. Xing, G. Jerkiewicz and D. Beauchemin, Anal. Chim. Acta, 2013, 785, 16-21.

170 C. M. Weekley, J. B. Aitken, L. Finney, S. Vogt, P. K. Witting and H. H. Harris, Nutrients, 2013, 5(5), 1734-1756.

171 Y. Ogra and Y. Anan, Biol. Pharm. Bull., 2012, 35(11), 18631869.

172 T. Maseko, D. L. Callahan, F. R. Dunshea, A. Doronila, S. D. Kolev and K. Ng, Food Chem., 2013, 141(4), 3681-3687.

173 P. Bhatia, F. Aureli, M. D'Amato, R. Prakash, S. S. Cameotra, T. P. Nagaraja and F. Cubadda, Food Chem., 2013, 140(1-2), 225-230.

174 R. V. S. Lavu, G. Du Laing, T. Van de Wiele, V. L. Pratti, K. Willekens, B. Vandecasteele and F. Tack, J. Agric. Food Chem., 2012, 60(44), 10930-10935.

175 S. Maneetong, S. Chookhampaeng, A. Chantiratikul, O. Chinrasri, W. Thosaikham, R. Sittipout and P. Chantiratikul, Microchem. J., 2013, 108, 87-91.

176 Y. Fang, W. J. Yang, N. Ma, X. Z. Tang, X. Chen and Q. H. Hu, Chin. J. Anal. Chem., 2013, 41(6), 882-887.

177 M. Sun, G. J. Liu and Q. H. Wu, Food Chem., 2013, 141(1), 66-71.

178 L. Ouerdane, F. Aureli, P. Flis, K. Bierla, H. Preud'homme, F. Cubadda and J. Szpunar, Metallomics, 2013, 5(9), 12941304.

179 J. Gomez-Espina, E. Blanco-Gonzalez, M. Montes-Bayon and A. Sanz-Medel, J. Anal. At. Spectrom., 2012, 27(11), 1949-1954.

180 Y. Ogra, A. Katayama, Y. Ogihara, A. Yawata and Y. Anan, Metallomics, 2013, 5(5), 429-436.

181 E. Rampler, S. Rose, D. Wieder, A. Ganner, I. Dohnal, T. Dalik, S. Hann and G. Koellensperger, Metallomics, 2012, 4(11), 1176-1184.

182 C. Arnaudguilhem, K. Bierla, L. Ouerdane, H. Preud'homme, A. Yiannikouris and R. Lobinski, Anal. Chim. Acta, 2012, 757, 26-38.

183 Y. Anan, Y. Hatakeyama, M. Tokumoto and Y. Ogra, Anal. Sci., 2013, 29(8), 787-792.

184 M. Roman, P. Jitaru, M. Agostini, G. Cozzi, S. Pucciarelli, D. Nitti, C. Bedin and C. Barbante, Microchem. J., 2012, 105, 124-132.

185 K. R. Chitta, J. A. Landero-Figueroa, P. Kodali, J. A. Caruso and E. J. Merino, Talanta, 2013, 114, 25-31.

186 N. Solovyev, A. Berthele and B. Michalke, Anal. Bioanal. Chem., 2013, 405(6), 1875-1884.

187 M. Prigol, C. W. Nogueira, G. Zeni, M. R. Bronze and L. Constantino, Chem.-Biol. Interact., 2012, 200(2-3), 65-72.

188 T. Jager, H. Drexler and T. Goen, J. Anal. At. Spectrom., 2013, 28(9), 1402-1409.

189 Y. Suzuki, Y. Hashiura, T. Sakai, T. Yamamoto, T. Matsukawa, A. Shinohara and N. Furuta, Metallomics, 2013, 5(5), 445-452.

190 Y. Anan and Y. Ogra, Toxicol. Res., 2013, 2(2), 115-122.

191 M. Briens, Y. Mercier, F. Rouffineau, V. Vacchina and P. A. Geraert, Br. J. Nutr., 2013, 110(4), 617-624.

192 D. T. Juniper and G. Bertin, Animal, 2013, 7(4), 562-570. 
193 U. Kristan, M. A. Arribere and V. Stibilj, Biol. Trace Elem. Res., 2013, 151(2), 240-246.

194 J. Moreda-Pineiro, A. Moreda-Pineiro, V. Romaris-Hortas, R. Dominguez-Gonzalez, E. Alonso-Rodriguez, P. LopezMahia, S. Muniategui-Lorenzo, D. Prada-Rodriguez and P. Bermejo-Barrera, Food Chem., 2013, 139(1-4), 872-877.

195 S. Mechora, M. Germ and V. Stibilj, Sci. Total Environ., 2012, 438, 122-126.

196 S. Mechora, V. Stibilj and M. Germ, Aquat. Toxicol., 2013, 128, 53-59.

197 J. L. Freeman, M. A. Marcus, S. C. Fakra, J. Devonshire, S. P. McGrath, C. F. Quinn and E. A. H. Pilon-Smits, PLoS One, 2012, 7(12), 12.

198 P. Wang, N. W. Menzies, E. Lombi, B. A. McKenna, M. D. de Jonge, D. J. Paterson, D. L. Howard, C. J. Glover, S. James, P. Kappen, B. Johannessen and P. M. Kopittke, Plant Physiol., 2013, 163(1), 407-418.

199 K. Schilling, T. M. Johnson and W. Wilcke, Chem. Geol., 2013, 352, 101-107.

200 M. Lenz, G. H. Floor, L. H. E. Winkel, G. Roman-Ross and P. F. X. Corvini, Environ. Sci. Technol., 2012, 46(21), 11988-11994.

201 G. H. Floor, E. Margui, M. Hidalgo, I. Queralt, P. Kregsamer, C. Streli and G. Roman-Ross, Chem. Geol., 2013, 352, 19-26.

202 J. T. Zhao, Y. X. Gao, Y. F. Li, Y. Hu, X. M. Peng, Y. X. Dong, B. Li, C. Y. Chen and Z. F. Chai, Environ. Res., 2013, 125, 7581.

203 F. Moreno, T. Garcia-Barrera and J. L. Gomez-Ariza, J. Chromatogr.A, 2013, 1300, 43-50.

204 A. Ohki, K. Hayashi, J. Ohsako, T. Nakajima and H. Takanashi, Microchem. J., 2013, 106, 357-362.

205 D. Sanchez-Rodas, F. Mellano, E. Morales and I. Giraldez, Talanta, 2013, 106, 298-304.

206 A. M. Serra, J. M. Estela and V. Cerda, J. Anal. At. Spectrom., 2012, 27(11), 1858-1862.

207 I. Lopez-Garcia, Y. Vicente-Martinez and M. HernandezCordoba, J. Agric. Food Chem., 2013, 61(39), 9356-9361.

208 J. Soto-Alvaredo, M. Montes-Bayon and J. Bettmer, Anal. Chem., 2013, 85(3), 1316-1321.

209 Y. Anan, M. Yoshida, S. Hasegawa, R. Katai, M. Tokumoto, L. Ouerdane, R. Lobinski and Y. Ogra, Metallomics, 2013, 5(9), 1215-1224.

210 S. Frelon, S. Mounicou, R. Lobinski, R. Gilbin and O. Simon, Chemosphere, 2013, 91(4), 481-490.

211 A. Richard, J. Cauzid, M. Cathelineau, M. C. Boiron, J. Mercadier and M. Cuney, Geofluids, 2013, 13(2), 101-111.

212 N. Kilibarda, S. E. Afton, J. M. Harrington, F. Yan and K. E. Levine, J. Chromatogr. A, 2013, 1304, 121-126.
213 C. A. Blindauer, J. Inorg. Biochem., 2013, 121, 145-155.

214 O. Leclerc, P. O. Fraisse, G. Labarraque, C. Oster, J. P. Pichaut, M. Baume, S. Jarraud, P. Fisicaro and S. Vaslin-Reimann, AnBio, 2013, 435(2), 153-158.

215 S. Fujii, K. Inagaki, S. Miyashita, K. Nagasawa, K. Chiba and A. Takatsu, Metallomics, 2013, 5(5), 424-428.

216 L. G. Hu, B. He, Y. C. Wang, G. B. Jiang and H. Z. Sun, Chin. Sci. Bull., 2013, 58(2), 169-176.

217 A. Lothian, D. J. Hare, R. Grimm, T. M. Ryan, C. L. Masters and B. R. Roberts, Front. Aging Neurosci., 2013, 5, 7.

218 C. G. Hartinger, M. Groessl, S. M. Meier, A. Casini and P. J. Dyson, ChSRv, 2013, 42(14), 6186-6199.

219 M. Groessl and C. G. Hartinger, Anal. Bioanal. Chem., 2013, 405(6), 1791-1808.

220 A. R. Timerbaev, K. Pawlak, S. S. Aleksenko, L. S. Foteeva, M. Matczuk and M. Jarosz, Talanta, 2012, 102, 164-170.

221 S. S. Aleksenko, M. Matczuk, X. F. Lu, L. S. Foteeva, K. Pawlak, A. R. Timerbaev and M. Jarosz, Metallomics, 2013, 5(8), 955-963.

222 S. P. McCormick, M. Chakrabarti, A. L. Cockrell, J. Park, L. S. Lindahl and P. A. Lindahl, Metallomics, 2013, 5(3), 232-241.

223 B. Michalke, M. Lucio, A. Berthele and B. Kanawati, Anal. Bioanal. Chem., 2013, 405(7), 2301-2309.

224 D. Kretschy, G. Koellensperger and S. Hann, Anal. Chim. Acta, 2012, 750, 98-110.

225 A. Sanz-Medel, M. Montes-Bayon, J. Bettmer, M. L. Fernandez-Sanchez and J. R. Encinar, TrAC, Trends Anal. Chem., 2012, 40, 52-63.

226 X. W. Yan, L. M. Yang and Q. Q. Wang, Anal. Bioanal. Chem., 2013, 405(17), 5663-5670.

227 R. Liu, X. D. Hou, Y. Lv, M. McCooeye, L. Yang and Z. Mester, Anal. Chem., 2013, 85(8), 4087-4093.

228 A. Holste, A. Tholey, C. W. Hung and D. Schaumloffel, Anal. Chem., 2013, 85(6), 3064-3070.

229 Z. B. Zhang, Q. Luo, X. W. Yan, Z. X. Li, Y. C. Luo, L. M. Yang, B. Zhang, H. F. Chen and Q. Q. Wang, Anal. Chem., 2012, 84(21), 8946-8951.

230 Y. C. Luo, X. W. Yan, Y. S. Huang, R. B. Wen, Z. X. Li, L. M. Yang, C. J. Yang and Q. Q. Wang, Anal. Chem., 2013, 85(20), 9428-9432.

231 G. J. Han, S. C. Zhang, Z. Xing and X. R. Zhang, Angew. Chem., Int. Ed., 2013, 52(5), 1466-1471.

232 M. S. Jimenez, L. Rodriguez, J. R. Bertolin, M. T. Gomez and J. R. Castillo, Anal. Bioanal. Chem., 2013, 405(1), 359-368.

233 S. Matsuyama, A. Matsunaga, S. Sakamoto, Y. Iida, Y. Suzuki, Y. Ishizaka, K. Yamauchi, T. Ishikawa and M. Shimura, Metallomics, 2013, 5(5), 492-500. 